\title{
EUROPIUM OXIDE AS A POTENTIAL LMFBR CONTROL MATERIAL
}

A. E. Pasto

\section{OAK RIDGE NATIONAL LABORATORY}

OPERATED BY UNION CARBIDE CORPORATION - FOR THE U.S. ATOMIC ENERGY COMMISSION 


\section{DISCLAIMER}

This report was prepared as an account of work sponsored by an agency of the United States Government. Neither the United States Government nor any agency Thereof, nor any of their employees, makes any warranty, express or implied, or assumes any legal liability or responsibility for the accuracy, completeness, or usefulness of any information, apparatus, product, or process disclosed, or represents that its use would not infringe privately owned rights. Reference herein to any specific commercial product, process, or service by trade name, trademark, manufacturer, or otherwise does not necessarily constitute or imply its endorsement, recommendation, or favoring by the United States Government or any agency thereof. The views and opinions of authors expressed herein do not necessarily state or reflect those of the United States Government or any agency thereof. 


\section{DISCLAIMER}

Portions of this document may be illegible in electronic image products. Images are produced from the best available original document. 
Printed in the United States of America. Available from Natinnal Technical Information Service

U.S. Department of Commerce

5285 Port Royal Road, Springfield, Virginia 22151

Price: Printed Copy \$5.45; Microfiche \$0.95

This report was prepared as an account of work sponsored by the United States Government. Neither the United States nor the United States Atomic Energy Commission, nor any of their employees, nor any of their contractors, subcontractors, or their employees, makes any warranty, express or implied, or assumes any legal liability or responsibility for the accuracy, completeness or usefulness of any information, apparatus, product or process disclosed, or represents that its use would not infringe privately owned rights. 
ORNL-TM-4226

UC-79b, -d, -e

(Liquid-Metal Fast Breeder Reactors)

Contract No. W-7405-eng-26

METALS AND CERAMICS DIVISION

EUROPIUM OXIDE AS A POTENTIAL LMFBR CONTROL MATERIAL

A. E. Pasto

NOTICE

This report was preparcd os an account nf work sponsored by the United States Government. Nelther

the United States nor the United States Atomic Energy

Commission, nor any of their employees, nor any of

Com

their con

makes any warranty, express or impled, or assumes any

legal liability or responsibilty for the accuracy, com-

pleteness or usefulness of any informatinn, apparatus,

product or process disclosed, or represents that its use

would not infringe privately owned rights.

\section{SEPTEMBER 1973}
OAK RIDGE NATIONAL LABORATORY
Oak Ridge. Tennessee 37830
operated by
UNION CARBIDE CORPORATION
for the

U.S. ATOMIC ENERGY COMMISSION 
THIS PAGE

WAS INTENTIONALLY

LEFT BLANK 


\section{CONTENTS}

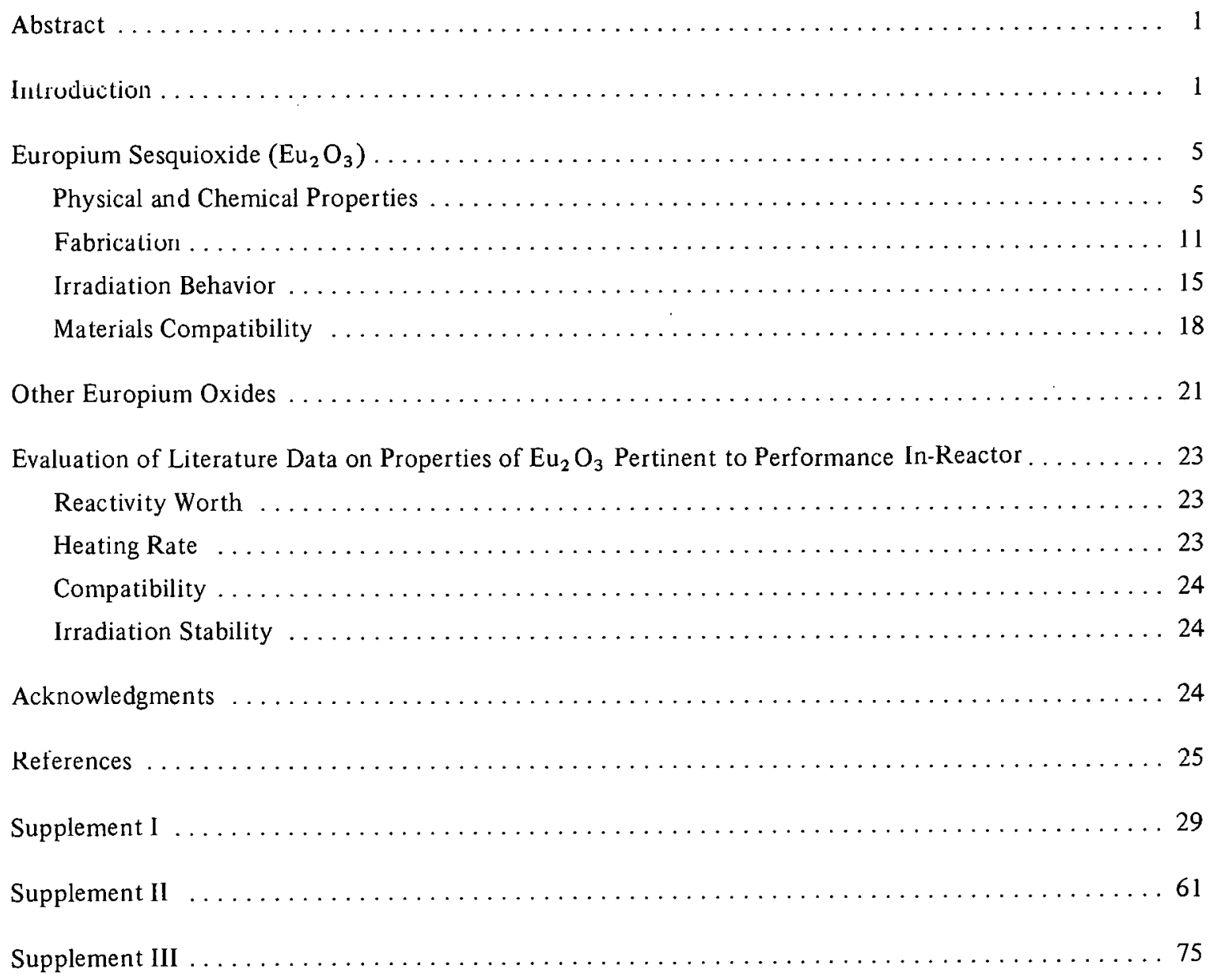




\title{
EUROPIUM OXIDE AS A POTENTIAL LMFBR CONTROL MATERIAL
}

\author{
A. E. Pasto
}

\begin{abstract}
Europium oxide has been suggested as a possible neutron absorber material for use in the control rods of LMFBRs. This document is a review of the available literature data for $\mathrm{Eu}_{2} \mathrm{O}_{3}$ concerning its physical properties and characteristics, and is an evaluation of the current status of the data regarding reactivity worth, compatibility, irradiation stability, and in-reactor heating rate. Preliminary fabrication experiments are also described.

It is concluded that the monoclinic form of $\mathrm{Eu}_{2} \mathrm{O}_{3}$ is an excellent candidate absorber material. It is readily fabricated into dense pellets by sintering or hot pressing, has an initial nuclear worth equivalent to that of natural $\mathrm{B}_{4} \mathrm{C}$, and retains a significant portion of this worth during burnup due to its "chain-type" neutron absorption behavior. However, few data are available regarding the fast neutron irradiation behavior of $\mathrm{Eu}_{2} \mathrm{O}_{3}$ pellets and their compatibility with structural materials and coolants.
\end{abstract}

A cursory evaluation of other oxides of europium is also included.

\section{INTRODUCTION}

Europium is a member of the family of elements that is commonly called the "rare earths." These elements constitute the group having atomic numbers from 57 (lanthanum) through 71 (lutetium). Two other elements, scandium and yttrium, exhibit properties similar to these and are commonly included in this family.

The first discovery of a "rare earth" was reported in 1794 by Johann Gadolin, who detected the existence of yttria in a rare Swedish ore from Ytterby. In the 1800's most of the rest of the "rare earths" were separated and reported. Since these occurred as oxides and exhibited properties resembling those of the common earths alumina and lime, they were called earths. In fact, of course, these elements are metals. The ores from which these "earths" were separated were quite rare, hence the name "rare earths." Actually, this is a misconception. These elements occur in low concentrations in many different and widely scattered minerals, with the result that they are as plentiful as the noble metal group, as is illustrated in Fig. 1. They constitute about one-sixth of all known elements - thus, the term "rare earth" is misleading. A more preferable term for these elements is "the lanthanides," a term that indicates the similarity of their properties to those of lanthanum. This terminology will be used throughout the remainder of this report.

Europium was discovered as a new element in 1886 by Boisbaudran and named by Demarcay in 1906 . It occurs in minor quantities in several minerals and is readily obtained from monazite sand. This sand is a chief source of thorium, and as the demand for thorium increases, the supply of by-product lanthanides (including europium) will increase.

Monazite sand is commonly broken down by sulfuric acid treatment, which converts the lanthanides to soluble sulfates. These are then converted to hydroxides by boiling with excess sodium hydroxide. Calcination of this product yields a mixture of lanthanide oxides. These can be taken back into solution and the individual elements separated out by any of several techniques, including solvent extraction, ion exchange, etc. Europium can readily be obtained with $99.99 \%$ purity in this manner. The chemical procedures are reviewed in the books by Sinha, ${ }^{1}$ Spedding and Daane, ${ }^{2}$ and Eyring. ${ }^{3}$

Naturally occurring europium consists of two isotopes, ${ }^{151} \mathrm{Eu}$ and ${ }^{153} \mathrm{Eu}$, of approximately equal abundance ( 47.8 and 52.2 at. \% respectively). This mixture possesses certain characteristics that are desirable in a material to be used as a control element for both thermal and fast nuclear reactors. In thermal reactors, it has a very high neutron absorption cross section, and it retains a significant portion of this cross section as a function of time. Its long life as an absorber is due to "chain-type" absorption behavior. That 


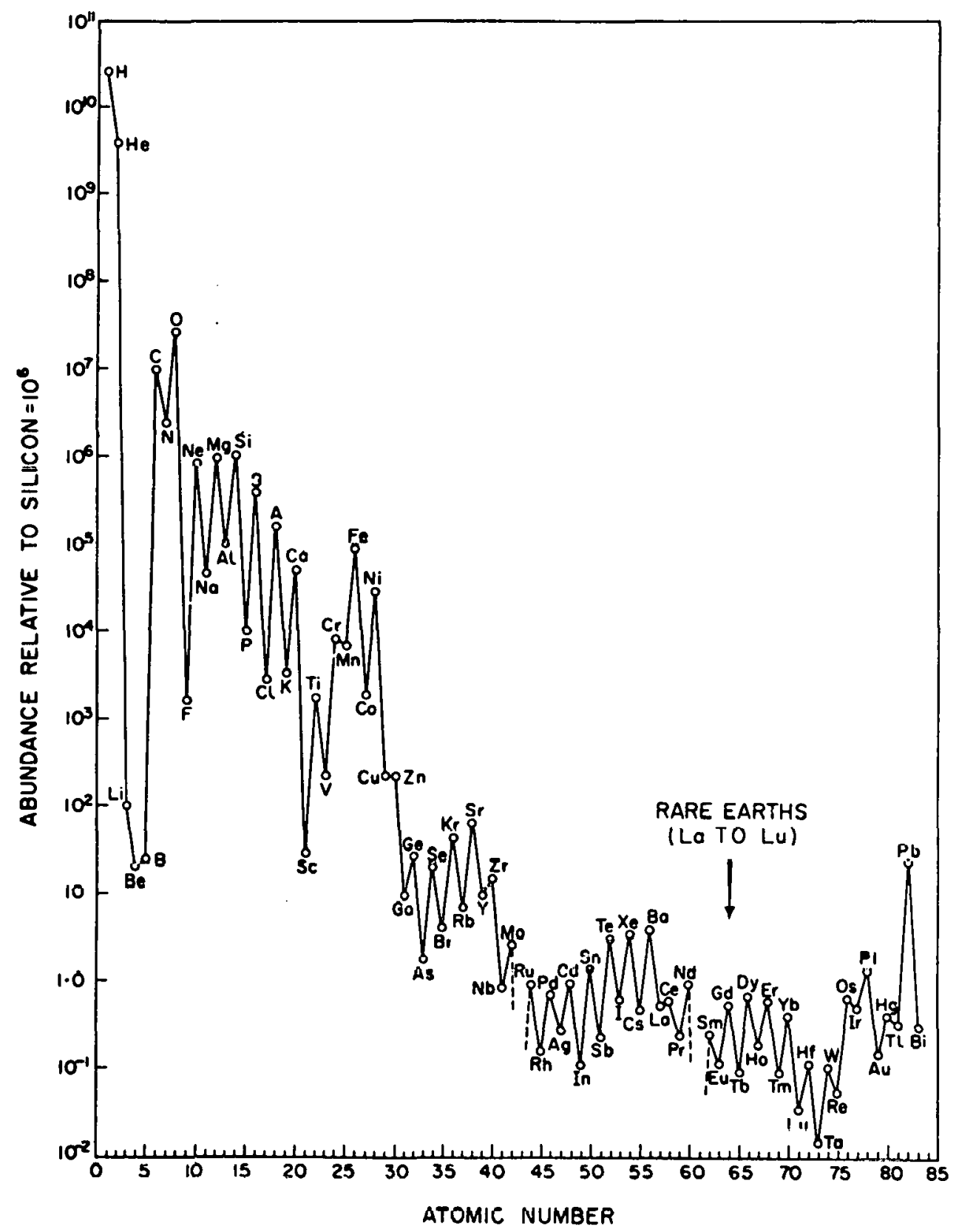

Fig. 1. Relative abundance of the elements. (Ref: L. H. Ahrens, "Aspects of the Geochemistry of the Rare Earths," in Progress in the Science and Technology of the Rare Earths, Vol. 1, ed. by LeRoy Eyring, Macmillan, New York, 1964) (Reprinted with permission trom L. H. Ahrens and Pergamon Yress, Inc.)

is, ${ }^{151} \mathrm{Eu}$ absorbs a neutron and produces ${ }^{152} \mathrm{Eu}$, which can absorb a neutron and form ${ }^{153} \mathrm{Eu}$, which can absorb a neutron to form ${ }^{154} \mathrm{Eu}$, etc. This behavior is in sharp contrast to that of samarium and gadolinium, both of which exhibit higher initial cross-section values, but lose their reactivity worth rapidly due to lack of a chain-type absorption mechanism. This type of behavior for europium is well documented in reviews by Martin and Beaver, ${ }^{4}$ Ray, ${ }^{5}$ and Anderson. ${ }^{6}$

Current designs for fast breeder reactors call for a core containing control rods bunched together into "pin clusters." To yield the maximum absorber density without causing the absorber element to run at 
excessively high temperatures requires the use of dense pellets stacked into rods. At present, $\mathrm{B}_{4} \mathrm{C}$ is the absorber material designated for the FFTF, with $\mathrm{Eu}_{2} \mathrm{O}_{3}$ as a backup. Nevertheless, $\mathrm{Eu}_{2} \mathrm{O}_{3}$ is potentially an even better material than $\mathrm{B}_{4} \mathrm{C}$ for this application. A recent article by Spenke ${ }^{7}$ discusses all the relevant factors involved in such a determination. Spenke's conclusions are:

1. Europium oxide is equivalent to natural boron carbide on a reactivity worth per unit volume basis.

2. Europium oxide will not produce helium gas on irradiation, as does $B_{4} C$.

3. The daughter products of europium are good neutron absorbers, leading to good retention of reactivity worth. The boron carbide daughter products do not absorb a significant number of neutrons.

Also, due to the retention of reactivity worth in $\mathrm{Eu}_{2} \mathrm{O}_{3}$, the control rods should not require replacement as often as for the rapidly burned-out $\mathrm{B}_{4} \mathrm{C}$. Both materials, however, have the problem of internal heat generation. The $(n, \gamma)$ reactions and subsequent decay of the europium isotopes may, in conjunction with the core gamma heating, generate substantial quantities of heat. (This aspect is discussed more fully in Supplement I.) The low thermal conductivity of $\mathrm{Eu}_{2} \mathrm{O}_{3}$ coupled with this heating effect may lead to high center-line temperatures in the pellets, thus limiting the size of pellets used.

Spenke notes that the afterheat of europium is dependent largely on the long half-lives of the ${ }^{152} \mathrm{Eu}$ and ${ }^{154} \mathrm{Eu}$ isotopes. Thus, after an initial rapid decrease (a few days time), the total decay energy varies only slightly over long periods. At this level, handling and storage of the elements present no special problems.

Concerning the reactivity worth of $\mathrm{Eu}_{2} \mathrm{O}_{3}$ in fast spectra, Spenke finds monoclinic $\mathrm{Eu}_{2} \mathrm{O}_{3}$ to possess a $33 \%$ better worth per volume than natural boron carbide. Early ORNL calculations ${ }^{8}$ have indicated that this number may range from 17 to $43 \%$, while Atomics International calculations show $\mathrm{Eu}_{2} \mathrm{O}_{3}$ to be better by about $24 \%$. These numbers vary mostly due to differences in the assumed neutron spectra, although there may also be a neutron self-shielding effect.

M. M. Martin of ORNL has made a preliminary assessment of probable changes in the reactivity worth of europium sesquioxide when exposed to a particular fast-neutron flux. For comparative purposes, he chose $94 \%$-dense $\mathrm{Eu}_{2} \mathrm{O}_{3}$ containing $2.55 \times 10^{22}$ atoms Eu/cm ${ }^{3}$ and $98 \%$-dense natural $\mathrm{B}_{4} \mathrm{C}\left(2.134 \times 10^{22}\right.$ atoms ${ }^{10} \mathrm{~B} / \mathrm{cm}^{3}$ ). Because of available data ${ }^{10,48,49}$ and ease of calculation, a monoenergetic $50-\mathrm{keV}$ flux of $1.8 \times 10^{15}$ neutrons $\mathrm{cm}^{-2} \mathrm{sec}^{-1}$ was assumed to represent the average condition in an outer control position (row 7 of the FFTF) of a fast reactor.

The principal capture reactions, half-lives, and capture cross sections of the pertinent europium and boron isotopes are shown below:

$$
\begin{aligned}
& { }^{151} \mathrm{Eu}+n \stackrel{1.0 \mathrm{~b}}{\longrightarrow}{ }^{152 m} \mathrm{Eu}(9.3 \mathrm{hr}), \\
& { }^{151} \mathrm{Eu}+n \stackrel{1.7 \mathrm{~b}}{\longrightarrow} 152 \mathrm{Eu}(13.2 \text { years }), \\
& { }^{152} \mathrm{Eu}(13.2 \text { years })+n \stackrel{4.4 \mathrm{~b}}{\rightarrow}{ }^{53} \mathrm{Eu}, \\
& { }^{153} \mathrm{Eu}+n \stackrel{2.1 \mathrm{~b}}{\longrightarrow}{ }^{15} \mathrm{Eu}(8.5 \text { years }), \\
& { }^{154} \mathrm{Eu}(8.5 \text { years })+n \stackrel{2.0 \mathrm{~b}}{\longrightarrow}{ }^{15} \mathrm{Eu}(5.0 \text { years }), \\
& { }^{10} \mathrm{~B}+n \stackrel{2.8 \mathrm{~b}}{\longrightarrow}{ }^{7} \mathrm{Li}+{ }^{4} \mathrm{He} .
\end{aligned}
$$




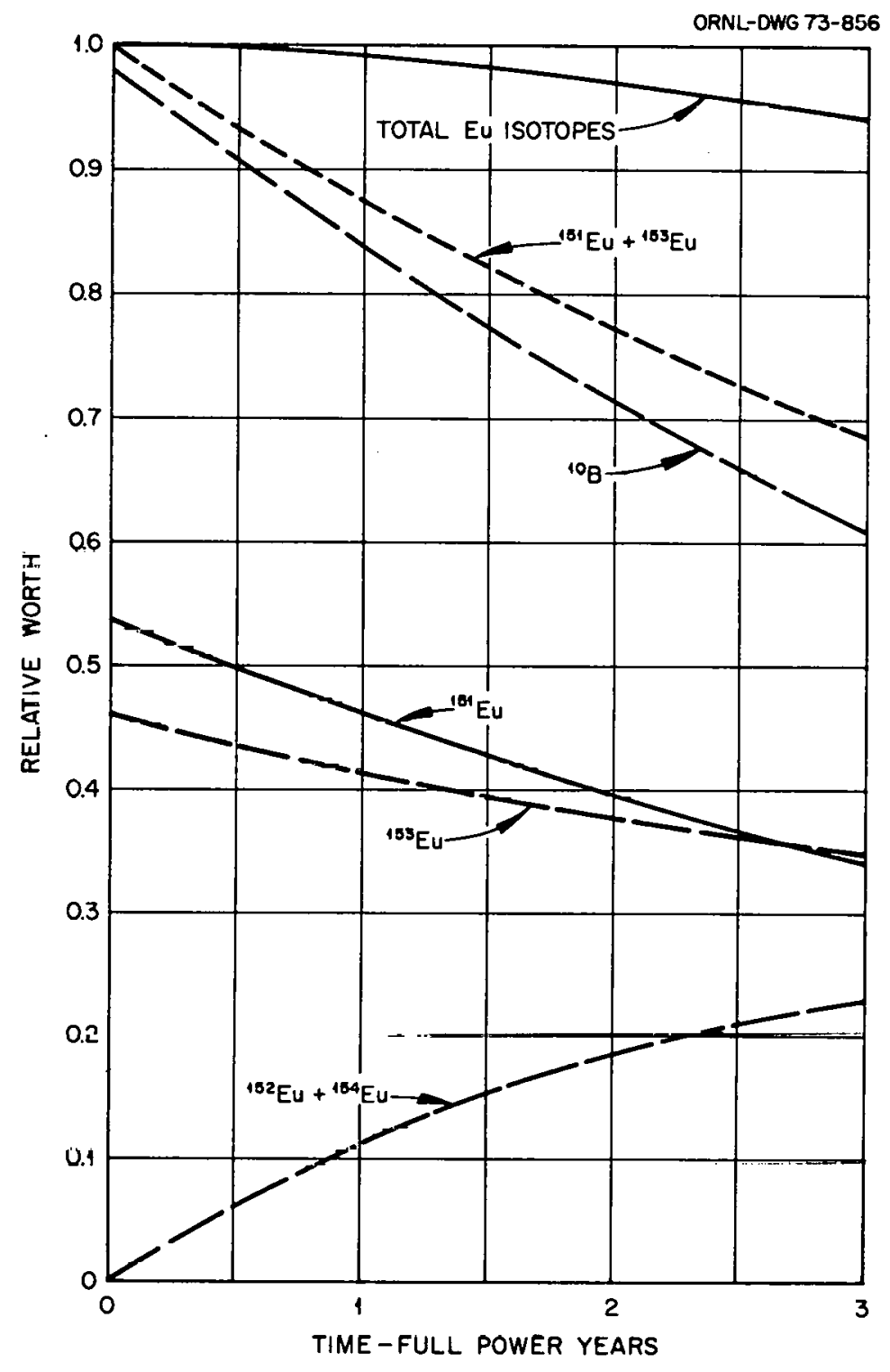

Fig. 2. Relative worth of Eu and ${ }^{10} \mathrm{~B}$ in-reactor.

The partial cross section of ${ }^{151} \mathrm{Eu}$ for formation of the 9.3-hr isomer of ${ }^{152} \mathrm{Eu}$ was taken to be $37 \%$ of the total capture cross section of ${ }^{151} \mathrm{Eu}$ (the factor used for exposure to thermal neutrons). Note also that the 9.3-hr isomer of ${ }^{152} \mathrm{Eu}$ does not decay to the ground state of ${ }^{15 \dot{2}} \mathrm{Eu}$ and that the contribution of gadolinium and samarium decay daughter products was ignored.

The results of the various neutron capture and radioactive growth and decay processes given in Eqs. (1) through (6) and their effects on nuclear worth are presented in Fig. 2. This is, at best, a first approximation. However, it is tentatively concluded that natural $\mathrm{B}_{4} \mathrm{C}$ and $\mathrm{Eu}_{2} \mathrm{O}_{3}$, in which only ${ }^{10} \mathrm{~B},{ }^{151} \mathrm{Eu}$, and ${ }^{153} \mathrm{Eu}$ isotopes are considered, should exhibit nearly identical initial reactivity worth on an equal-volume basis in fast reactors. As shown in Fig. 2, the buildup of the principal europium capture products of ${ }^{152} \mathrm{Eu}$ and ${ }^{154} \mathrm{Eu}$ leads to a relatively slower rate of loss of reactivity worth with fluence and increases the useful life of $\mathrm{Eu}_{2} \mathrm{O}_{3}$-bearing absorbers. For example, let us assume that the life of a fast-reactor neutron absorber is 
established solely from a reduction in reactivity worth of $10 \%$. From Fig. 2 it is readily observed that the life of an $\mathrm{Eu}_{2} \mathrm{O}_{3}$-bearing absorber should be at least three times longer than that of a $\mathrm{B}_{4} \mathrm{C}$-bearing absorber.

A. M. Perry of ORNL has cursorily estimated the relative worth vs full-power years for $\mathrm{Eu}_{2} \mathrm{O}_{3}$ in row 7 of EBR-II. Although his assessment used conservative values for capture cross sections of ${ }^{152} \mathrm{Eu}$ and ${ }^{154} \mathrm{Eu}$ and somewhat different half-lives, the results given in Appendix A of Supplement I also indicate a long control-rod lifetime to achieve a $10 \%$ reduction in worth.

The absence of helium production coupled with the economical incentive of a possible significant increase in useful lifetime in comparison to natural $\mathrm{B}_{4} \mathrm{C}$ makes $\mathrm{Eu}_{2} \mathrm{O}_{3}$ an extremely attractive control material for fast reactors. However, more work should be done to firmly establish the reactivity worth of $\mathrm{Eu}_{2} \mathrm{O}_{3}$ for anticipated neutron spectra in the FFTF and the demonstration LMFBR. This assessment should elucidate (1) pertinent nuclear data gaps (especially for the neutron capture cross sections of ${ }^{151} \mathrm{Eu}$, ${ }^{152} \mathrm{Eu},{ }^{153} \mathrm{Eu},{ }^{154} \mathrm{Eu},{ }^{152} \mathrm{Gd}$, and ${ }^{152} \mathrm{Sm}$ ) and probable accuracy of the existing information, (2) the need for additional experimentally determined nuclear data, and (3) the total heating rates during operation and subsequent cooling periods. A few absorber design configurations should also be given a first look to assess probable heating rates.

\section{EUROPIUM SESQUIOXIDE $\left(\mathrm{Eu}_{2} \mathrm{O}_{3}\right)$}

Europium will not be used in a reactor in the metallic state, since the metal is extremely reactive toward water and atmospheric water vapor and oxygen, and fabrication is thus difficult. One of the most easily obtainable forms of the lanthanides has been the sesquioxide. This material is readily fabricated into shapes and requires no special handling. A further advantage of the oxide form of europium is that it possesses a higher europium density than the metal. Hence most of the nuclear applications of europium and the other lan thanides have involved use of the sesquioxide.

\section{Physical and Chemical Properties}

The product remaining after the extraction of the lanthanides from the raw ore and the separation of europium may be the oxalate, nitrate, carbonate, hydroxide, sulfate, fluoride, or chloride. Calcination of any of these salts in air will yield the sesquioxide, one of the most thermodynamically stable europium compounds. Stecura ${ }^{11}$ has published thermograms of several europium salts along with data on times and temperatures required to yield $\mathrm{Ea}_{3} \mathrm{O}_{3}$ (see Table 1). The thermograms are illustrated in Figs. 3 and 4.

The crystal form of $\mathrm{Eu}_{2} \mathrm{O}_{3}$ derived from calcination of europium oxalate, hydroxide, carbonate, and nitrate is body-centered cubic, analogous to the structure of $\mathrm{Mn}_{2} \mathrm{O}_{3}$. It is commonly called the $\mathrm{C}$ form. The unit cell contains 16 molecules of $\mathrm{Eu}_{2} \mathrm{O}_{3}$ and has an edge length ${ }^{12}$ of $10.869 \AA$. Using these values, the theoretical density can be calculated to be $7.28 \mathrm{~g} / \mathrm{cm}^{3}$, with a corresponding europium density of $2.49 \times 10^{22}$ atoms $\mathrm{Eu} / \mathrm{cm}^{3}$. This cubic polymorph transforms on heating to a monoclinic form (the $\mathrm{B}$ form) through a diffusion-controlled reconstructive transformation. ${ }^{1}$ Typical of this type of phase change, the kinetics are strongly temperature dependent. Complete conversion from cubic to monoclinic takes from several days at $1050^{\circ} \mathrm{C}$ to less than an hour at $1300^{\circ} \mathrm{C}$. This behavior is illustrated in Fig. 5. The reverse reaction (transformation from monoclinic to cubic) has not been observed even after subjecting the monoclinic form to prolonged heat treatments at temperatures just below the transformation temperature. ${ }^{13,14}$ (For a further discussion, see Supplement II.) Warshaw and Roy ${ }^{15}$ have induced the monoclinic form to transform to the cubic by hydrothermal techniques. However, their technique brought the monoclinic form of europium oxide into contact with water at high temperatures. This could easily have converted the material to the hydroxide. The water was then removed at $974^{\circ} \mathrm{C}$ and the resulting 
Table 1. Decomposition products of lanthanide salts ${ }^{a}$

(Ref: S. Stecura, "Crystallographic Modifications and Phase Transformation Rates of Five Rare Earth Sesquioxides," U.S. Bureau of Mines Report of Investigations 6616)

\begin{tabular}{|c|c|c|c|c|c|c|}
\hline \multirow[b]{2}{*}{ Rare-earth salt } & \multicolumn{2}{|c|}{ lst decomposition } & \multicolumn{2}{|c|}{$2 \mathrm{~d}$ decomposition } & \multicolumn{2}{|c|}{ 3d decomposition } \\
\hline & $\begin{array}{l}\text { Tempera- } \\
\text { ture }\left({ }^{\circ} \mathrm{C}\right)\end{array}$ & Product & $\begin{array}{l}\text { Tempera- } \\
\text { ture }\left({ }^{\circ} \mathrm{C}\right)\end{array}$ & Product & $\begin{array}{l}\text { Tempera- } \\
\text { ture }\left({ }^{\circ} \mathrm{C}\right)\end{array}$ & Product \\
\hline \multicolumn{7}{|l|}{ Carbonates: } \\
\hline $\mathrm{La}_{2}\left(\mathrm{CO}_{3}\right)_{3}$ & 500 & $\mathrm{La}_{2} \mathrm{O}_{2} \mathrm{CO}_{3}$ & 830 & $\mathrm{La}_{2} \mathrm{O}_{3}$ & & \\
\hline $\mathrm{Nd}_{2}\left(\mathrm{CO}_{3}\right)_{3} \cdot 2 \mathrm{H}_{2} \mathrm{O}$ & 300 & $\mathrm{Nd}_{2}\left(\mathrm{CO}_{3}\right)_{3}$ & 480 & $\mathrm{Nd}_{2} \mathrm{O}_{2} \mathrm{CO}_{3}$ & 720 & $\mathrm{Nd}_{2} \mathrm{O}_{3}$ \\
\hline $\mathrm{Sm}_{2}\left(\mathrm{CO}_{3}\right)_{3} \cdot 2 \mathrm{H}_{2} \mathrm{O}$ & 320 & $\mathrm{Sm}_{2}\left(\mathrm{CO}_{3}\right)_{3}$ & 500 & $\mathrm{Sm}_{2} \mathrm{O}_{2} \mathrm{CO}_{3}$ & 630 & $\mathrm{Sm}_{2} \mathrm{O}_{3}$ \\
\hline $\mathrm{Eu}_{2}\left(\mathrm{CO}_{3}\right)_{3} \cdot 2 \mathrm{H}_{2} \mathrm{O}$ & 270 & $\mathrm{Eu}_{2}\left(\mathrm{CO}_{3}\right)_{3}$ & 500 & $\mathrm{Eu}_{2} \mathrm{O}_{2} \mathrm{CO}_{3}$ & 620 & $\mathrm{Eu}_{2} \mathrm{O}_{3}$ \\
\hline $\mathrm{Gd}_{2}\left(\mathrm{CO}_{3}\right)_{3} \cdot 4 \mathrm{H}_{2} \mathrm{O}$ & 500 & $\mathrm{Gd}_{2} \mathrm{O}_{2} \mathrm{CO}_{3}$ & 620 & $\mathrm{Gd}_{2} \mathrm{O}_{3}$ & & \\
\hline \multicolumn{7}{|l|}{ Oxalates: } \\
\hline $\mathrm{La}_{2}\left(\mathrm{C}_{2} \mathrm{O}_{4}\right)_{3} \cdot 4 \mathrm{H}_{2} \mathrm{O}$ & 320 & $\mathrm{La}_{2}\left(\mathrm{C}_{2} \mathrm{O}_{4}\right)_{3}$ & 530 & $\mathrm{La}_{2} \mathrm{O}_{2} \mathrm{CO}_{3}$ & 800 & $\mathrm{La}_{2} \mathrm{O}_{3}$ \\
\hline $\mathrm{Nd}_{2}\left(\mathrm{C}_{2} \mathrm{O}_{4}\right)_{3} \cdot 10 \mathrm{H}_{2} \mathrm{O}$ & 280 & $\mathrm{Nd}_{2}\left(\mathrm{C}_{2} \mathrm{O}_{4}\right)_{3}$ & 510 & $\mathrm{Nd}_{2} \mathrm{O}_{2} \mathrm{CO}_{3}$ & 670 & $\mathrm{Nd}_{2} \mathrm{O}_{3}$ \\
\hline $\mathrm{Sm}_{2}\left(\mathrm{C}_{2} \mathrm{O}_{4}\right)_{3} \cdot 8 \mathrm{H}_{2} \mathrm{O}$ & 250 & $\mathrm{Sm}_{2}\left(\mathrm{C}_{2} \mathrm{O}_{4}\right)_{3}$ & 510 & $\mathrm{Sm}_{2} \mathrm{O}_{2} \mathrm{CO}_{3}$ & 630 & $\mathrm{Sm}_{2} \mathrm{O}_{3}$ \\
\hline $\mathrm{Eu}_{2}\left(\mathrm{C}_{2} \mathrm{O}_{4}\right)_{3} \cdot 5 \mathrm{H}_{2} \mathrm{O}$ & 290 & $\mathrm{Eu}_{2}\left(\mathrm{C}_{2} \mathrm{O}_{4}\right)_{3}$ & 330 & $\mathrm{Eu}_{2} \mathrm{O}_{2} \mathrm{C}_{2} \mathrm{O}_{4}$ & 450 & $\mathrm{Eu}_{2} \mathrm{O}_{2} \mathrm{CO}_{3}^{b}$ \\
\hline $\mathrm{Gd}_{2}\left(\mathrm{C}_{2} \mathrm{O}_{4}\right)_{3} \cdot 8 \mathrm{H}_{2} \mathrm{O}$ & 250 & $\mathrm{Gd}_{2}\left(\mathrm{C}_{2} \mathrm{O}_{4}\right)_{3}$ & 600 & $\mathrm{Gd}_{2} \mathrm{O}_{2} \mathrm{CO}_{3}$ & 670 & $\mathrm{Gd}_{2} \mathrm{O}_{3}$ \\
\hline \multicolumn{7}{|l|}{ Nitrates: } \\
\hline $\mathrm{La}\left(\mathrm{NO}_{3}\right)_{3} \cdot 6 \mathrm{H}_{2} \mathrm{O}$ & 220 & $\mathrm{La}\left(\mathrm{NO}_{3}\right)_{3}$ & 420 & $\mathrm{LaONO}_{3}$ & 670 & $\mathrm{La}_{2} \mathrm{O}_{3}$ \\
\hline $\mathrm{Nd}\left(\mathrm{NO}_{3}\right)_{3} \cdot 6 \mathrm{H}_{2} \mathrm{O}$ & 260 & $\mathrm{Nd}\left(\mathrm{NO}_{3}\right)_{3}$ & 410 & $\mathrm{NdONO}_{3}$ & 660 & $\mathrm{Nd}_{2} \mathrm{O}_{3}$ \\
\hline $\mathrm{Sm}\left(\mathrm{NO}_{3}\right)_{3} \cdot 6 \mathrm{H}_{2} \mathrm{O}$ & 300 & $\mathrm{Sm}\left(\mathrm{NO}_{3}\right)_{3}$ & 400 & $\mathrm{SmONO}_{3}$ & 490 & $\mathrm{Sm}_{2} \mathrm{O}_{3}-\mathrm{SmONO}_{3}{ }^{c}$ \\
\hline $\mathrm{Eu}\left(\mathrm{NO}_{3}\right)_{3} \cdot 4 \mathrm{H}_{2} \mathrm{O}$ & 290 & $\mathrm{Eu}\left(\mathrm{NO}_{3}\right)_{3}$ & 390 & $\mathrm{EuONO}_{3}$ & 500 & $\mathrm{Eu}_{2} \mathrm{O}_{3}-\mathrm{EuONO}_{3}{ }^{d}$ \\
\hline $\mathrm{Gd}\left(\mathrm{NO}_{3}\right)_{3} \cdot 6 \mathrm{H}_{2} \mathrm{O}$ & 290 & $\mathrm{Gd}\left(\mathrm{NO}_{3}\right)_{3}$ & 410 & $\mathrm{GdONO}_{3}$ & 520 & $\mathrm{Gd}_{2} \mathrm{O}_{3}-\mathrm{GdONO}_{3}{ }^{e}$ \\
\hline \multicolumn{7}{|l|}{ Sulfates: } \\
\hline $\mathrm{La}_{2}\left(\mathrm{SO}_{4}\right)_{3} \cdot 6 \mathrm{H}_{2} \mathrm{O}$ & 350 & $\mathrm{La}_{2}\left(\mathrm{SO}_{4}\right)_{3}$ & 1150 & $\mathrm{La}_{2} \mathrm{O}_{2} \mathrm{SO}_{4}$ & 1450 & $\mathrm{La}_{2} \mathrm{O}_{3}$ \\
\hline $\mathrm{Nd}_{2}\left(\mathrm{SO}_{4}\right)_{3} \cdot 8 \mathrm{H}_{2} \mathrm{O}$ & 280 & $\mathrm{Nd}_{2}\left(\mathrm{SO}_{4}\right)_{3}$ & 1000 & $\mathrm{Nd}_{2} \mathrm{O}_{2} \mathrm{SO}_{4}$ & 1,400 & $\mathrm{Nd}_{2} \mathrm{O}_{3}$ \\
\hline $\mathrm{Sm}_{2}\left(\mathrm{SO}_{4}\right)_{3} \cdot 7 \mathrm{H}_{2} \mathrm{O}$ & 400 & $\mathrm{Sm}_{2}\left(\mathrm{SO}_{4}\right)_{3}$ & 1000 & $\mathrm{Sm}_{2} \mathrm{O}_{2} \mathrm{SO}_{4}$ & 1340 & $\mathrm{Sm}_{2} \mathrm{O}_{3}$ \\
\hline $\mathrm{Eu}_{2}\left(\mathrm{SO}_{4}\right)_{3} \cdot 8 \mathrm{H}_{2} \mathrm{O}$ & 330 & $\mathrm{Eu}_{2}\left(\mathrm{SO}_{4}\right)_{3}$ & 900 & $\mathrm{Eu}_{2} \mathrm{O}_{2} \mathrm{SO}_{4}$ & 1330 & $\mathrm{Eu}_{2} \mathrm{O}_{3}$ \\
\hline $\mathrm{Gd}_{2}\left(\mathrm{SO}_{4}\right)_{3} \cdot 8 \mathrm{H}_{2} \mathrm{O}$ & 200 & $\mathrm{Frd}_{2}\left(\mathrm{SO}_{4}\right)_{3}$ & 900 & $\mathrm{Crd}_{2} \mathrm{O}_{2} \mathrm{SO}_{4}$ & 1280 & $\mathrm{Gd}_{2} \mathrm{O}_{3}$ \\
\hline \multicolumn{7}{|l|}{ Chiorides: } \\
\hline $\mathrm{LaCl}_{3} \cdot 6 \mathrm{H}_{2} \mathrm{O}$ & 195 & $\mathrm{La}_{2} \mathrm{OCl}_{4}-\mathrm{LaCl}_{3}$ & 580 & $\mathrm{LaOCl}-\mathrm{La}_{2} \mathrm{O}_{3}$ & 1450 & $\mathrm{La}_{2} \mathrm{O}_{3}$ \\
\hline $\mathrm{NdCl}{ }_{3} \cdot 5 \dot{H}_{2} \mathrm{O}$ & 270 & $\mathrm{Nd}_{2} \mathrm{OCl}_{4}$ & 730 & $\mathrm{NdOCl}-\mathrm{Nd}{ }_{2} \mathrm{O}_{3}$ & 1450 & $\mathrm{Nd}_{2} \mathrm{O}_{3}$ \\
\hline $\mathrm{SmCl}_{2}$ & 450 & $\mathrm{SmOCl}$ & 1300 & $\mathrm{Sm}_{2} \mathrm{O}_{3}$ & & \\
\hline $\mathrm{EuCl}_{3} \cdot 5 \mathrm{H}_{2} \mathrm{O}$ & 190 & $\mathrm{Eu}_{2} \mathrm{OCl}_{4}$ & 420 & EuOCl & 1400 & $\mathrm{Eu}_{2} \mathrm{O}_{3}$ \\
\hline $\mathrm{GdCl}_{3} \cdot 5 \mathrm{H}_{2} \mathrm{O}$ & 280 & $\mathrm{Gd}_{2} \mathrm{OCl}_{4}$ & 440 & $\mathrm{GdOCl}$ & 1200 & $\mathrm{Gd}_{2} \mathrm{O}_{3}$ \\
\hline \multicolumn{7}{|l|}{ Fluorides: } \\
\hline $\mathrm{La} \Gamma_{3}$ & 550 & $\mathrm{La}_{4} \mathrm{O}_{3} \mathrm{~F}_{6}$ & 1150 & $\mathrm{LdOF}$ & 1500 & $\mathrm{La}_{2} \mathrm{O}_{3}$ \\
\hline $\mathrm{NuF}_{2} \cdot 1 / 2 \mathrm{H}_{2} \mathrm{O}$ & 300 & $\mathrm{NdF}_{2}$ & 920 & $\mathrm{Nd}_{3} \mathrm{O}_{2} \mathrm{~F}_{5}$ & 1140 & $\mathrm{NdOF}^{f}$ \\
\hline $\mathrm{SmF}_{2} \cdot 1 / 2 \mathrm{H}_{2} \mathrm{O}$ & 900 & $\mathrm{SmF}_{2}$ & 1000 & $\mathrm{Sm}_{3} \mathrm{O}_{2} \mathrm{~F}_{5}$ & 1200 & $\mathrm{SmOF}^{g}$ \\
\hline $\mathrm{EuF}_{2} \cdot 1 / 2 \mathrm{H}_{2} \mathrm{O}$ & 350 & $\mathrm{EuF}_{2}$ & 1250 & EuOF & 1480 & $\mathrm{Eu}_{3} \mathrm{O}_{3}$ \\
\hline $\mathrm{GdF}_{2} \cdot 1 / 2 \mathrm{H}_{2} \mathrm{O}$ & 330 & $\mathrm{GdF}_{2}$ & 740 & $\mathrm{Gd}_{3} \mathrm{O}_{2} \mathrm{~F}_{5}$ & 1060 & GdOF $h$ \\
\hline
\end{tabular}

${ }^{a}$ Temperatures correspond to the points on the thermogram at which the intermediate compounds are initially observed.

${ }^{b} \mathrm{Eu}_{2} \mathrm{O}_{2} \mathrm{CO}_{3}$ at $630^{\circ} \mathrm{C}$ decomposes to $\mathrm{Eu}_{2} \mathrm{O}_{3}$.

${ }^{c} \mathrm{Sm}_{2} \mathrm{O}_{3}-\mathrm{SmONO}_{3}$ at $680^{\circ} \mathrm{C}$ decomposes to $\mathrm{Sm}_{2} \mathrm{O}_{3}$.

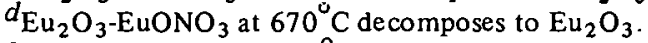

$e^{e} \mathrm{Gd}_{2} \mathrm{O}_{3}-\mathrm{GdONO}_{3}$ at $670^{\circ} \mathrm{C}$ decomposes to $\mathrm{Gd}_{2} \mathrm{O}_{3}$.

$f_{\mathrm{NdUl}}$ at $1,500^{\circ} \mathrm{C}$ decomposes to $\mathrm{Nd}_{2} \mathrm{O}_{3}$.

$g_{\mathrm{SinOF}}$ at $1,500^{\circ} \mathrm{C}$ decomposes to $\mathrm{Sm}_{2} \mathrm{O}_{3}$.

$h_{\mathrm{GdOF}}$ at $1,490^{\circ} \mathrm{C}$ decomposes to $\mathrm{Gd}_{2} \mathrm{O}_{3}$. 


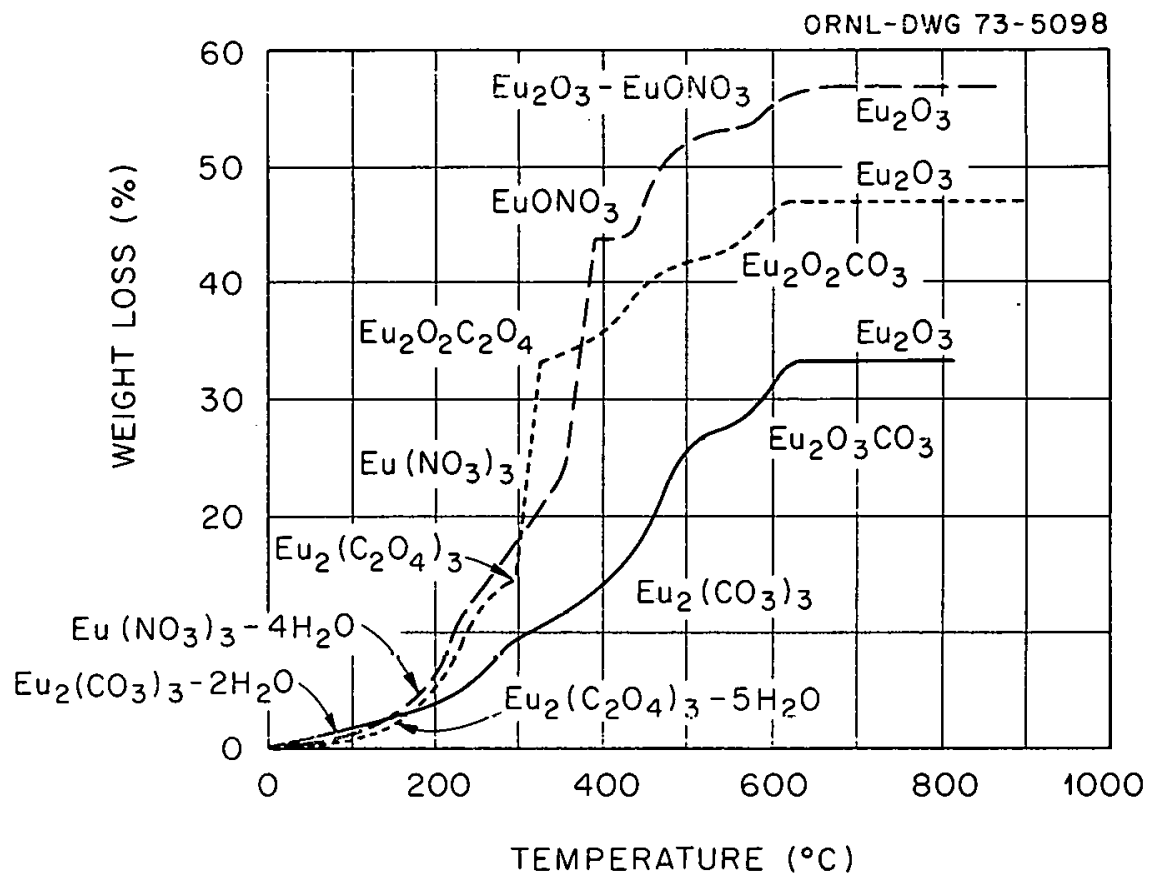

Fig. 3. Europium carbonate, nitrate, and oxalate thermograms. (Ref: S. Stecura, "Crystallographic Modifications and Phase Transformation Rates of Five Rare Earth Sesquioxides," U.S. Bureau of Mines Report of Investigations 6616)

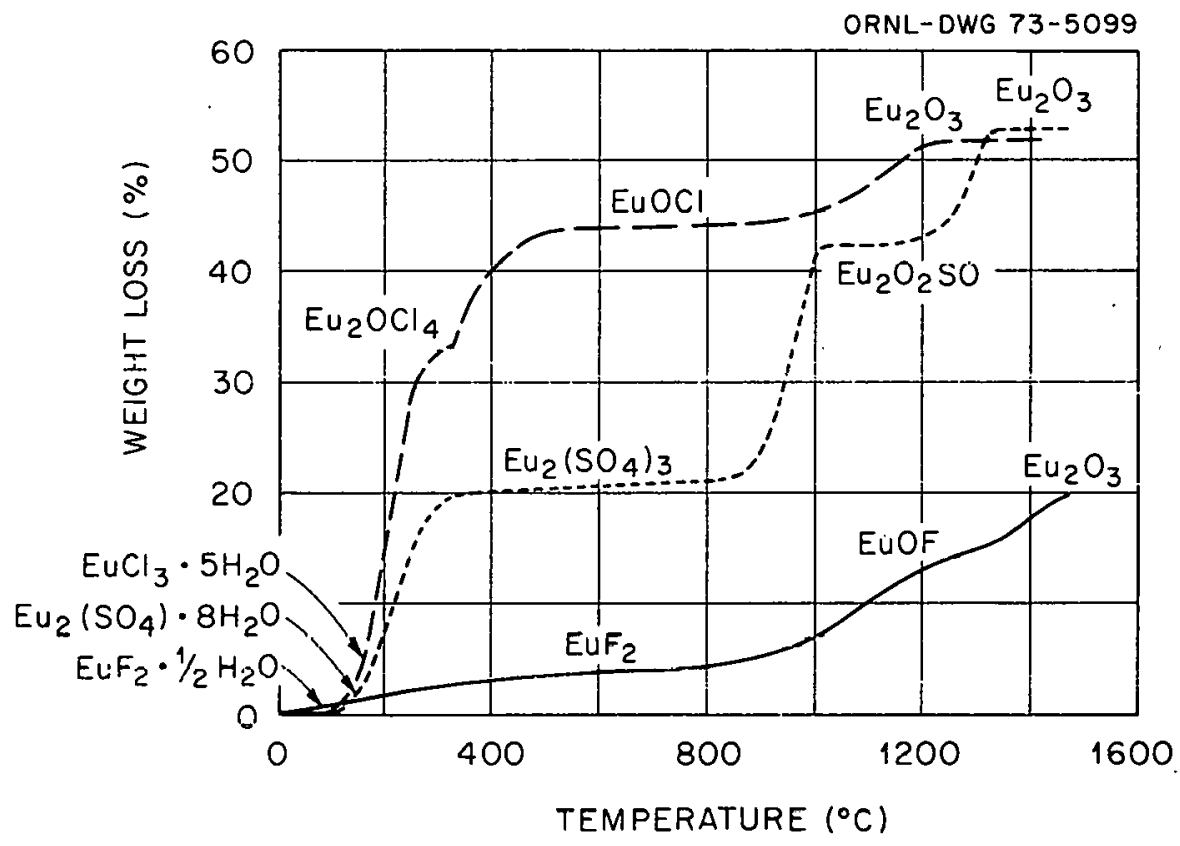

Fig. 4. Europium chloride, fluoride, and sulfate thermograms. (Ref: S. Stecura, "Crystallographic Modification's and Phase Transformation Rates of Five Rare Earth Sesquioxides," U.S. Bureau of Mines Report of Investigations 6616) 


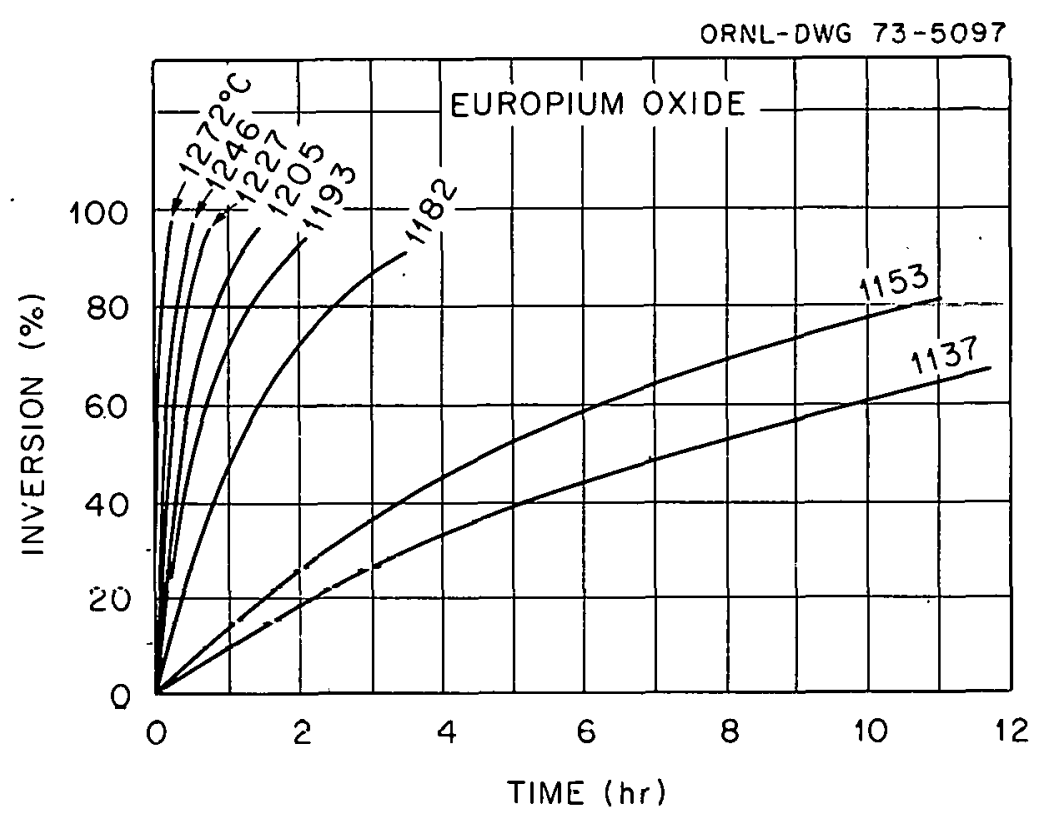

Fig. 5. Kinetic isotherms for $\mathrm{Eu}_{2} \mathrm{O}_{3} \mathrm{C}$ to $\mathrm{B}$ transformation. (Ref: S. Stecura, "Crystallographic Modifications and Phase Transformation Rates of Five Rare Earth Sesquioxides," U.S. Bureau of Mines Report of Investigations 6616)

product was cubic $\mathrm{Eu}_{2} \mathrm{O}_{3}$. This would be expected if the hydroxide had formed, since the hydroxide decomposes to the cubic form of the sesquioxide on calcination at this temperature. Thus their data, suggesting that the transformation is reversible, are questionable. Further data concerning the relative stability of the $\mathrm{B}$ and $\mathrm{C}$ forms suggest that perhaps the transformation from monoclinic to cubic does not occur because the cubic form is metastable. That is, the low-temperature cubic form is considered to be derived from the calcination process through a hindered or topotactic solid-to-solid reaction, which does not allow true thermodynamic equilibrium. The so-called transformation temperature, under this theory, is simply that at which the atoms in the lattice obtain sufticient energy to become mobile. This was deduced by Brauer, ${ }^{16}$ who precipitated europium sesquioxide from a sodium-potassium-europium nitrate melt. The precipitation commenced around $380^{\circ} \mathrm{C}$ and was completed at $420^{\circ} \mathrm{C}$, the range in which the cubic phase should be formed. However, the melt-precipitated europium sesquioxide was the B-type monoclinic form, which was not supposed to occur below $1050^{\circ} \mathrm{C}$. Even the addition of some "seed" C-type cubic powder to the melt did not prevent the appearance of the monoclinic form.

Judging from the latest free-energy data $^{17}$ (Tables 2 and 3) the $C$ form is thermodynamically more stable than the B form from room temperature up to about $1127^{\circ} \mathrm{C}$. But the monoclinic form has not been observed to transform back to the cubic form in this temperature range, probably because there is insufficient mobility of the atoms in the lattice.

The unit cell of the monoclinic structure contains six molecules of $\mathrm{Eu}_{2} \mathrm{O}_{3}$. Several different sets of lattice parameters have been reported from which one can calculate several values for the theoretical density. Some of these are listed in Table 4.

Yer mole of oxygen atoms, the heat of formation of monoclinic europia $(-132 \mathrm{kcal} / \mathrm{mole} O$ at room temperature) is comparable with those of other highly stable oxides ( -134 for $\mathrm{HfO}_{2},-132$ for $\mathrm{ZrO}_{2}$, and -135 for $\left.\mathrm{Al}_{2} \mathrm{O}_{3}\right) \cdot{ }^{18}$ The melting point of $\mathrm{Eu}_{2} \mathrm{O}_{3}$ was originally reported to be near $2050^{\circ} \mathrm{C}^{19}$ but later measurements put it at $2330^{\circ} \mathrm{C} .{ }^{20}$ This value is more in line with the melting points of the neighbor compounds to europia $\left(\mathrm{Sm}_{2} \mathrm{O}_{3}, 2300^{\circ} \mathrm{C} ; \mathrm{Gd}_{2} \mathrm{O}_{3}, 2330^{\circ} \mathrm{C}\right){ }^{19}$ Above $2000^{\circ} \mathrm{C}$, europia undergoes phase 
Table 2. Thermodynamic functions for the formation of cubic $\mathrm{Eu}_{2} \mathrm{O}_{3}$

[Ref: G. C. Fitzgibbon, E. J. Huber, Jr., and C. E. Holley, Jr., "Enthalpy of Formation of Europium Sesquioxide," J. Chem. Thermo. 4, 349-58 (1972)]

\begin{tabular}{|c|c|c|c|c|}
\hline \multicolumn{2}{|c|}{ Temperature } & \multirow{2}{*}{$\begin{array}{c}\Delta H_{f}^{\circ}(T) \\
(\mathrm{cal} / \mathrm{mole})\end{array}$} & \multirow{2}{*}{$\begin{array}{c}\Delta S_{f}^{\circ}(T) \\
\left(\operatorname{cal} K^{-1} \mathrm{~mole}^{-1}\right)\end{array}$} & \multirow{2}{*}{$\begin{array}{c}\Delta G_{f}^{\circ}(T) \\
\text { (cal/mole) }\end{array}$} \\
\hline${ }^{\circ} \mathrm{C}$ & ${ }^{\mathrm{o}} \mathrm{K}$ & & & \\
\hline 25.15 & 298.15 & $-397,400 \pm 900$ & $-78 \pm 2$ & $-374,000 \pm 1100$ \\
\hline 27 & 300 & $-397,400 \pm 900$ & $-78 \pm 2$ & $-373,900 \pm 1100$ \\
\hline 127 & 400 & $-396,700 \pm 900$ & $-76 \pm 2$ & $-366,100 \pm 1200$ \\
\hline 227 & 500 & $-395,900 \pm 900$ & $-75 \pm 2$ & $-358,600 \pm 1400$ \\
\hline 327 & 600 & $-395,100 \pm 900$ & $-73 \pm 2$ & $-351,100 \pm 1500$ \\
\hline 427 & 700 & $-394,400 \pm 900$ & $-72 \pm 2$ & $-343,900 \pm 1700$ \\
\hline 527 & 800 & $-393,600 \pm 900$ & $-71 \pm 2$ & $-336,700 \pm 1900$ \\
\hline 627 & 900 & $-392,900 \pm 900$ & $-71 \pm 2$ & $-329,000 \pm 2100$ \\
\hline 727 & 1000 & $-392,400 \pm 900$ & $-70 \pm 2$ & $-322,700 \pm 2300$ \\
\hline 827 & 1100 & $-396,400 \pm 900$ & $-73 \pm 2$ & $-315,700 \pm 2500$ \\
\hline$y<1$ & 12000 & $-393,800 \pm 900$ & $-73 \div 2$ & $-300,300 \perp 2700$ \\
\hline 1027 & 1300 & $-395,200 \pm 1000$ & $-72 \pm 2$ & $-301,200 \pm 2900$ \\
\hline 1127 & 1400 & $-394,600 \pm 1000$ & $-72 \pm 2$ & $-293,800 \pm 3100$ \\
\hline \multicolumn{5}{|c|}{$\Delta G_{f}^{\circ}(T)=-399,600-16.3 T \log _{10} T+126 T \mathrm{cal} / \mathrm{mole}, 0<T<1090^{\circ} \mathrm{K}$} \\
\hline
\end{tabular}

Table 3. Thermodynamic functions for the formation of monoclinic $\mathrm{Eu}_{2} \mathrm{O}_{3}$

[Ref: G. C. Fitzgibbon, E. J. Huber, Jr., and C. E. Holley, Jr., "Enthalpy of Formation of Europium Sesquioxide," J. Chem. Thermo. 4, 349-58(1972)]

\begin{tabular}{ccccc}
\hline \multicolumn{2}{c}{ Temperature } & $\begin{array}{c}\Delta H_{f}^{\circ}(T) \\
(\mathrm{cal} / \mathrm{mole})\end{array}$ & $\begin{array}{c}\Delta S_{f}^{\circ}(T) \\
\left(\mathrm{cal} K^{-1} \mathrm{~mole}^{-1}\right)\end{array}$ & $\begin{array}{c}\Delta G_{f}^{\circ}(T) \\
(\mathrm{cal} / \mathrm{mole})\end{array}$ \\
\hline${ }^{\circ} \mathrm{C}$ & ${ }^{\circ} \mathrm{K}$ & $-394,700 \pm 800$ & $-76 \pm 2$ & $-372,000 \pm 1000$ \\
25.15 & 298.15 & $-394,700 \pm 800$ & $-76 \pm 2$ & $-371,900 \pm 1000$ \\
27 & 300 & $-394,100 \pm 800$ & $-74 \pm 2$ & $-364,400 \pm 1100$ \\
127 & 400 & $-393,400 \pm 800$ & $-73 \pm 2$ & $-357,000 \pm 1300$ \\
227 & 500 & $-392,700 \pm 800$ & $-72 \pm 2$ & $-349,800 \pm 1400$ \\
327 & 600 & $-392,000 \pm 810$ & $-70 \pm 2$ & $-342,700 \pm 1600$ \\
427 & 700 & $-391,300 \pm 810$ & $-69 \pm 2$ & $-335,700 \pm 1800$ \\
527 & 800 & $-390,600 \pm 810$ & $-69 \pm 2$ & $-328,200 \pm 2000$ \\
627 & 900 & $-390,100 \pm 820$ & $-68 \pm 2$ & $-322,000 \pm 2200$ \\
727 & 1000 & $-394,100 \pm 840$ & $-72 \pm 2$ & $-315,100 \pm 2400$ \\
827 & 1100 & $-393,600 \pm 850$ & $-71 \pm 2$ & $-308,000 \pm 2500$ \\
927 & 1200 & $-393,000 \pm 870$ & $-71 \pm 2$ & $-301,000 \pm 2700$ \\
1027 & 1300 & $-392,500 \pm 900$ & $-70 \pm 2$ & $-293,800 \pm 2900$ \\
1127 & 1400 & $\Delta G_{f}^{\circ}(T)=-396,600-14.2 T \log _{10} T+118 T \mathrm{cal} / \mathrm{mole}, 0<T<1090^{\circ} \mathrm{K}$ \\
& &
\end{tabular}

transformations to three other polymorphic forms. From about 2040 to $2140^{\circ} \mathrm{C}, \mathrm{Eu}_{2} \mathrm{O}_{3}$ takes a hexagonal structure (the $\mathrm{A}$ form), which converts to another hexagonal form (the $\mathrm{H}$ form) from 2140 to about $2260^{\circ} \mathrm{C}$, and it finally converts to an unknown structure (the $\mathrm{X}$ form) just before it melts. ${ }^{21}$ The $\mathrm{A} \rightleftharpoons \mathrm{H}$ transformation is probably of the "displacive" type, involving small thermal effects and no hysteresis. The $\mathrm{H} \rightleftharpoons \mathrm{X}$ transformation, on the other hand, is assumed to be more like the $\mathrm{C} \rightleftharpoons \mathrm{B}$ transformation, classified as "reconstructive." This is also.true for the $\mathrm{B} \rightleftharpoons \mathrm{A}$ phase inversion. The phase stability relations of $\mathrm{Eu}_{2} \mathrm{O}_{3}$ and the other lanthanide oxides are illustrated on a plot of atomic number vs temperature, given as Fig. 6. 
Table 4. Comparative values of lattice parameters and density of B-type $\mathrm{Eu}_{2} \mathrm{O}_{3}$

\begin{tabular}{|c|c|c|c|c|c|}
\hline \multicolumn{4}{|c|}{ Lattice parameter } & \multirow{2}{*}{$\begin{array}{l}\text { Theoretical } \\
\text { density } \\
\left(\mathrm{g} / \mathrm{cm}^{3}\right) \\
\text { calculated }\end{array}$} & \multirow[b]{2}{*}{ Reference } \\
\hline$a(\AA)$ & $b(\AA)$ & $c(\AA)$ & $\begin{array}{c}\beta \\
(\mathrm{deg})\end{array}$ & & \\
\hline 14.110 & 3.603 & 8.805 & 100.05 & 7.95 & 43 \\
\hline 14.12 & 3.600 & 8.801 & 99.98 & 7.96 & 21 \\
\hline 14.09 & 3.601 & 8.790 & 99.8 & 7.98 & 11 \\
\hline 14.082 & 3.604 & 8.778 & 100.0 & 7.99 & 12 \\
\hline 14.1133 & 3.6025 & 8.8080 & 100.026 & 7.951 & ORNL measurement \\
\hline 13.944 & 3.581 & 8.676 & 98.5 & 8.18 & 13 \\
\hline
\end{tabular}

${ }^{a}$ Theoretical density calculated as follows:

$$
\begin{aligned}
\mathrm{g} / \mathrm{cm}^{3} \equiv \frac{351.92 \mathrm{~g} \mathrm{Eu}_{2} \mathrm{O}_{3}}{1 \mathrm{~mole} \mathrm{Eu} 2 \mathrm{O}_{3}} \times \frac{1 \mathrm{~mole} \mathrm{Eu}_{2} \mathrm{O}_{3}}{6.023 \times 10^{23} \text { molecules Eu} \mathrm{O}_{3}} \\
\quad \times \frac{6 \text { molecules } \mathrm{Eu}_{2} \mathrm{O}_{3}}{1 \text { unit cell }} \times \frac{1 \text { unit cell }}{\text { volume }\left(\mathrm{cm}^{3}\right)},
\end{aligned}
$$

where unit ccll volumc $\left(\mathrm{cm}^{3}\right)=(a)(b)(c)(\sin \beta) \times 10^{-24}$.

ORNL-DWG 73-7458

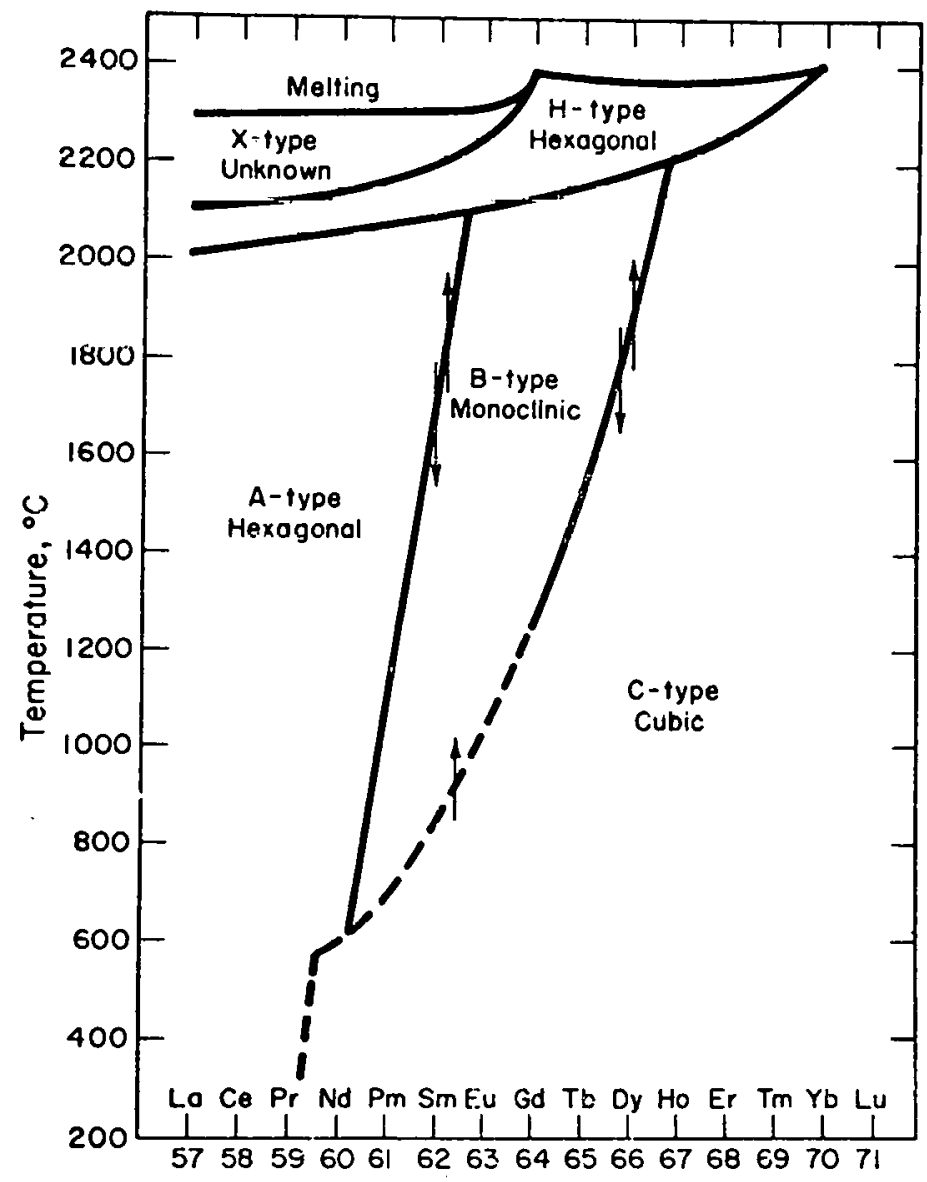

Fig. 6. Stabilities of lanthanide sesquioxides. Data taken from W. C. Mosley, "B-Type ${ }^{244} \mathrm{Cm}_{2} \mathrm{O}_{3}-$ a Candidate Isotopic Power Fucl," DP-MS-67-104. 
The thermal properties of monoclinic $\mathrm{Eu}_{2} \mathrm{O}_{3}$ have been thoroughly investigated. The specific heat, thermal expansion coefficient, and thermal conductivity values are given in Table 5, where they can be compared with those of $\mathrm{B}_{4} \mathrm{C}$. The thermal expansion data are plotted vs temperature in Fig. 7 . Figures 8 and 9 illustrate the temperature dependence of thermal conductivity and show how it correlates with other materials. The thermal expansion is relatively high for a ceramic material, while the thermal conductivity is very low. This combination of properties is likely to lead to a low thermal shock resistance, since the low conductivity can cause high thermal gradients and the high expansion will then bring about large thermal stresses. Some evidence of this poor thermal behavior was noted during the sintering experiments described below, where cracking was observed if the dense materials were cooled too rapidly after firing.

\section{Fabrication}

The higher europium atom density for the monoclinic form as compared with the cubic form indicates that monoclinic $\mathrm{Eu}_{2} \mathrm{O}_{3}$ is the preferred material. Furthermore, in the event that the control-rod center-line temperature should attain $1050^{\circ} \mathrm{C}$ or over, the monoclinic form would not undergo a large volume shrinkage such as would occur if the rod utilized cubic $\mathrm{Eu}_{2} \mathrm{O}_{3}$. For these reasons, europia has been incorporated into reactors in the monoclinic form.

Europia has been fabricated in to many different neutron-absorber-element configurations, but these have nearly always been in the form of a powder dispersed in a metallic matrix for use in thermal reactors.

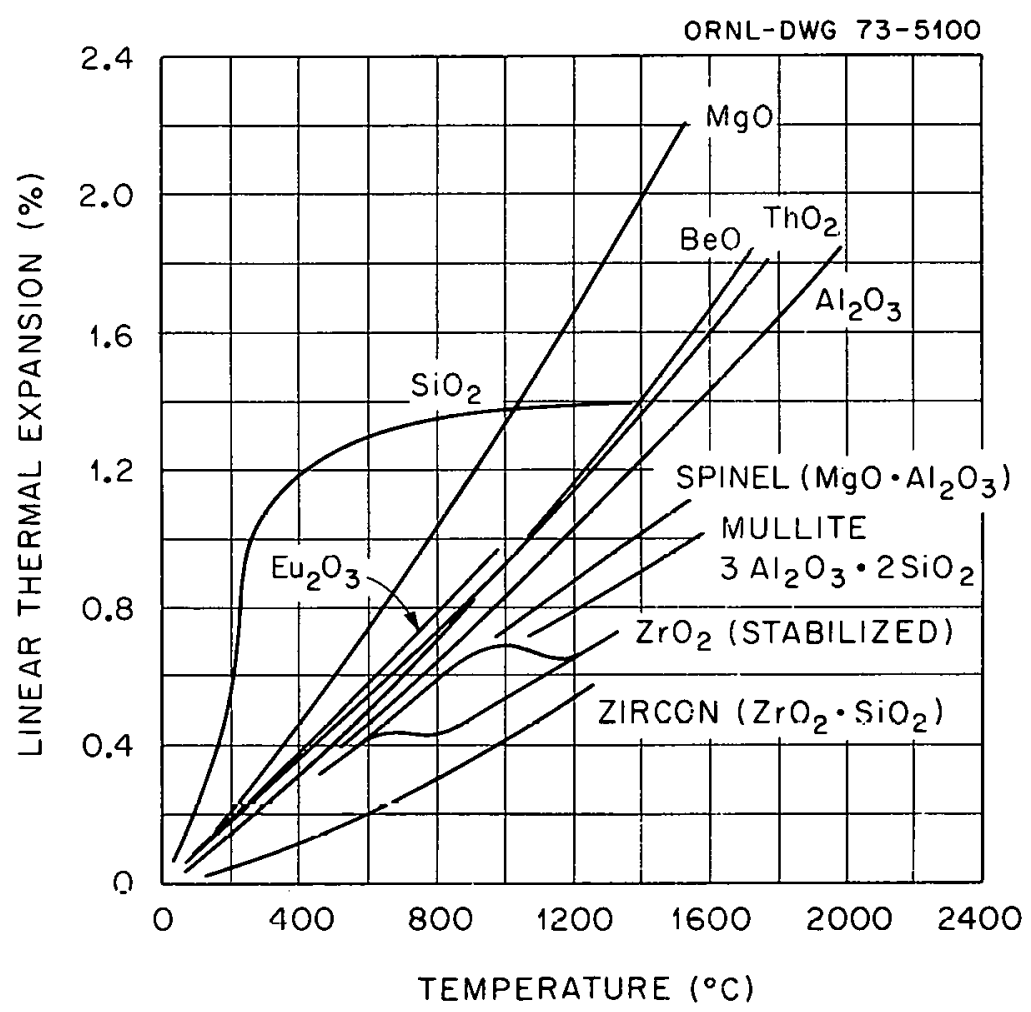

Fig. 7. Linear thermal expansion of several oxides, including $\mathrm{Eu}_{2} \mathbf{O}_{3}$. (Ref: Z. B. Jastrzebski, Nature and Properties of Engineering Materials, p. 361, Wiley, New York, 1959; used with permission of publisher) Europia data from R. L. Wilfong et al., "Thermal Expansion of the Oxides of Yttrium, Cerium, Samarium, Europium, and Dysprosium," U.S. Bureau of Mines Report of Investigations 6180. 
Table 5. Comparison of structure and properties of $\mathrm{Eu}_{2} \mathrm{O}_{3}$ and $\mathrm{B}_{4} \mathrm{C}$

\begin{tabular}{|c|c|c|c|c|c|}
\hline \multirow{2}{*}{ Structure or property } & \multicolumn{3}{|c|}{$\mathrm{Eu}_{2} \mathrm{O}_{3}$} & \multirow{2}{*}{$\mathrm{B}_{4} \mathrm{C}$} & \multirow{2}{*}{ Reference } \\
\hline & Form I & Form II & Reference & & \\
\hline Structure type & Body-centered cubic & Monoclinic & $a$ & Rhomobohedral & $b$ \\
\hline Lat tice parameter, $\AA$ & $a_{0}=10.866$ & $\begin{array}{l}a_{0}=14.1133 \\
b_{0}=3.6025 \\
c_{0}=8.8080 \\
\beta=100.026 \mathrm{deg}\end{array}$ & $a$ & $\alpha_{R}=65.60 \mathrm{deg}$ & $b$ \\
\hline Theoretical density, $\mathrm{g} / \mathrm{cm}^{3}$ & 7.287 & 7.951 & $c$ & 2.51 & $d$ \\
\hline $\begin{array}{l}\text { Absorber cation } \\
\text { density, atoms } / \mathrm{cm}^{3}\end{array}$ & $2.49 \times 10^{22}$ & $2.72 \times 10^{22}$ & $c$ & $2.17 \times 10^{22}$ & $c$ \\
\hline \multicolumn{6}{|l|}{$\begin{array}{l}\text { Free energy of formation, } \\
\mathrm{kcal} / \mathrm{mole}\end{array}$} \\
\hline $\begin{array}{l}\text { at } 25^{\circ} \mathrm{C} \\
\text { at } 727^{\circ} \mathrm{C}\end{array}$ & $\begin{array}{l}-374 \\
-322.7\end{array}$ & $\begin{array}{l}-372 \\
-322\end{array}$ & $\begin{array}{l}e \\
e\end{array}$ & $\begin{array}{l}-12.55\left(527^{\circ} \mathrm{C}\right) \\
-8.68\left(2227^{\circ} \mathrm{C}\right)\end{array}$ & $\begin{array}{l}f \\
f\end{array}$ \\
\hline Melting point, " C & & .2300 & $g$ & $3350 \cdots 2500$ & $d$ \\
\hline \multicolumn{6}{|l|}{$\begin{array}{l}\text { Specific heat, } \\
\text { cal mole } \\
-1 \\
\left({ }^{\circ} \mathrm{C}\right)^{-1}\end{array}$} \\
\hline 0 to $800^{\circ} \mathrm{C}$ & & 33.3 & $h$ & $16.6\left(260^{\circ} \mathrm{C}\right)$ & $i$ \\
\hline \multicolumn{6}{|l|}{$\begin{array}{l}\text { Linear coefficient } \\
\text { of thermal expansion, }\left({ }^{\circ} \mathrm{C}\right)^{-1}\end{array}$} \\
\hline 30 to $840^{\circ} \mathrm{C}$ & & $10.5 \times 10^{-6}$ & $j$ & $\begin{array}{l}4.5 \times 10^{-6} \\
\left(25-800^{\circ} \mathrm{C}\right)\end{array}$ & $i$ \\
\hline 0 to $1000^{\circ} \mathrm{C}$ & & $10.35 \times 10^{-6}$ & $k$ & $\begin{array}{l}5.54 \times 10^{-6} \\
\left(25-1000^{\circ} \mathrm{C}\right)\end{array}$ & $d$ \\
\hline 0 to $1200^{\circ} \mathrm{C}$ & & $10.3 \times 10^{-6}$ & $h$ & $\begin{array}{l}6.02 \times 10^{-6} \\
\left(25-1500^{\circ} \mathrm{C}\right)\end{array}$ & $d$ \\
\hline \multicolumn{6}{|l|}{$\begin{array}{l}\text { Thermal conductivity, } \\
\mathrm{W} \mathrm{m}^{-1}(\mathrm{C} C)^{-1}\end{array}$} \\
\hline at $25^{\circ} \mathrm{C}$ & & 3.42 & $l$ & $33.5\left(25^{\circ} \mathrm{C}\right)$ & $m$ \\
\hline at $1000^{\circ} \mathrm{C}$ & & 2.38 & $n$ & $12.6\left(800^{\circ} \mathrm{C}\right)$ & $m$ \\
\hline $\begin{array}{l}\text { Young's modulus, psi at } 25^{\circ} \mathrm{C} \\
\text { Transformation rate }\end{array}$ & & $4.5 \times 10^{6}$ & $h$ & $65 \times 10^{6}$ & $d$ \\
\hline at $1100^{\circ} \mathrm{C}$ & Several days & & $p$ & & \\
\hline at $13 m n^{n}$ : & Lesss thàn I hr̃ & & $p$ & & \\
\hline
\end{tabular}

${ }^{a}$ ORNL measurements.

$b_{\mathrm{J}}$. L. Hoard and R. E. Hughes, The Chemistry of Boron and Its Compounds, ed. by E. L. Muetterties, Wiley, London, pp. $25-154,1967$.

$c_{\text {ORNL calculation. }}$

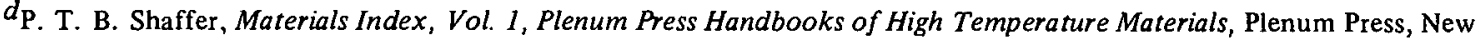
York, 1964 .

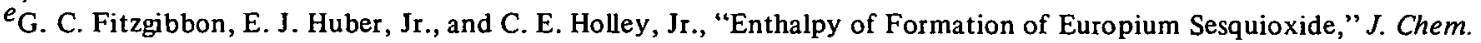
Thermo. 4, 349-58 (1972).

$J_{J A N A F}$ Thermochemical Tables 1960-65, P.B. 168, 370, Dow Chemical Company, New York.

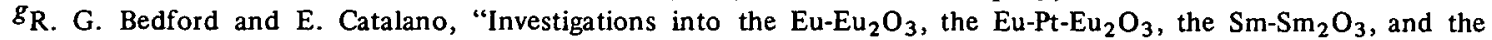
$\mathrm{Yb}-\mathrm{Yb}_{2} \mathrm{O}_{3}$ Systems," J. Solid State Chem. 3, 112-24 (1971).

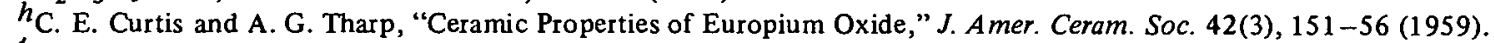

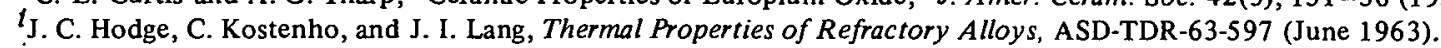

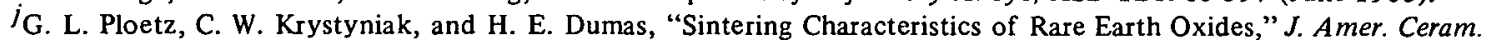
Soc. 41(12), 551-54 (1958).

$k_{\mathrm{K}}$. L. Wilfong et al., Thermal Expansion of the Oxides of Yttrium, Cerium, Samarium, Europium, and Dysprosium, U.S. Bureau of Mines Report of Investigations 6180.

l Kiparisov et al., "Thermal Conductivity of $\mathrm{Eu}_{2} \mathrm{O}_{3}, "$ I.A.N. Neorg. Mater. 7, 1073 (1971).

$m_{\mathrm{H}}$. W. Deems and C. F. Lucks, Thermal Conductivity of Boron Carbide from $100^{\circ} \mathrm{C}$ to $800^{\circ} \mathrm{C}$, BMI-713, Battelle Memorial Institute (December 10, 1951).

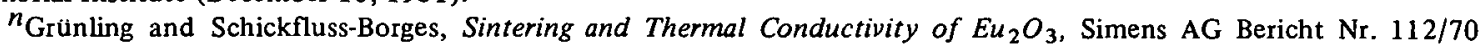
(1970).

${ }^{\circ}$ Cubic $\rightarrow$ monoclinic (time to obtain $100 \%$ monoclinic form at given temperature).

$p_{\mathrm{S}}$. Stecura, Crystallographic Modifications and Phase Transformation Rates of Five Rare Earth Sesquioxides, U.S. Bureau of Mines Report of Investigations 6616. 


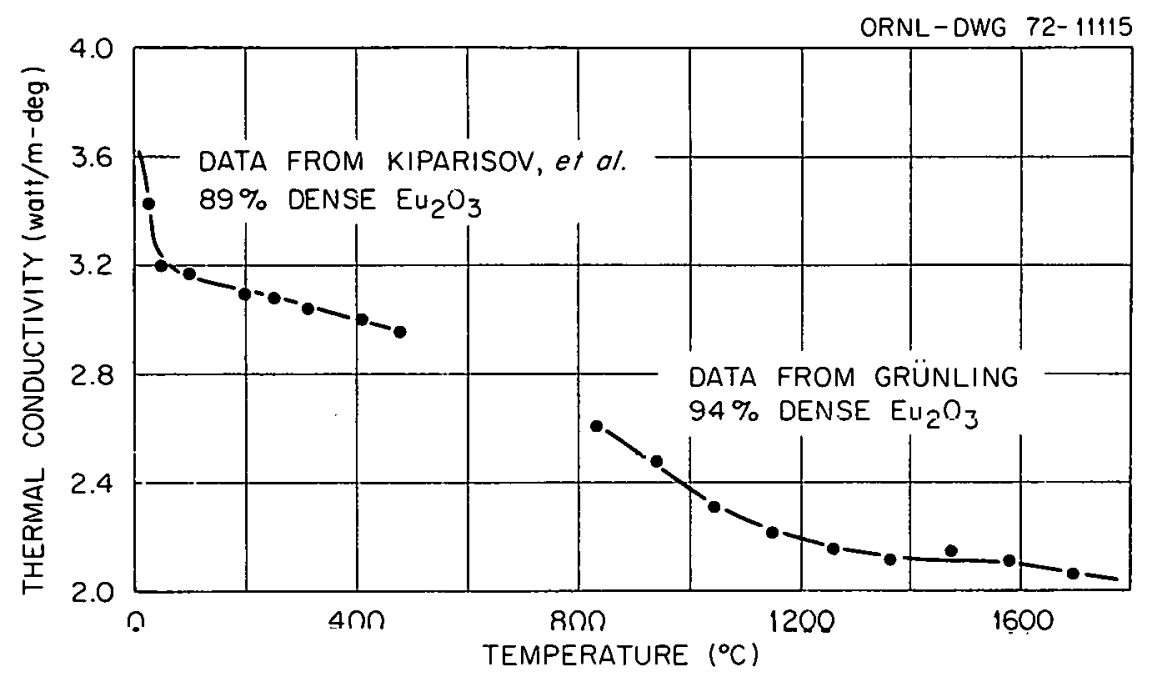

Fig. 8. Thermal conductivity of $\mathrm{Eu}_{2} \mathrm{O}_{3}$. [Refs: Grünling and Schickfluss-Borges, "Sintering and Thermal Conductivity of $\mathrm{Eu}_{2} \mathrm{O}_{3}$," Siemens AG Bericht Nr. 112/70 (1970); Kiparisov et al., "Thermal Conductivity of $\mathrm{Eu}_{2} \mathrm{O}_{3}$," I.A.N. Neorg. Mater. 7, 1073 (1971)]

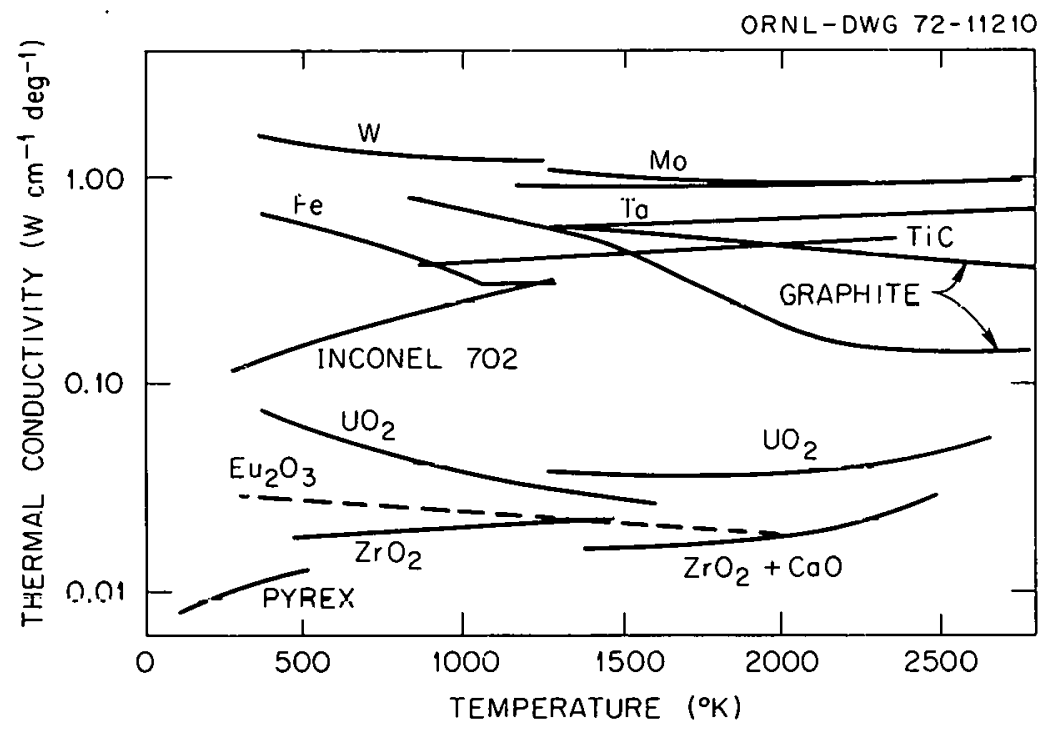

Fig. 9. Thermal conductivity of $\mathrm{Eu}_{2} \mathrm{O}_{3}$ relative to several other materials. (Ref: D. L. McElroy and J. P. Moore, "Radial Heat Flow Methods for the Measurement of the Thermal Conductivity of Solids," in Thermal Conductivity, Vol. 1, ed. by R. P. Tye, Academic Press, New York, 1969) Europia data from Grünling and Schickfluss-Borges, "Sintering and Thermal Conductivity of $\mathrm{Eu}_{2} \mathrm{O}_{3}$," Siemens AG Bericht Nr. 112/70 (1970); Kiparisov et al., "Thermal Conductivity of $\mathrm{Eu}_{2} \mathrm{O}_{3}, "$ I.A.N. Neorg. Mater. 7, 1073 (1971).

These elements have performed well, as will be discussed later; however, because the LMFBR operates with a fast-neutron spectrum, a higher concentration of europium atoms is required due to the rapid falloff of absorption crnss sections with neutron energy. Hence, a solid pellet of $\mathrm{Eu}_{2} \mathrm{O}_{3}$ is the desirable form."

Dense pellets have been prepared by several investigators without much difficulty. Researchers at General Electric in 196? rondur.ted irradiation studies of lanthanide compounds for which they prepared monoclinic $\mathrm{Eu}_{2} \mathrm{O}_{3}$ pellets of 93 to $96 \%$ theoretical density. ${ }^{22}$ They cold pressed their powder at about 
$50,000 \mathrm{psi}$ and sintered the resulting pellet at $1500^{\circ} \mathrm{C}$ for $16 \mathrm{hr}$ in air. Grünling and Schickfluss-Borges ${ }^{23}$ describe the fabrication of monoclinic $\mathrm{Eu}_{2} \mathrm{O}_{3}$ pellets by isostatically pressing and sintering. Using isostatic pressures of 73,500 to $14 \%, 000 \mathrm{psi}$, densities of 96 to $97 \%$ of theoretical were obtained on subsequent sintering at $1500^{\circ} \mathrm{C}$ in an oxidizing atmosphere. Their sintering times ranged from about 3.3 to $11 \mathrm{hr}$. It was stated by these authors that the fabrication conditions employed were far from optimum, and that higher densities could certainly be obtained by further work.

Pellets of monoclinic $\mathrm{Eu}_{2} \mathrm{O}_{3}$ of $94 \pm 2 \%$ density (using $7.95 \mathrm{~g} / \mathrm{cm}^{3}$ as theoretical density for the B-type phase) were recently produced at ORNL for irradiation test purposes, and one objective of the test was to determine if there would be any behavior difference due to method of fabrication. Hence, both hot pressing and sintering were investigated. Initial cold pressing and sintering experiments yielded dense pellets, but these cracked quite extensively after sintering. The same effect was found in the hot-pressed pellets, which had been cooled by simply shutting off the furnace. The cracking behavior was similar to the type seen in other materials that have poor thermal shock resistance, so slower conling rates were empinyed. This eliminated the problem completely.

Tho otarting matorial wa3 $99.99 \%$ pure $\mathrm{Eu}_{2} \mathrm{O}_{3}$ jüwdis in llie culic (C-lype) funt1. Ruds were isostatically pressed at 40,000 psi and sintered in a vacuum furnace. The heating rate was approximately $15^{\circ} \mathrm{C} / \mathrm{min}$ to $1750^{\circ} \mathrm{C}$, at which temperature the furnace was held for $1 \mathrm{hr}$ under a vacuum of $2 \times 10^{-5}$ torr. A cooling rate of about $3^{\circ} \mathrm{C} / \mathrm{min}$ down to $850^{\circ} \mathrm{C}$ yielded uncracked rods with densities of 92 to $95 \%$ of theoretical. These rods were dark gray to black on removal from the furnace, probably due to a loss of oxygen from the $\mathrm{Eu}_{2} \mathrm{O}_{3}$ leading to a slightly reduced state. This small loss of oxygen has been documented ${ }^{24}$ for $\mathrm{Eu}_{2} \mathrm{O}_{3}$. To restore the oxygen and clean the surface, the rods were heated to $1000^{\circ} \mathrm{C}$ in air and held for $1 \mathrm{hr}$. The resulting pieces were yellowish-tan in color.

Hot pressing as a fabrication method has the advantage of producing a given density at either a lower temperature or a shorter time than the sintering technique. The hot-pressed product can then have a smaller grain size, which is usually desirable. Pellets of 93 to $95 \%$ density have heen vacounm hot pressed by the author, utilizing cubic $\mathrm{Eu}_{2} \mathrm{O}_{3}$ as the starting material. The powder was prepressed in a steel die into pellets, which were subsequently loaded into a graphite die. Hot pressing was done at $1500^{\circ} \mathrm{C}$ under a vacuum of approximately $5 \times 10^{-4}$ torr. Pressurc was applicd slowly and reached 5000 psi after abuut 45 min. Pressing was stopped when proper density was obtained. The furnace was then cooled slowly, keeping the pellets under pressure. The carbon layer adhering to the pellets was burned off at $1000^{\circ} \mathrm{C}$ in air, leaving a palc-pink pcllct.

Both the hot pressed and the sintered pellets were then machined to final size. These are illustrated in Figs. 10 and 11. As expected, the lower temperature used for hot pressing resulted in a finer grained product, but in both samples the grains appear equiaxed. Figures 12 and 13 illustrate the microstructures of the europia pellets.

Further densification experiments have been continuing at ORNL. Both cubic and monoclinic forms have been hot pressed to greater than $90 \%$ density.

Researchers at $\mathrm{HEDL}$ have produced $90 \pm 2 \%$-dense $\mathrm{C}$-form $\mathrm{Eu}_{2} \mathrm{O}_{3}$ by hot pressing under argon at 950 to $1000^{\circ} \mathrm{C}^{25}$ This work led the author to attempt densification of the monoclinic form by first pressing at around $1000^{\circ} \mathrm{C}$ to obtain high-density $\mathrm{C}$ form and then heating under pressure to $1300^{\circ} \mathrm{C}$ to convert to $\mathrm{B}$ form. This proved very successtul. Preliminary results show that pressing the cubic powder at $1000^{\circ} \mathrm{C}$ for 1 $\mathrm{hr}$ and heating under pressure at $1300^{\circ} \mathrm{C}$ for $1 \mathrm{hr}$ yields $96 \%$-dense pellets. Initial pressing at $1050^{\circ} \mathrm{C}$ and then at $1300^{\circ} \mathrm{C}$ results in $97 \%$ density, while $98.8 \%$ density was obtained by first pressing at $1100^{\circ} \mathrm{C}$. When this experiment was performed at $1125^{\circ} \mathrm{C}$, a printout of the ram travel vs time showed that all of the densification was occurring at $1125^{\circ} \mathrm{C}$, while no further density was gained at the subsequent $1300^{\circ} \mathrm{C}$ 


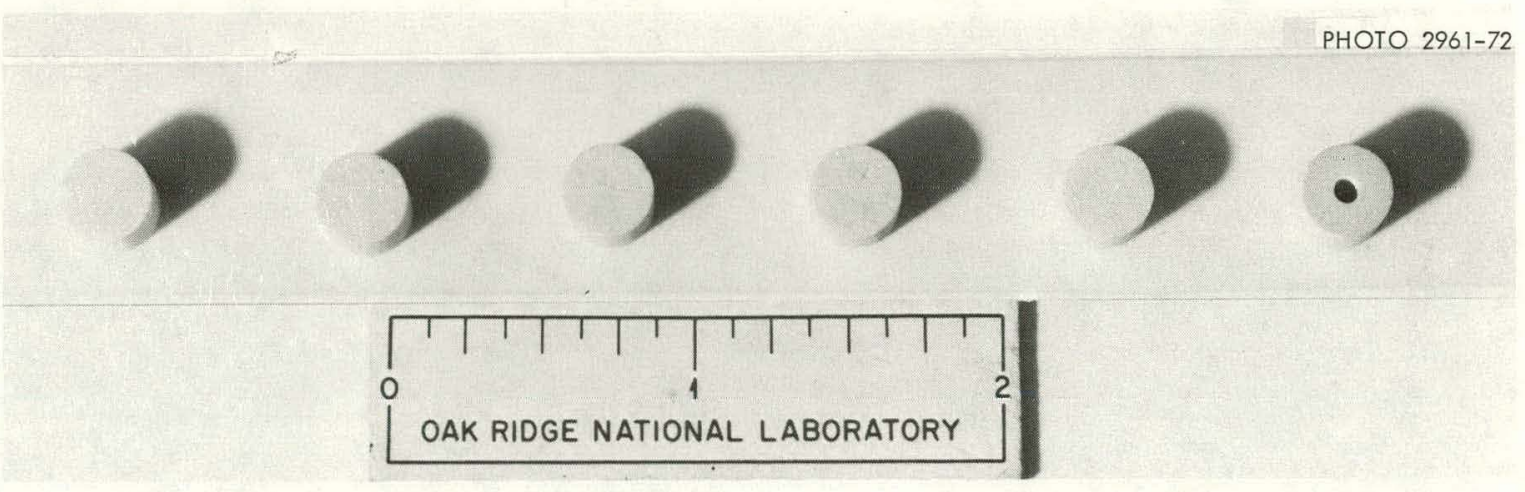

Fig. 10. $\mathrm{Eu}_{2} \mathrm{O}_{3}$ specimens isostatically pressed at 40,000 psi and sintered at $1750^{\circ} \mathrm{C}$ and $2 \times 10^{-5}$ torr.

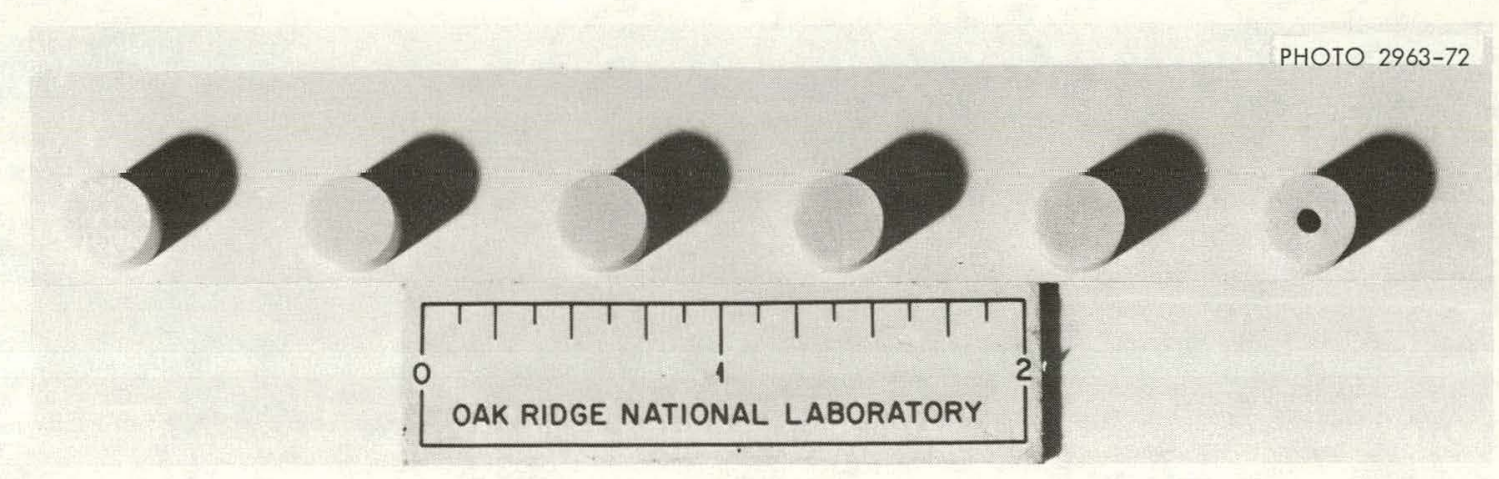

Fig. 11. $\mathrm{Eu}_{2} \mathrm{O}_{3}$ specimens vacuum hot pressed at $1500^{\circ} \mathrm{C}$ and $5 \times 10^{-4}$ torr.

pressing. The pellets from this experiment yielded immersion densities of 7.89 to $7.95 \mathrm{~g} / \mathrm{cm}^{3}$. This corresponds to 99 to $100 \%$ of a theoretical density of $7.95 \mathrm{~g} / \mathrm{cm}^{3}$. Thus, $100 \%$-dense monoclinic $\mathrm{Eu}_{2} \mathrm{O}_{3}$, as illustrated in Fig. 14, can be prepared by vacuum hot pressing the cubic powder at $1125^{\circ} \mathrm{C}$ for $1 \mathrm{hr}$. As a matter of fact, the ram travel data indicate that this may be accomplished in even less time. This hot-pressing development, along with a sintering study, is continuing.

\section{Irradiation Behavior}

It is a recognized fact that $\mathrm{Eu}_{2} \mathrm{O}_{3}$ serves as an excellent control material for thermal reactors. Several reactors have made use of its high cross section and long lifetime, such as the High Flux Isotope Reactor at ORNL, the U.S. Army "SM" and "PM" reactors, and the High Flux Beam Reactor at Brookhaven. In these instances the oxide was incorporated into a metal matrix in the form of a cermet. This was done to protect the oxide from contact with high-temperature water, which severely attacks $i^{26}$ and which could cause swelling and loss of control-rod integrity. The cermet also exhibits good structural strength and prevents the 


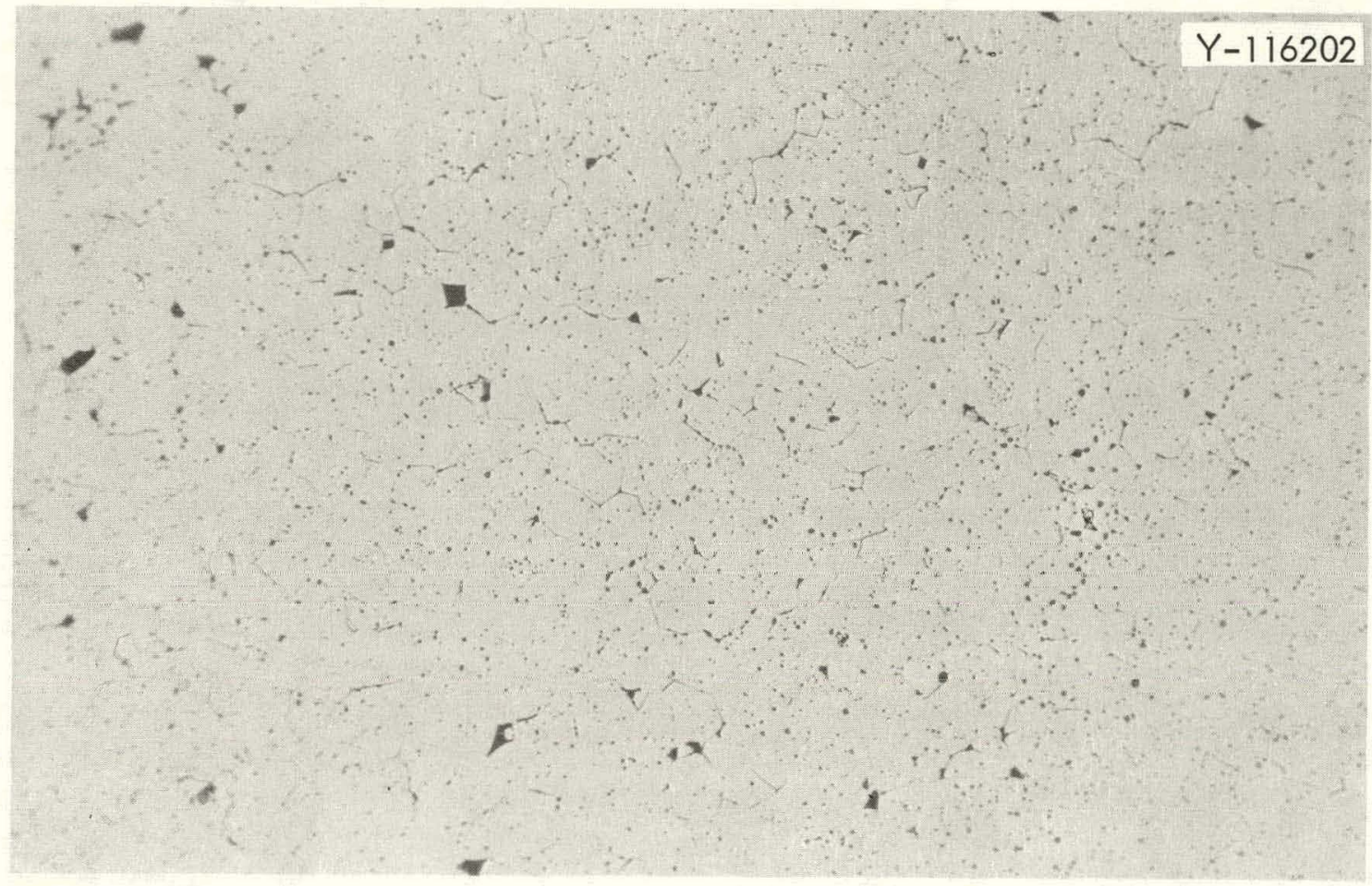

Fig. 12. Micrograph of sintered $93 \%$-dense $\mathrm{Eu}_{2} \mathrm{O}_{3} .100 \times$.

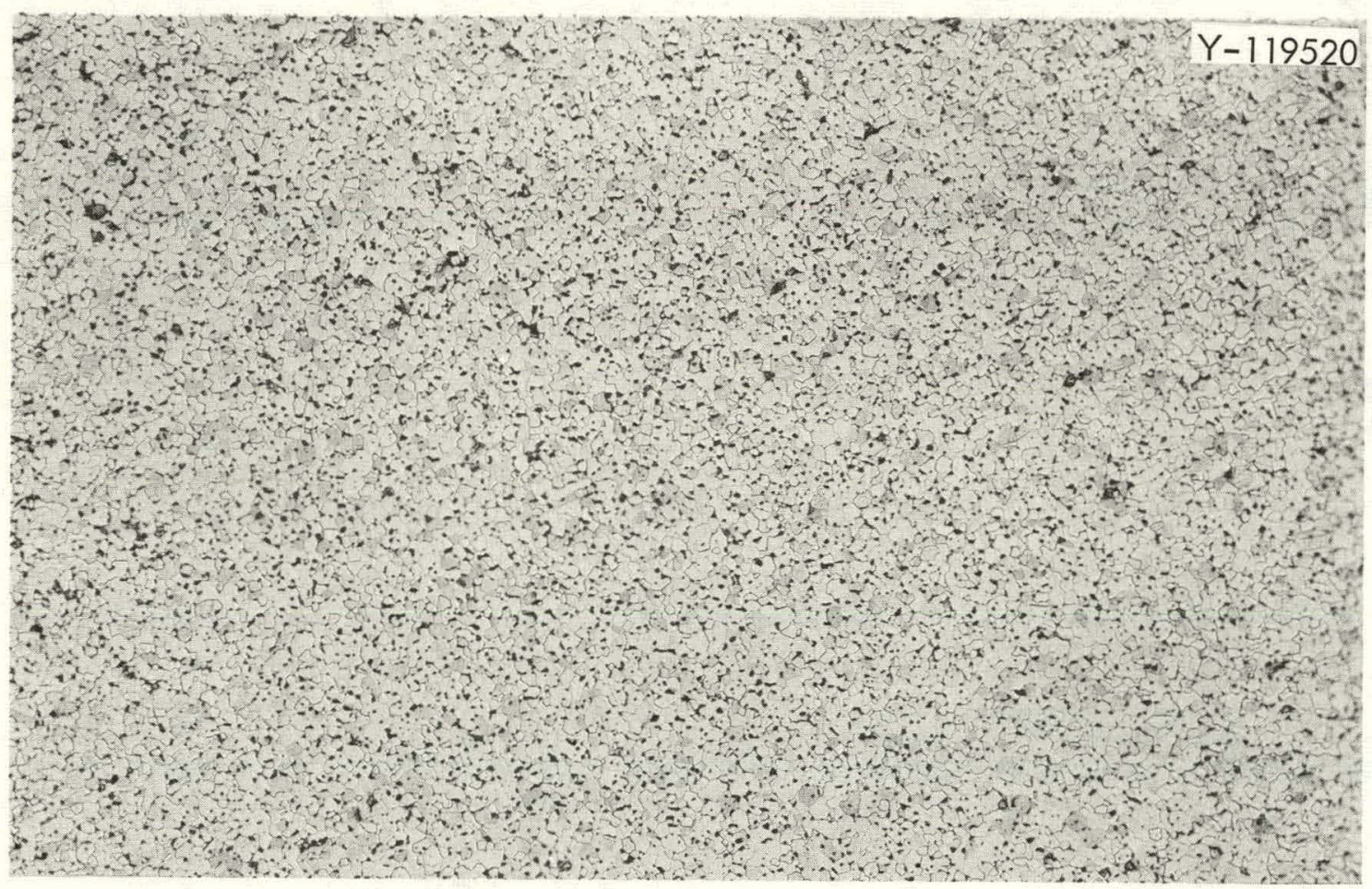

Fig. 13. Micrograph of hot-pressed $93 \%$-dense $\mathrm{Eu}_{2} \mathrm{O}_{3} .100 \times$. 


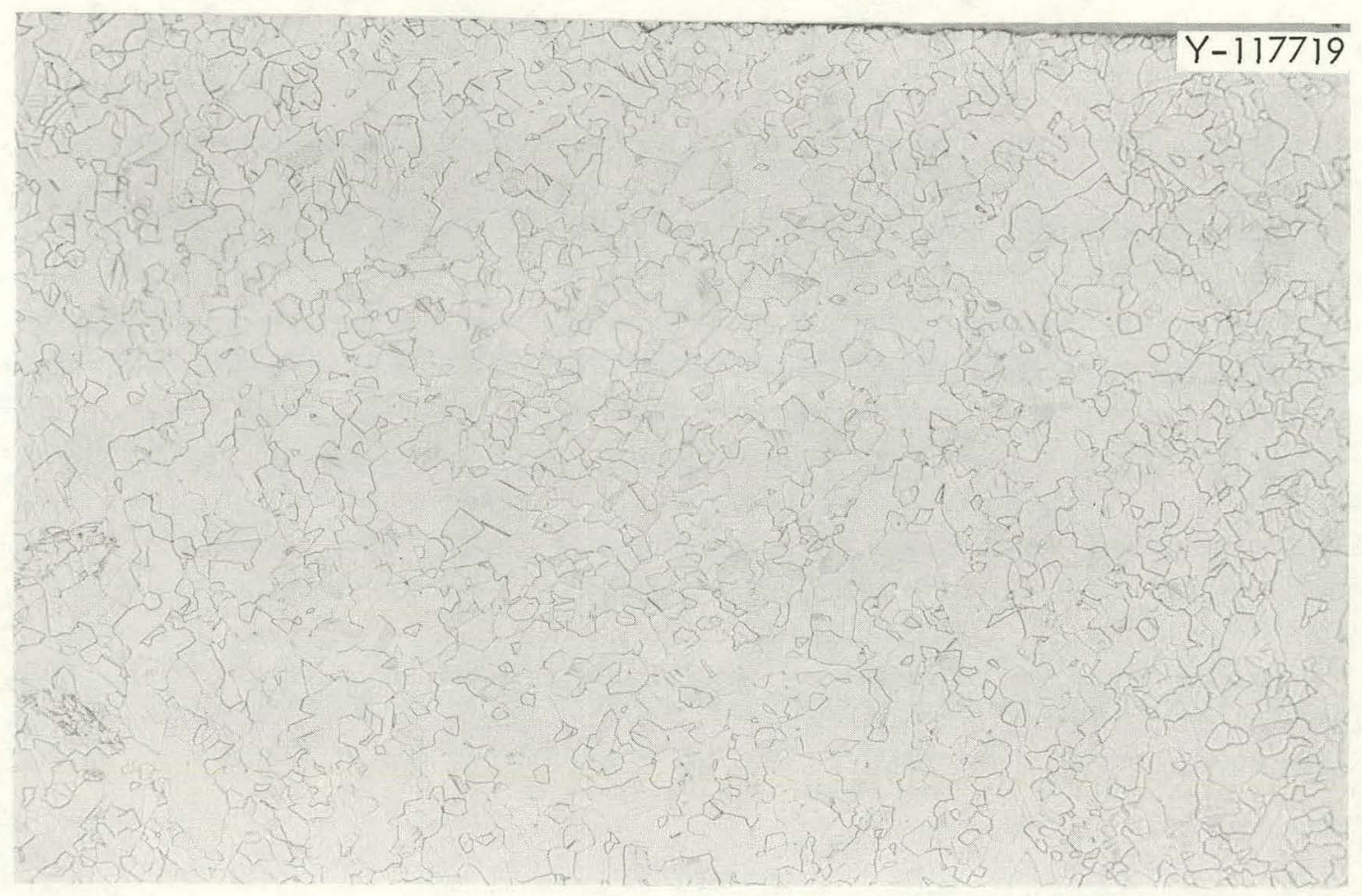

Fig. 14. Micrograph of fully dense hot pressed $\mathrm{Eu}_{2} \mathrm{O}_{3} .100 \times$.

possible leaching of radioactive isotopes into the coolant. ${ }^{27}$ Postirradiation inspection of these control-rod elements has indicated excellent dimensional stability, good retention of reactivity worth, and lack of particle degradation. ${ }^{28-33}$ Indeed, an $\mathrm{Eu}_{2} \mathrm{O}_{3}$ - $\mathrm{Al}$ dispersion-type control element from the HFIR that had undergone more than $48,000 \mathrm{MWd}$ of irradiation showed no significant loss of nuclear worth. ${ }^{29}$ This same element exhibited no conre-cladding separation, matrix cracking, or chemical reaction between the $\mathrm{Eu}_{2} \mathrm{O}_{3}$ and the aluminum. Most of the other reports concern dispersion of $\mathrm{Eu}_{2} \mathrm{O}_{3}$ in stainless steel, and the results are essentially the same.

Irradiation performance data on dense pellets of pure $\mathrm{Eu}_{2} \mathrm{O}_{3}$ are scarce, as europia has not been used in reactors in this form. However, some U.S. data from researchers at General Electric and some Russian data have been published. The GE report is quite detailed, concerning several lanthanide oxides and borates. ${ }^{22}$ The $\mathrm{Eu}_{2} \mathrm{O}_{3}$ was sintered intn pelle.ts of 93 to $96 \%$ of theoretical density and irradiated in the GETR. The pellets received an integrated thermal neutron flux of from 1.2 to $1.9 \times 10^{21}$ neutrons $/ \mathrm{cm}^{2}$ at a maximum operating temperature of $150^{\circ} \mathrm{C}$. One pellet exhibited minor radial cracking, whereas the more dense pellet did not. No gross fracturing was observed, and dimensional changes were insignificant. Metallographic examination of pre- and postirradiation samples revealed that no significant changes had occurred during irradiation, yet $\mathrm{x}$-ray diffraction indicated that gross damage had occurred in the crystal structure. The pellets gave no x-ray diffraction peaks, indicating that the monoclinic structure may have become amorphous. Goltsev et al. ${ }^{34}$ reported identical observations, except that the pellet density had decreased by $1 \%$ after receiving an integrated flux of about $1 \times 10^{22}$ neutrons $/ \mathrm{cm}^{2}$ at 350 to $600^{\circ} \mathrm{C}$. 


\section{Materials Compatibility}

Another important consideration in determining the suitability of a material for use in a reactor environment is its compatibility with cladding or other structural materials. Of prime importance is the occurrence or lack of occurrence of reactions that could lead to control-rod failure. Failure can be defined in several ways, such as cladding-absorber separation possibly leading to absorber thermal degradation, absorber-induced cladding swelling and resulting hot spots in the reactor, etc. The present fast reactor absorber design involves encapsulation of absorber pellets in type 316 stainless steel pins. This steel's composition is roughly 16 to $18 \mathrm{wt} \% \mathrm{Cr}, 10$ to $14 \mathrm{wt} \% \mathrm{Ni}$, and 2 to $3 \mathrm{wt} \% \mathrm{Mo}$, with $0.1 \%$ maximum carbon, $2 \%$ maximum manganese, and $1 \%$ maximum silicon. ${ }^{35}$ Leitten $^{36}$ studied the compatibility of stainless steels with $\mathrm{Eu}_{2} \mathrm{O}_{3}$ in the temperature range 900 to $1250^{\circ} \mathrm{C}$. $\mathrm{He}$ found that $\mathrm{Eu}_{2} \mathrm{O}_{3}$ reacted with the austenitic steel, resulting in swelling and the formation of a compound containing europium and silicon. The degree of reaction increased with time, temperature, and amount of silicon present in the steel. It was determined that $\mathrm{Eu}_{2} \mathrm{O}_{3}$ and stainless steels made from elemental powders containing less than $58 \mathrm{ppm} \mathrm{Si}$ were stable in contact at $1230^{\circ} \mathrm{C}$. His tests were of quite short duration, however, from 1.5 to $16 \mathrm{hr}$.

Compatibility studies of lanthanide oxides with various metal powders were reported by Hoyt et al. ${ }^{22}$ Their data, given in Table 6, were obtained after $2 \mathrm{hr}$ of heating in vacuum at the given temperatures. It can be seen that $\mathrm{Eu}_{2} \mathrm{O}_{3}$ reacts with iron (probably), nickel, and type 304 stainless steel at temperatures below $1200^{\circ} \mathrm{C}$.

Table 6. Compatibility of lanthanide oxides and various metals

[Ref: E. W. Hoyt et al., Rare Earth Oxides and Rare Earth Borates: Corrosion, Compatibility. and Radiation Effects, GEAP-3909 (April 17, 1962)]

\begin{tabular}{llll}
\hline Matrix & Oxide & $\begin{array}{c}\text { Temp. } \\
(\mathrm{C})\end{array}$ & Redcliun \\
\hline $\mathrm{Fe}$ & $\mathrm{Dy}_{2} \mathrm{O}_{3}$ & 1150 & No \\
$\mathrm{Fe}$ & $\mathrm{Sm}_{2} \mathrm{O}_{3}$ & 1150 & No \\
$\mathrm{Fe}$ & $\mathrm{Eu}_{2} \mathrm{O}_{3}$ & 1150 & Uncertain \\
$\mathrm{Ni}$ & $\mathrm{Dy}_{2} \mathrm{O}_{3}$ & 1150 & Yes \\
$\mathrm{Ni}$ & $\mathrm{Sm}_{2} \mathrm{O}_{3}$ & 1150 & Yes \\
$\mathrm{Ni}$ & $\mathrm{Eu}_{2} \mathrm{O}_{3}$ & 1150 & Y'es \\
SS-304 & $\mathrm{Dy}_{2} \mathrm{O}_{3}$ & 1200 & No \\
SS-304 & $\mathrm{Sm}_{2} \mathrm{O}_{3}$ & 1200 & No \\
SS-304 & $\mathrm{Eu}_{2} \mathrm{O}_{3}$ & 1200 & Yes \\
$\mathrm{Hastelloy-B}$ & $\mathrm{Dy}_{2} \mathrm{O}_{3}$ & 1120 & No \\
$\mathrm{Hastelloy-B}$ & $\mathrm{Sm}_{2} \mathrm{O}_{3}$ & 1120 & No \\
$\mathrm{Hastelloy-B}$ & $\mathrm{Eu}_{2} \mathrm{O}_{3}$ & 1120 & Yes \\
Inconel-X & $\mathrm{Dy}_{2} \mathrm{O}_{3}$ & 1120 & No \\
Inconel-X & $\mathrm{Sm}_{2} \mathrm{O}_{3}$ & 1120 & No \\
Inconel-X & $\mathrm{Eu}_{2} \mathrm{O}_{3}$ & 1120 & Yes \\
Mo & $\mathrm{Dy}_{2} \mathrm{O}_{3}$ & 1900 & No \\
Mo & $\mathrm{Sm}_{2} \mathrm{O}_{3}$ & 1900 & No \\
Mo & $\mathrm{Eu}_{2} \mathrm{O}_{3}$ & 1900 & No \\
Nb & $\mathrm{Dy}_{2} \mathrm{O}_{3}$ & 1800 & No \\
Nb & $\mathrm{Sm}_{2} \mathrm{O}_{3}$ & 1800 & No \\
Nb & $\mathrm{Eu}_{2} \mathrm{O}_{3}$ & 1800 & No \\
W & $\mathrm{Dy}_{2} \mathrm{O}_{3}$ & 2000 & No \\
W & $\mathrm{Sm}_{2} \mathrm{O}_{3}$ & 2000 & No \\
W & $\mathrm{Eu}_{2} \mathrm{O}_{3}$ & 2000 & No \\
\hline
\end{tabular}


Longer-term compatibility tests of $\mathrm{Eu}_{2} \mathrm{O}_{3}$ have been conducted at ORNL by M. M. Martin. In these tests, pellets of $93 \%$-dense monoclinic $\mathrm{Eu}_{2} \mathrm{O}_{3}$ were placed inside cylinders of various metals. The test conditions are as follows:

\section{Couples}

$$
\begin{aligned}
& \mathrm{Eu}_{2} \mathrm{O}_{3}-316 \text { stainless steel (annealed) } \\
& \mathrm{Eu}_{2} \mathrm{O}_{3}-\mathrm{TZM} \text { (annealed) } \\
& \mathrm{Eu}_{2} \mathrm{O}_{3}-\mathrm{W} \text { (annealed) }
\end{aligned}
$$

Types of $\mathrm{Eu}_{2} \mathrm{O}_{3}$

Hot-pressed: $\quad 1500^{\circ} \mathrm{C}-4,000 \mathrm{psi}-45 \mathrm{~min}$

Monoclinic - $93 \%$ dense

Isostatically pressed: R.T. $-40,000 \mathrm{psi}$, then sintered: $1750^{\circ} \mathrm{C}-60 \mathrm{~min}$ Monoclinic - $93 \%$ dense

\section{Conditions}

$117 \mathrm{hr}$ at $870^{\circ} \mathrm{C}-\mathrm{He}$ bonded

$118 \mathrm{hr}$ at $980^{\circ} \mathrm{C}-\mathrm{He}$ bonded

The results are listed below:

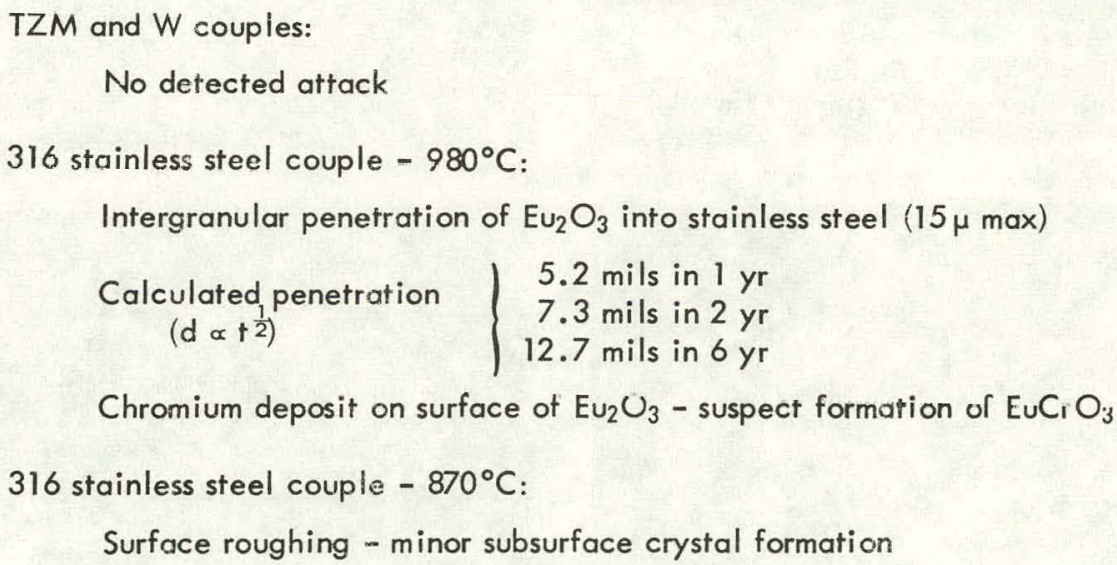

After $118 \mathrm{hr}$ at $980^{\circ} \mathrm{C}$, both TZM (Mo- $0.5 \mathrm{wt} \% \mathrm{Ti}-0.1 \mathrm{wt} \% \mathrm{Zr}$ ) and tungsten in contact with $\mathrm{Eu}_{2} \mathrm{O}_{3}$ showed no interaction. This is in line with the data of Hoyt et al. (Table 6). The stainless steel- $\mathrm{Eu}_{2} \mathrm{O}_{3}$ couple, however, showed significant interaction. The $\mathrm{Eu}_{2} \mathrm{O}_{3}$ appears to have penetrated into the stecl surface to a depth of about $15 \mu \mathrm{m}$. Further, a chromium-rich deposit is observed on the surface of the $\mathrm{Eu}_{2} \mathrm{O}_{3}$. These interactions can best be shown by $\mathrm{x}$-ray scans of the interface of a hot-pressed $\mathrm{Eu}_{2} \mathrm{O}_{3}-$ type 316 stainless steel couple that ran $118 \mathrm{hr}$ at $980^{\circ} \mathrm{C}$ (Fig. 15). The europium can be plainly seen to have penetrated into the steel surface in the photograph on the left middle. The chromium deposit on the 
Stainless Steel Surface

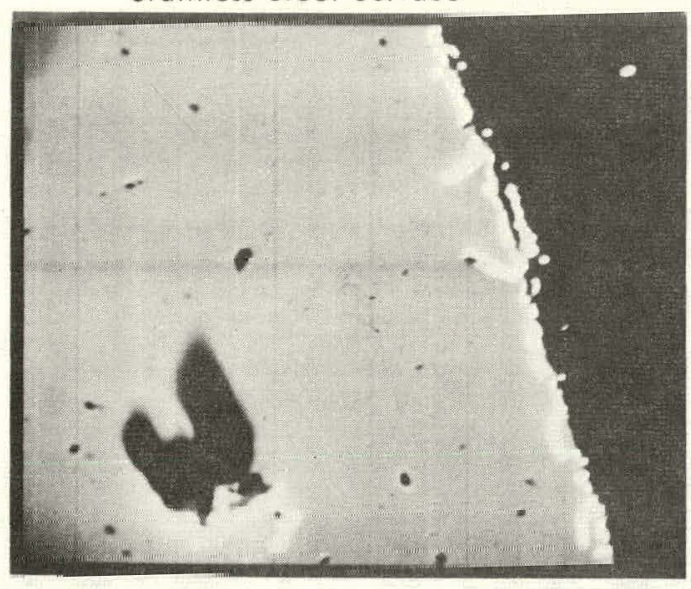

Europium Oxide Surface

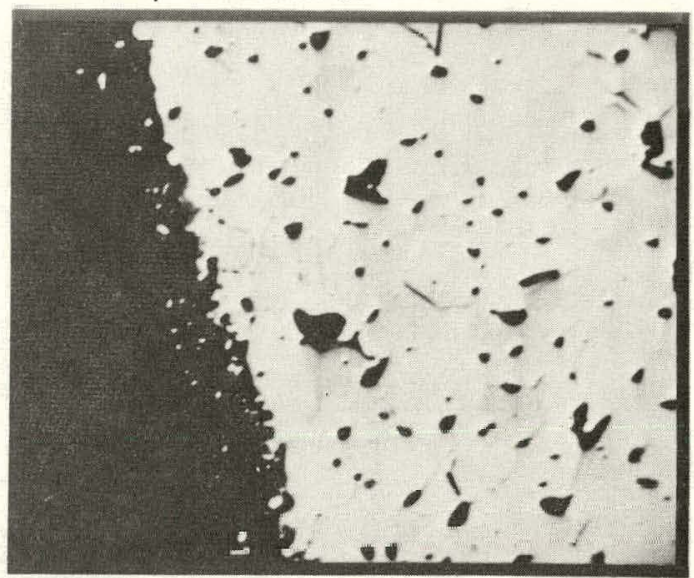

Backscattered Electrons
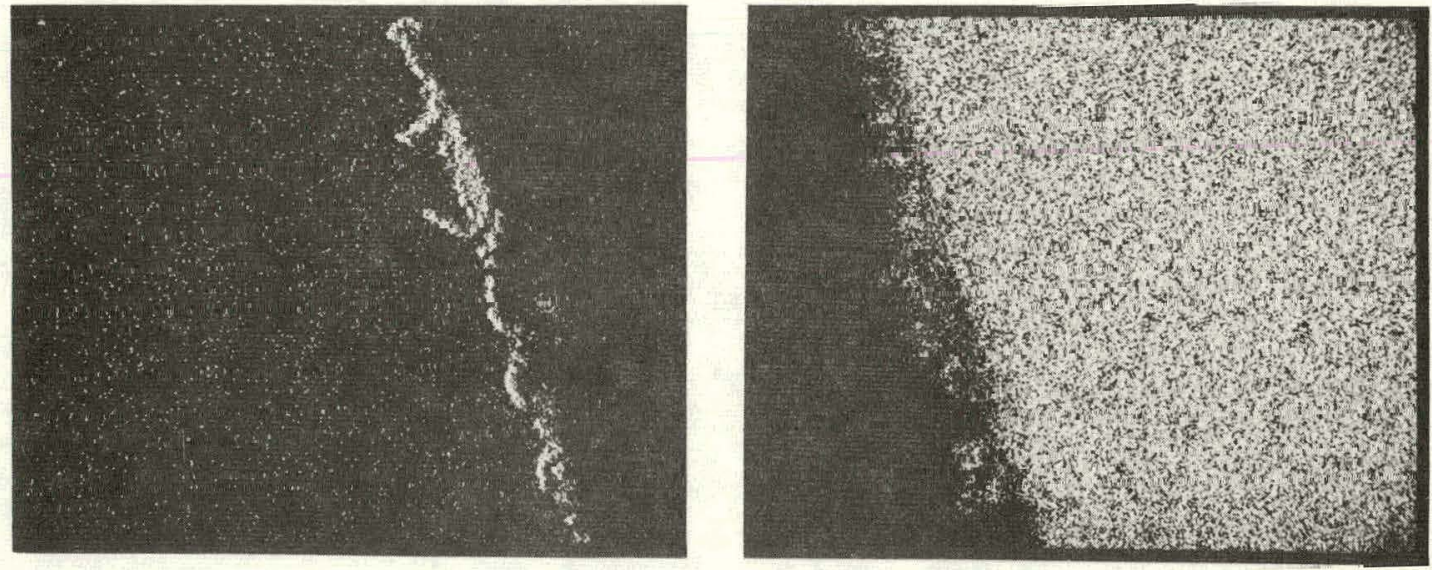

EuL $\alpha$ X-Kays
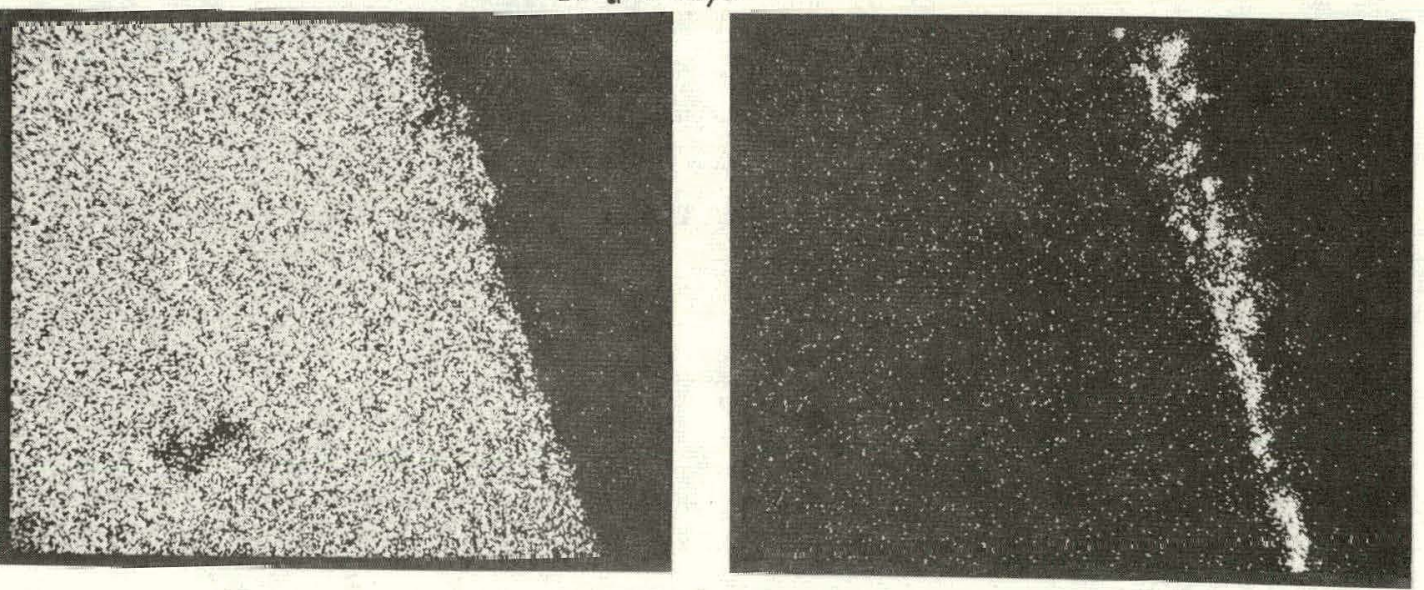

$\mathrm{CrK}_{\alpha} \mathrm{X}$-Rays

Fig. 15. Electron beam scanning images of type 316 stainless steel-europium oxide interface after 118-hr exposure at $980^{\circ} \mathrm{C}$, showing intergranular penetration of europium into the stainless steel and chromium deposition on the europium oxide surface. 
europia surface is visible in the lower right photograph. Although the true significance of these tests in regard to the actual operating conditions of a sodium-cooled type 316 stainless-steel-clad europia absorber pin is not known, the presence of such reactions might suggest that perhaps the oxide pellets should be encapsulated with a layer of a nonreactive metal, such as tungsten or molybdenum. Further out-of-reactor compatibility tests, including $\mathrm{Na}-\mathrm{Eu}_{2} \mathrm{O}_{3}$-type 316 stainless steel, are in process.

\section{OTHER EUROPIUM OXIDES}

Europium's ground-state electronic structure can be represented as $(\mathrm{Xe}) 4 f^{7} 6 s^{2}$, where (Xe) represents the core electrons of the europium atom, which take the xenon atom configuration. Loss of two outer-shell electrons leads to $\mathrm{Eu}^{2+}$ with the electronic configuration $(\mathrm{Xe}) 4 f^{7} 6 s^{0}$. The half-filled $f$ shell $\left(4 f^{7}\right)$ is a highly stable state for the lanthanide compounds, and hence one might expect to be able to form $\mathrm{Eu}^{2+}$ ions readily. However, in combination with oxidizing substances such as oxygen, $\mathrm{Eu}^{2+}$ loses another electron and takes up the (Xe) $4 f^{6} 6 s^{0}$ electronic configuration. This is the stable state found in $\mathrm{Eu}_{2} \mathrm{O}_{3}$. The $2+$ state will form EuO under proper reducing conditions. The presence of both a $2+$ and $3+$ oxidation state allows the formation of yet another oxide, $\mathrm{Eu}_{3} \mathrm{O}_{4}$, or better $\mathrm{Eu}^{\mathrm{Il}} \mathrm{Eu}^{\mathrm{III}}{ }_{2} \mathrm{O}_{4}$, in analogy to iron and manganese oxides. Under atmospheric pressure the most stable of these oxides with increasing temperatures is $\mathrm{Eu}_{2} \mathrm{O}_{3}$, as illustrated by their vaporization behavior. The reactions followed on heating have been given by Hashke and Eick $^{37,38}$ as

$$
\begin{aligned}
& 4 \mathrm{EuO}(\mathrm{s}) \rightarrow \mathrm{Eu}_{3} \mathrm{O}_{4}(\mathrm{~s})+\mathrm{Eu}(\mathrm{g}), \\
& 3 \mathrm{Eu}_{3} \mathrm{O}_{4}(\mathrm{~s}) \rightarrow 4 \mathrm{Eu}_{2} \mathrm{O}_{3}(\mathrm{~s})+\mathrm{Eu}(\mathrm{g}) .
\end{aligned}
$$

These relationships and other thermodynamic considerations have led to the Eu-O phase diagram given by $\mathrm{McC}$ arthy and White ${ }^{39}$ and reproduced here in Fig. 16. It will be noticed from this figure that $\mathrm{Eu}_{2} \mathrm{O}_{3}$ has the ability to lose small amounts of oxygen at elevated temperatures to form $\mathrm{Eu}_{2} \mathrm{O}_{3-x}$. This loss of oxygen was reported by Barrett and Barry ${ }^{24}$ in 1965. Their experiments showed that $\mathrm{Eu}_{2} \mathrm{O}_{3}$ can readily be partially reduced by hydrogen gas at temperatures as low as $650^{\circ} \mathrm{C}$ to form oxygen-deficient compounds such as $\mathrm{Eu}_{2} \mathrm{O}_{2.9856}$. Fabrication experiments at $\mathrm{ORNL}$ have shown a change of color in $\mathrm{Eu}_{2} \mathrm{O}_{3}$ specimens on firing to temperatures around $1500^{\circ} \mathrm{C}$ in vacuum. This can be reversed by refiring in air at $1000^{\circ} \mathrm{C}$, which leads to the possible explanation that the $\mathrm{Eu}_{2} \mathrm{O}_{3}$ is becoming oxygen deficient on firing in vacuum. The refired specimens lose their gray to black discoloration and gain a small amount of weight. Barrett and Barry further state that $\mathrm{Eu}_{2} \mathrm{O}_{3}$ cannot be induced to take up excess oxygen. One might expect this to be so, since it would require oxidation of some $\mathrm{Eu}^{3+}$ to $\mathrm{Eu}^{4+}$, a highly unlikely process in view of the high stability of the $\mathrm{Eu}^{3+}$ state.

The phase relations and preparation of compounds in the system $\mathrm{Eu}-\mathrm{Eu}_{2} \mathrm{O}_{3}$ have recently been discussed in a paper by Bedford and Catalano. ${ }^{40}$ They indicate that the monoclinic sesquioxide is stable over the composition range $\mathrm{Eu}_{2} \mathrm{O}_{2.90}$ to $\mathrm{Eu}_{2} \mathrm{O}_{3.00}$ at $1500^{\circ} \mathrm{C}$. On the other hand, EuO exhibits a very narrow composition range. This compound was initially of some interest as a possible absorber material, since it is cubic ( $\mathrm{fcc}$ ) and possesses a higher density of europium atoms per unit volume than for the sesquioxide $\left(2.94 \times 10^{22}\right.$ atoms $/ \mathrm{cm}^{3}$ for $\mathrm{EuO}, 2.72 \times 10^{22}$ atoms $/ \mathrm{cm}^{3}$ for $\mathrm{Eu}_{2} \mathrm{O}_{3}$ ). This fact would give $\mathrm{EuO}$ a higher macroscopic neutron absorption cross section than that of $\mathrm{Eu}_{2} \mathrm{O}_{3}$. The reported melting point for $\mathrm{EuO}$ is high, in the neighborhood of 1900 to $2015^{\circ} \mathrm{C} .^{39,40}$ However, at approximately $1520^{\circ} \mathrm{C}$, Reed $^{41}$ has calculated that the pressure of $\mathrm{Eu}(\mathrm{g})$ over EuO will reach $1 \mathrm{~atm}$ and that EuO will dissociate into $\mathrm{Eu}_{3} \mathrm{O}_{4}(\mathrm{~s})+\mathrm{Eu}(\mathrm{g})$. The presence of gaseous europium could have an adverse effect on absorber element performance if the element reached such operating temperatures. But this problem could probably be 


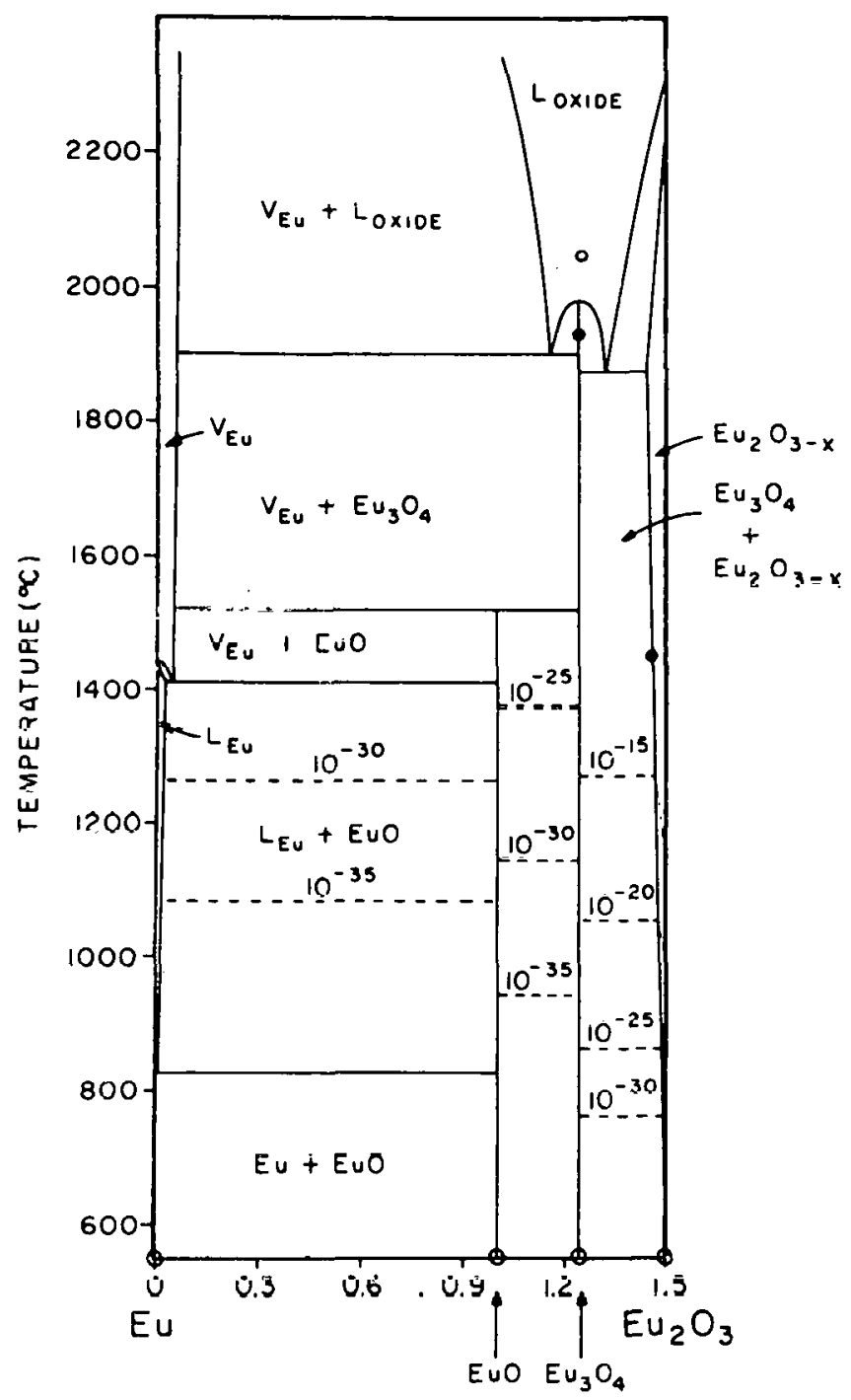

$x$ in $\mathrm{Eu} \mathrm{O}_{x}$

Fig. 16. Portion of a possible Eu-O phase diagram at $1 \mathrm{~atm}$ pressure. [Ref: G. J. McCarthy and W. B. White, "On the Stabilities of the Lower Oxides of the Rare Earths," J. Less-Common Metals 22, 409-17 (1970); assembled from the literature and best estimates of what the diagram should look like. Used with permission of authors.]

controlled by suppressing the dissociation reaction. A more formidable obstacle to the utilization of EuO would be the fabrication of dense shapes of the oxide. Attempts to sinter $\mathrm{EuO}$ in vacuum would likely lead to dissociation into $\mathrm{Eu}_{3} \mathrm{O}_{4}$ or $\mathrm{Eu}_{2} \mathrm{O}_{3}$; sintering in oxidizing atmospheres would certainly lead to production of $\mathrm{Eu}_{2} \mathrm{O}_{3}$. Perhaps it could be sintered under an atmosphere of controlled oxygen partial pressure. Hot pressing in graphite would yield carbon contamination, which could not be oxidized off without forming $\mathrm{Eu}_{2} \mathrm{O}_{3}$. It might, however, be possible to line the die with a refractory metal such as tungsten to prevent carbon contamination.

The oxide $\mathrm{Eu}_{3} \mathrm{O}_{4}$ has not been seriously considered due to difficulty in preparation of the pure compound. ${ }^{40}$ Furthermore, the material is nonisotropic, possessing an orthorhombic structure. ${ }^{42}$ The theoretical density calculated from Rau's lattice parameter is $8.11 \mathrm{~g} / \mathrm{cm}^{3}$, which corresponds to a europium atom density of $2.818 \times 10^{22} \mathrm{Eu}$ atoms $/ \mathrm{cm}^{3}$. This value is just slightly more than the $2.72 \times 10^{22}$ 
atoms $/ \mathrm{cm}^{3}$ calculated for monoclinic $\mathrm{Eu}_{2} \mathrm{O}_{3}$ but less than the $2.94 \times 10^{22}$ atoms $/ \mathrm{cm}^{3}$ calculated for EuO.

Thus it appears at this time that $\mathrm{Eu}_{2} \mathrm{O}_{3}$ is the prime candidate of the europium oxides for use as a fast-reactor control material, particularly because of its stability under usual reactor operating conditions. A possible alternate is $\mathrm{EuO}$, but much more research is required to determine its stability. That is, one must determine if it can be reproducibly formed, fabricated, and handled, and then determine its behavior in the reactor environment.

\section{EVALUATION OF LITERATURE DATA ON PROPERTIES OF $\mathrm{Eu}_{2} \mathrm{O}_{3}$ PERTINENT TO PERFORMANCE IN-REACTOR}

For $\mathrm{Eu}_{2} \mathrm{O}_{3}$ to be utilized as an absorber material in a fast breeder reactor, several critical properties must be well known. These include:

1. reactivity worth,

2. heating rate,

3. compatibility with cladding,

4. stability in a fast neutron flux.

\section{Reactivity Worth}

The available literature on nuclear cross sections for the isotopes involved is neither consistent nor complete. For example, the cross section for the ${ }^{151} \mathrm{Eu}(n, \gamma)$ reaction at $10 \mathrm{keV}$ is given as $8.5 \mathrm{~b}$ by Barr and Devaney, ${ }^{10}$ about 8 b by Liu, ${ }^{43}$ and 4.65 b by Benzi et al. ${ }^{44}$ For ${ }^{153} \mathrm{Eu}$, the same authors give $6.5,5$, and $4.68 \mathrm{~b}$. Another very important cross section involved in the Eu absorption chain is that of ${ }^{152} \mathrm{Eu}$. Barr and Devaney ${ }^{10}$ indicate that this number may be between 9 and $20 \mathrm{~b}$ at $10 \mathrm{keV}$. Also, Barr and Devaney ${ }^{10}$ indicate that for the ${ }^{154} \mathrm{Eu}(n, \gamma)$ reaction, the cross section is near $6 \mathrm{~b}$ at $10 \mathrm{keV}$, while $\mathrm{Liu}^{43}$ indicates this number to be near $18 \mathrm{~b}$. Thus it becomes apparent that further cross-section determinations are required if the worth of $\mathrm{Eu}_{2} \mathrm{O}_{3}$ is to be accurately calculated. Perhaps a better way of obtaining the worth would be an actual reactivity worth measurement in a reactor mockup facility. However, this would only determine europia's initial worth and would tell little about its long-term life, since we could not determine the effect of ${ }^{152} \mathrm{Eu},{ }^{154} \mathrm{Eu}$, and the other isotopes of $\mathrm{Eu}, \mathrm{Gd}$, and $\mathrm{Sm}$ which are built in during irradiation. The effect of these isotopes can be determined only by individual cross-section measurements or long-term reactivity worth measurements on irradiated $\mathrm{Eu}_{2} \mathrm{O}_{3}$. Also, Perry notes that the partial cross section of

$1^{4}$ 'Eu fur furmatiun of the 9.3-hr isomer of ${ }^{15}$ ? Eu is not well known for fast neutron spectra.

The fraction of ${ }^{151} \mathrm{Eu}$ atoms forming this isomer decay to $\mathrm{Gd}$ and $\mathrm{Sm}$ isotopes which are thought to have low cross sections, whereas the long-lived isotope of ${ }^{152} \mathrm{Eu}$ has a substantial cross section and contributes significantly to long-term worth. For thermal neutrons the fraction of ${ }^{152 m} \mathrm{Eu}$ from ${ }^{151} \mathrm{Eu}$ is about 0.35 . For $25-\mathrm{keV}$ neutrons it appears that the fraction is closer to 0.7. Averaged over the EBR-II spectra, Perry guesses that the fraction might be in the range of 0.5 to 0.7 , or even higher. In order to better estimate the long-term worth of $\mathrm{Eu}_{2} \mathrm{U}_{3}$, this partial cross section needs to be determined for fast neutrons.

\section{Heating Rate}

Another parameter which is important in the design of control rods is the core $\gamma$ contribution to the heating rate in the assembly. In $\mathrm{Eu}_{2} \mathrm{O}_{3}$ the sum of the $(n, \gamma)$ and decay $\gamma$ heating is not the major contributor to total heating rate. A. M. Perry of ORNL [in a preliminary analysis (Supplement I)] calculates that the decay $\gamma$ heating rate may be between 0.18 to $0.36 \mathrm{~W} / \mathrm{g}$ in EBR-II, while HEDL ${ }^{45}$ has calculated the $(n, \gamma)$ heating rate in EB̈R-III to be about $1.2 \mathrm{~W} / \mathrm{g}$. 'This gives a total of about 1.4 to $1.6 \mathrm{~W} / \mathrm{g}$ for decay $\gamma$ and $(n, \gamma)$ heating, while Perry indicates that the core- $\gamma$ contribution may be between 2 and 6 
$\mathrm{W} / \mathrm{g}$, most likely 2 to $2.5 \mathrm{~W} / \mathrm{g}$. Of course, a similar situation would prevail in the FFTF and the demonstration LMFBR. It is then apparent that this core $\gamma$ heating rate should also be measured in order to properly design an absorber rod configuration.

\section{Compatibility}

The literature data ${ }^{36,22}$ concerning compatibility of $\mathrm{Eu}_{2} \mathrm{O}_{3}$ with stainless steel indicate that an interaction occurs at temperatures above $800^{\circ} \mathrm{C}$. The extent and consequences of such an interaction in a control-rod configuration operating with a temperature gradient between the $\mathrm{Eu}_{2} \mathrm{O}_{3}$ and stainless steel cladding are not known and should be determined. However, if such interaction does prove to be a problem, the europia could be sheathed in tungsten or molybdenum, since no reaction is observed with these metals. The consequences of accidental sodium intrusion or the feasibility of utilizing sodium bonding in an $\mathrm{Eu}_{2} \mathrm{O}_{3}$ control-rod element is also unknown.

\section{Irradiation Stability}

Stability in the rcactor environment includes possible polymorphic transformations, swelling, cracking, and the resultant effect on thermal conductivity.

The literature concerning phase stability has been considered in some detail by V. L. Burdick. Sections of his report are included here as Supplement 11. His conclusion is that, in a fast neutron flux, the monoclinic modification would be more stable than the cubic form, but that this cannot be considered settled until actual reactor irradiation experiments are completed.

Swelling and cracking behavior cannot be predicted except in a qualitative manner. It may be expected that the europia lattice will swell as a result of defect formation arising from fast-neutron displacement effects, but this swelling may be at least partially offset by the conversion of europium atoms to gadolinium atoms, which have a smaller tonic padlus. Thermal redecior irradialiurs described previuusly $2.2_{i}, 34$ have indicated no more than a $1 \%$ density decrease $(\approx 1 \%$ volume swelling) in europia pellets after receiving an integrated flux of about $1 \times 10^{22}$ neutrons $/ \mathrm{cm}^{2}$ at 350 to $600^{\circ} \mathrm{C}$.

Cracking is likewise unpredictable, but some radial and circunferential cracking is likely to be observed in at least some fraction of the pellets. This general conclusion is drawn from a radiation damage study involving ceramics such as $\mathrm{MgO}, \mathrm{Al}_{2} \mathrm{O}_{3}$, and $\mathrm{Y}_{2} \mathrm{O}_{3} \cdot{ }^{46}$ Irradiation tests with $\mathrm{Eu}_{2} \mathrm{O}_{3}$ can be expected to provide data on this effect.

The literature data concerning the thermal conductivity of $\mathrm{Eu}_{2} \mathrm{O}_{3}$ have been examined by J. P. Moore of ORNL, and his observations are included in Supplement III of this report. He concludes that a good estimate of the (unirradiated) thermal conductivity for monoclinic $\mathrm{Eu}_{2} \mathrm{O}_{3}$ would be about $0.04 \mathrm{~W} \mathrm{~cm}$ $\left({ }^{\circ} \mathrm{C}^{-1}\right.$ at room temperature, decreasing to about $0.028 \mathrm{~W} \mathrm{~cm}^{-1}\left({ }^{\circ} \mathrm{C}\right)^{-1}$ at $900^{\circ} \mathrm{C}$. These numbers can be expected to decrease by factors ranging from $1 / 2$ to $1 / 100$ after fast neutron irradiation, depending on the type of damage incurred. The worst possible case would be complete separation of the grains of $\mathrm{Eu}_{2} \mathrm{O}_{3}$ at the grain boundaries as observed in $\mathrm{BeO} .^{47}$ Again, only a comprehensive irradiation test program will provide such data.

\section{ACKNOWLEDGMENTS}

The technical contributions of the following people are acknowledged: M. M. Martin, Metals and Ceramics Division of ORNL, for the preliminary compatibility and reactivity worth data; J. P. Moore, Metals and Ceramics Division of ORNL, for his evaluation of the thermal conductivity data; R. A. Potter, Metals and Ceramics Division of ORNL, for his sintering data on $\mathrm{Eu}_{2} \mathrm{O}_{3} ; \mathrm{A}$. M. Perry, Reactor Division of ORNL, for his evaluation of reactivity worth and heating rate; V. L. Burdick, Associate Professor of 
Ceramic Engineering, New York State College of Ceramics at Alfred University, Alfred, New York, for his evaluation of the relative stabilities of the $\mathrm{Eu}_{2} \mathrm{O}_{3}$ crystal structures.

Special thanks are extended to the many members of the ORNL Central Research Library staff for their assistance in the collection of the documents utilized as a basis for this report.

The author is also appreciative of the guidance of R. G. Donnelly, Coordinator, ORNL LMFBR Neutron Absorber Program, from conception through finalization of the report.

\section{REFERENCES}

1. Shyama P. Sinha, Europium, Springer-Verlag, New York, 1967.

2. F. H. Spedding, "Historical Introduction to the Rare Earths," in The Rare Earths, ed. by F. H. Spedding and A. H. Daane, Wiley, New York, 1961.

3. K. J. Bril, "Mass Extraction and Separation"; J. E. Powell, "The Separation of Rare Earths by Ion Exchange"; Boyd Weaver, "Liquid-Liquid Extraction of the Rare Earths"; and D. F. Peppard, "Frạctinnation of Rare Farths hy I.iquid-I.iquid Extraction Using Phosphorus-Based Extractants," in Progress in the Science and Technology of the Rare Earths, Vol. 1., ed. by LeRoy Eyring, Macmillan, New York, 1964.

4. R. J. Beaver and M. M. Martin, The Status of Europium Compounds for Reactivity Control in Nuclear Reactors, ORNL-4368 (February 1969).

5. W. E. Ray, "The Lanthanons as Nuclear Control Materials," Nucl. Eng. Des. 17, 377-96 (1971).

6. W. K. Anderson, "Nuclear Applications of Yttrium and the Lanthanons," in The Rare Earths, ed. by F. H. Spedding and A. H. Daane, Wiley, New York, 1961.

7. H. Spenke, "Eignung von Europium als Absorbermaterial in Schnellen Reaktoren," Atomwirtschaft 17(3), 161-64 (1972).

8. J. G. Delene, Reactor Division, ORNL, personal communication, Aug. 29, 1968.

9. Annual Technical Progress Report, LMFBR Physics Programs, GFY 1971, Al-AEC-13005 (1971).

10. Donald W. Barr and Joseph J. Devaney, Kilovolt Europium Capture Cross Sections, LA-3643 (April $7,1967)$.

11. S. Stecura, "Crystallographic Modifications and Phase Transformation Rates of Five Rare Earth Sesquioxides," U.S. Bureau of Mines Report of Investigations 6616.

12. R. C. Rau, "X-Ray Crystallographic Studies of Europium Oxides and Hydroxides," in Proceedings of the 3rd Conference on Rare Earth Research, 1963, Gordon \& Breach, New York, 1964.

13. C. E. Curtis and A. G. Tharp, "Ceramic Properties of Europium Oxide," J. Amer. Ceram. Soc. 42(3), 151-56 (1959).

14. R. S. Roth and S. J. Schneider, "Phase Equilibria in Systems Involving the Rare-Earth Oxides. Part I. Polymorphism of the Oxides of the Trivalent Rare-Earth Ions," J. Kes. Nat. Bur. Stand. A; Phys. Chem. 64A, 309 (1960).

15. I. Warshaw and R. Roy, "Polymorphism of the Rare Earth Sesquioxides," J. Phys. Chem. 65, 2048-51 (1961).

16. Georg Brauer, "Precipitation of Rare Earth Oxides from Molten Salts," in Proceedings of the 6th Rare Earth Research Conference, Gatlinburg, Tennessee, $196 \%$.

17. G. C. Fitzgibbon, E. J. Huber, Jr., and C. E. Holley, Jr., "Enthalpy of Formation of Europium Sesquioxide,"J. Chem. Thermo. 4, 349-58 (1972).

18. "Heat of Formation of Inorganic Oxides," pp. D-22-D-27 in CRC Handbook of Chemistry and Physics, 48th ed., 1967.

19. L. G. Wisnyi and S. Pijanowski, Metallurgy Report of the Technical Department, KAPL-1564 (March-May 1965).

20. M. Foex, "Etude des points de solidification des oxydes et des chromites de terres rares," Compt. Rend. H. Acad. Sci. 260, 6389 (1965).

21. M. Foex referenced by Georg Brauer, "Structural and Solid State Chemistry of Pure Rare Earth Oxides and Hydroxides," in Progress in the Science and Technology of the Rare Earths, Vol. 3, ed. by LeRoy Eyring, Macmillan, New York, 1968.

22. E. W. Hoyt et al., Rare Earth Oxides and Rare Earth Borates: Corrosion, Compatibility, and Radiation Effects, GEAP-3909 (April 17, 1962). 
23. Grünling and Schickfluss-Borges, "Sintering and Thermal Conductivity of $\mathrm{Eu}_{2} \mathrm{O}_{3}$," Simens $\mathrm{AG}$ Bericht Nr. 112/70 (1970).

24. M. F. Barrett and T. I. Barry, "Non-Stoichiometry in Neodymium and Europium Oxides in Relation to their Interaction with Oxygen and Hydrogen," J. Inorg. Nucl. Chem. 27, 1483-87 (1965).

25. A. L. Pitner and Wayne Ross, Hanford Engineering Development Laboratory, personal communication, Aug. 31, 1972.

26. R. A. McNees and R. A. Potter, Army Reactor Program Progress Report, ORNL-3231, pp. 21-22 (January 1962).

27. C. F. Leitten, Jr., and R. J. Beaver, "Use of Lanthanide Oxide Neutron Absorbers in Pressurized Water Reactors," Nucl. Appl. 4(6), 399-417 (June 1968).

28. R. J. Beaver, A. E. Richt, and M. M. Martin, Irradiation Behavior of Aluminum-Base Dispersions Containing Europium Oxides, ORNL-4199 (January 1968).

29. R. W. Knight and A. E. Richt, "Evaluation of Absorber Materials Pcrformance in HFIR Control Cylinders," Nucl. Technol. 15, 384-90 (1972).

30. C. F. Lcitten, Jr., A. E. Richt, and R. J. Bcaver, Irradiation Bchavior of $\mathrm{Eu}_{2} \mathrm{O}_{3} \ldots$ Stainless Stcel Dispersions, ORNL-4104 (June 1967).

31. A. E. Richt, Interim Postirradiation Examination of a Europium-Bearing Control Rod from the Stationary Medium Power Reactor, ORNL-TM-1 407 (March 1966).

32. A. E. Richt and V. O. Haynes, Inspection of turopum-Bearing Control Rods from the Army SM-1A Stationary Medium Power Reactor, ORNL-TM-2349 (January 1969).

33. A. E. Richt and V. O. Haynes, Inspection of Europium-Bearing Control Rod Absorber OM-2 from Core II and Core III of the Army SM-1A Stationary Medium Power Reactor, ORNL-TM-3647 (April 1972).

34. V. P. Goltsev et al., "Radiation Resistance of Absorber Materials for Nuclear Reactors," in Fourth United Nations International Conference on the Peaceful Uses of Atomic Energy, A/CONF 49/p/704, June 1971.

35. Stainless Steel Fabrication, p. 7, Allegheny Ludlum Steel Corp., 1958.

36. C. F. Leitten, Jr., The Stability of Europium Oxide irt Silicon-Beuring Stuintiess Steel, ORNL-2946; M.S. Thesis, The University of Tennessee, August 1960.

37. J. M. Hashke and H. Eick, "The Vaporization Thermodynamics of Trieuropium Tetraoxide," in Proceedings of the 7th Rare Earth Research Conference, Coronado, California, 1968.

38. J. M. Hashke and H. $\Lambda$. Eick, "The Vaporization Thermodynamics of Europium Monoxide," $J$. Phys. Chem 73, 374-77 (1969).

39. G. J. McCarthy and W. B. White, "On the Stabilities of the Lower Oxides of the Rare Earths," J. Less-Common Metals 22, 409-17 (1970).

40. R. G. Bedford and E. Catalano, "Investigations into the $E u-E u_{2} \mathrm{O}_{3}$, the Eu-Pt-Eu $\mathrm{O}_{2} \mathrm{O}_{3}$, the Sm-Sm ${ }_{2} \mathrm{O}_{3}$, and the $\mathrm{Yb}-\mathrm{Yb}_{2} \mathrm{O}_{3}$ Systems," J. Solid State Chem. 3, 112-24 (1971).

41. T. B. Reed, MIT Lincoln Laboratories, referenced in McCarthy and White, ref. 39.

42. R. C. Rau, "The Crystal Structure of $\mathrm{Eu}_{3} \mathrm{O}_{4}$," Acta Cryst. 20, 716-23 (1966).

43. Y. Liu, "Zur Behandlung des Spaltprodukte in Abbrandrechnungen unter Berücksichtigung neuer nuklearer Daten angewandt auf Graphitreaktoren," Jul 678-RG (July 1970).

44. V. Benzi, R. D'Orazi, G. Reffo, and M. Vaccari, "Fast Neutron Radiative Capture Cross Sections of Stable Nuclei with $29 \leqslant Z \leqslant 79$," RT/FI (72) 6 .

45. A. L. Pitner, "Addendum to Data Package for Instrumented Irradiation of the YY02 Boron Carbide Test in the EBR-II INCOT Facility (BICM-1)," Addendum to Attachment to W/FFTF-723725 (August 1972).

46. G. W. Keilholtz, R. E. Moore, and H. E. Robertson, Effects of Fast Neutrons on Polycrystalline Alumina and Other Electrical Insulators at Temperatures from $60^{\circ}$ to $1230^{\circ} \mathrm{C}$, ORNL-4678 (May 1971).

47. G. W. Keilholtz, J. E. Lee, Jr., and R. E. Moore, "Irradiation Damage to Sintered Beryllium Oxide as a Function of Fast-Neutron Dose and Flux at 110,650 , and $1100^{\circ} \mathrm{C}$," Nucl. Sci. Engr. 26, 329-38 (1966).

48. J. F. Emery, S. A. Reynolds, and E. I. Wyatt, "Half-Lives of Radionuclides-IV," Nucl. Sci. Engr. $48,319-24(1972)$.

49. S. J. Friesenhahn et al, Measurements of the ${ }^{10} B\left(n, \alpha_{1} \gamma\right)$ and ${ }^{10} B(n, \alpha)$ Cross Sections, Gulf-RT, A 12210 (Oct. 16, 1972). 
SUPPLEMENT I

A PRELIMINARY ASSESSMENT OF $\mathrm{Eu}_{2} \mathrm{O}_{3}$ DECAY HEAT AND BURNUP IN EBR-II 
THIS PAGE

WAS INTENTIONALLY

LEFT BLANK 
SUPPLEMEIT I

A PRELIMINARY ASSESSMENT OF $\mathrm{Eu}_{2} \mathrm{O}_{3}$ DECAY HEAT

AND BURNUP IN EBR-II

CONTENTS

$\underline{\text { Page }}$

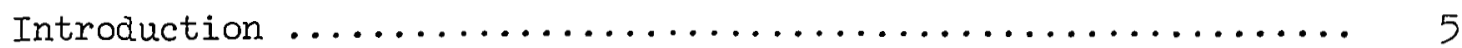

1. Afterheat in $\mathrm{Eu}_{2} \mathrm{O}_{3}$ Specimens in EBR-II (Row 7) ........ 5

1.1 Ca.lculation of Neutron Absorption Rate in $\mathrm{Eu}_{2} \mathrm{O}_{3}$ in

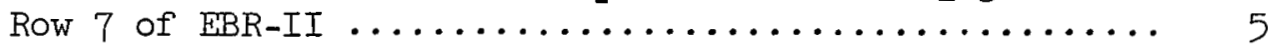

1.2 Decay Energetics ....................... 7

1.3 Self-Absorption Factors for Gamma Rays ............ 10

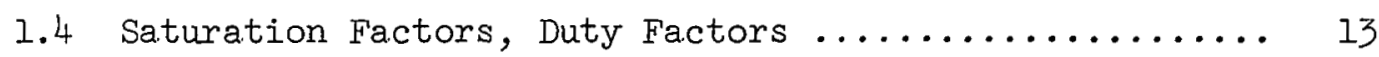

1.5 Results of Afterheat Calculations .............. 15

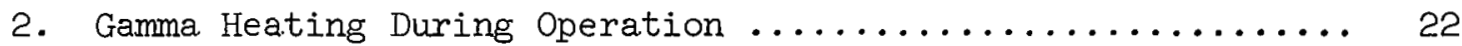

2.1 Energy-Absorption Cross Sections .............. 22

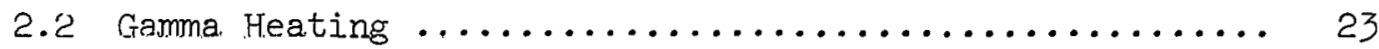

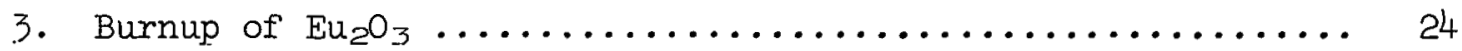

Appendix A: Self-Shielding and Volumetric Reactivity Worths .... 27

Appendix B: Cross Sections ........................ 29

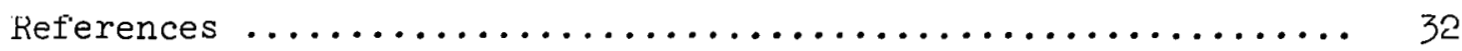




\title{
A PRELIMINARY ASSESS MENT OF $\mathrm{Eu}_{2} \mathrm{O}_{3}$ DECAY HEAT* AND BURNUP IN EBR-II
}

\author{
A. M. Perry
}

\section{ABSTRACT}

The amount of afterheat to be expected in $\mathrm{Eu}_{2} \mathrm{O}_{3}$ pins irradiated for one year in Row 7 of EBR-II is estimated to be in the neighborhood of 1.5 to $2 \mathrm{w} / \mathrm{cm}^{3}$ immediately after shutdown, decaying with a 9.3-hr half life to a much lower, long-lived afterheat level of about $0.1 \mathrm{w} / \mathrm{cm}^{3}$. In addition, gamma heating during operation from gamma rays originating outside the samples is estimated to be about 2 to $2.5 \mathrm{w} / \mathrm{g}$. Loss of. reactivity worth due to burnup of the europium is estimated to be roughly $3 \%$ per full-power year under conditions similar to those in EBR-II (Row 7); this result may be scaled for different flux levels in other reactors.

*Research sponsored by the U.S. Atomic Energy Commission under contract with the Union Carbide Corporation. 


\section{INTRODUCTION}

We have taken a first look at certain aspects of the testing of $\mathrm{Eu}_{2} \mathrm{O}_{3}$ in EBR-II (Row 7) as a possible control material for fast reactors. These aspects include:

1. Afterheat of $\mathrm{Eu}_{2} \mathrm{O}_{3}$ test specimens (as compared, for example, with Ta.).

2. Probable gamma-heating rates in the specimens during operation.

3. Probable change in reactivity worth of irradiated $\mathrm{Eu}_{2} \mathrm{O}_{3}$ rods as a result of composition changes.

'l'hese aspects are discussed in the Iollowng sections.

\section{AFTERHEAT IN EU $\mathrm{O}_{3}$ SPECIMENS IN EBR-II (ROW 7)}

\subsection{Ca.lculation of Neutron Absorption} Rate in $\mathrm{Eu}_{2} \mathrm{O}_{3}$ in Row 7 of EBR-II

George Ragan has calculated the rate of neutron absorptions in $\mathrm{Ta}$ rods at midplane in Row 7 of $E B R-I I^{I}(R=30.9 \mathrm{~cm}, Z=-1.2 \mathrm{~cm})$ using fluxes recently obta.ined from Argonne National Laboratory ${ }^{2}$ and using Ta cross sections, both shielded and unshielded ("infinitely dilute") as recently published by Tuttle and Springer. ${ }^{3}$ The result of this calculation was a neutron absorption rate, at full power, of $3.3 \times 10^{13}$ neutrons $/ \mathrm{cm}^{3} \mathrm{sec}$ with dilute (small-sample) cross sections (i.e., unshielded) or $2.5 \times 10^{13}$ neutrons $/ \mathrm{cm}^{3} \mathrm{sec}$ with shielded cross sections (for rods of about $0 . \sigma_{7}$ in. diam).

About four years ago, Jerry Delene estimated that $\mathrm{Eu}_{2} \mathrm{O}_{3}$ should be worth about 1.6 times as much as $\mathrm{Ta}$, on an equal volume basis, in either a "soft-spectrum" or a. "hard-spectrum" LMFBR.4 Also, on the basis of the average cross-section ratio, $\bar{\sigma}(\mathrm{Eu}) / \bar{\sigma}(\mathrm{Ta}) \sim 3.8$, and the a.tom-density ratio, $\mathrm{N}(\mathrm{Eu}) / \mathrm{N}(\mathrm{Ta}) \sim 0.42$, we estimate a macroscopic cross- 
section ratio $\Sigma(\mathrm{Eu}) / \Sigma(\mathrm{Ta}) \sim 1.6$. We therefore assume, tentatively, that the neutron capture rate per unit volume in $\mathrm{Eu}_{2} \mathrm{O}_{3}$ in $\mathrm{EBR}$-II would be 1.5 to 2 times as high as in Ta.* For purposes of the present calculations, we use the factor 2 , and proceed on the assumption of $5 \times 10^{13}$ neutrons $/ \mathrm{cm}^{3} \mathrm{sec}$ absorbed in EBR-II, Row 7. The effect of changing this assumption is easily estimated, since the heating rates calculated below are directly proportional to this absorption rate.

Self-shielding in the $\mathrm{Eu}_{2} \mathrm{O}_{3}$ samples is neglected, and this neglect would appear to be justified, at least for the smaller EBR-II samples, by the results given in Ref. 3. (See Appendix A of this memorandum.)

As for the distribution of these captures between ${ }^{151_{\mathrm{Eu}}}$ and ${ }^{152} \mathrm{Eu}$, we note that the cross-section ratio (between ${ }^{151} \mathrm{Eu}$ and ${ }^{153} \mathrm{Eu}$ ) is about 1.4-1.5 over the important neutron-energy range, 1-100 keV, and - pending more detailed calculation of average cross sections - we assume that the specific capture rate in ${ }^{151} \mathrm{Eu}$ is 1.5 times as great as in ${ }^{153} \mathrm{Eu}$ (the two species are about equally abundant in natural europium). Thus, $60 \%$ of the captures initially are in ${ }^{151} \mathrm{Eu}$, and $40 \%$ in ${ }^{153} \mathrm{Eu}$, i.e., $3 \times 10^{13}$ and $2 \times 10^{13}$ neutrons $/ \mathrm{cm}^{3}$ sec respectively.

Finally, we must assume something about the fraction of captures in ${ }^{151} \mathrm{Eu}$ that lead to the $9.3 \mathrm{hr}$ isomer of ${ }^{152} \mathrm{Eu}$, rather than to the $12 \mathrm{yr}$

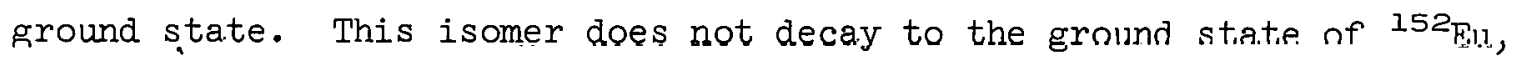
but instead decays directly by electron capture to stable ${ }^{152} \mathrm{Sm}(23 \%)$ or by beta emission to $10^{14}$-year ${ }^{152} \mathrm{Gd}(77 \%)$. In a thermal-neutron spectrum, $35 \%$ of the ${ }^{15 I} \mathrm{Eu}$ captures produce the isomer. Whi le we do not yet know what this percentage should be in a fast-neutron spectrum, we assume tentatively that it will lie in the range of 20 to $50 \%$, and will subsequently test the sensitivity of our afterheat estimates to assumed variations in this percentage.

\footnotetext{
* This range is consistent with Ref. 3 (see Appendix A).
} 


\subsection{Decay Energetics}

The principal radioactive processes relevant to a discussion of afterheat in irradiated $\mathrm{Eu}_{2} \mathrm{O}_{3}$ are shown below.

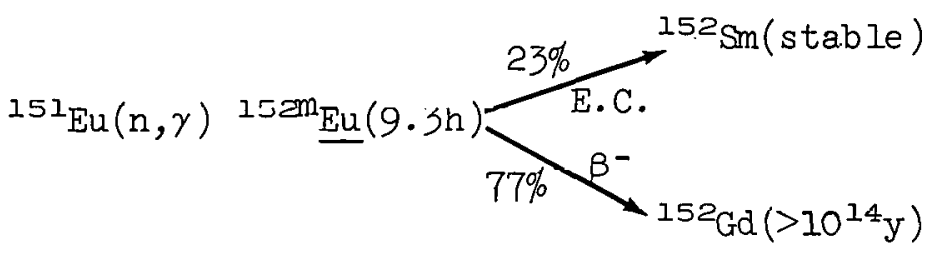

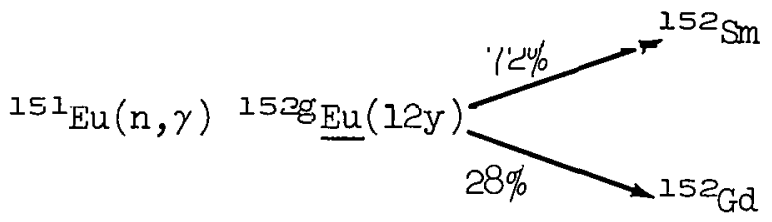

$$
\begin{aligned}
& { }^{153} \mathrm{Eu}(\mathrm{n}, \gamma){ }^{154} \underline{\mathrm{Eu}}(16 \mathrm{y}) \stackrel{\beta-}{\longrightarrow}{ }^{154} \mathrm{Gd}(\text { stable })
\end{aligned}
$$

Note that the 9.3-hr isomer of ${ }^{152} \mathrm{Eu}$ does not decay to the ground state of ${ }^{152} \mathrm{Eu}$. Also, we neglect the $96-\mathrm{min}$ isomer of ${ }^{152} \mathrm{Eu}$ which is produced in very minor amounts (roughly $1 \%$ of the production rate of the 9.3-hr isomer ${ }^{5}$ ) and which decays entirely to the 9.3-hr state (not to the ground state); thus, production of the 96 -min isomer is effectively equivalent to production of the $9.3 \mathrm{~h}$ isomer. (If the production rate were much larger, and if the half-lives of the two isomers differed by a much larger factor, this neglect might not be acceptable for short cooling times; however, under the circumstances that actually prevail, the neglect is justified.)

These are the processes considered in the present analysis. Other activities that should be considered in a more detailed calculation, especially for long irradiations, include:

$$
\begin{aligned}
& { }^{152} \mathrm{Sm}(\mathrm{n}, \gamma){ }^{153} \mathrm{Sm}(47 \mathrm{~h}) \stackrel{B-}{\rightarrow}{ }^{153} \mathrm{Eu} \\
& { }^{152} \mathrm{Gd}(\mathrm{n}, \gamma){ }^{153} \mathrm{Gd}(242 \mathrm{~d}) \stackrel{\mathrm{EC}}{\longrightarrow}{ }^{153} \mathrm{Eu}
\end{aligned}
$$

The gadolinium isotopes t'rom 154 through 138 are stáble. 
The energy available for absorption from the decay of each species of nucleus is the average kinetic energy of all the beta particles emitted plus the energy of the ensuing gamma rays emitted as the product nucleus decays to its ground state. The ratio of the average beta. energy to the maximum (end-point) energy, for each group of betas, depends both on the maximum energy of the betas, on the $Z$ of the (product) nucleus, and on the spin and parity changes in the transition. For the Eu $\stackrel{B^{-}}{\longrightarrow}$ Gd transitions $(z=64)$, the ratio ranges (for allowed transitions) from 0.27 for $0.2 \mathrm{MeV}$ end-point to 0.38 for $2 \mathrm{MeV}$ end-point. (A plot of this ratio may be cound, for example, in Ref. 6 , and is reproducel buere as Fig. 1.)

Decay schemes for the europium isotopes were taken from Ref. 7. The beta and gamma energy emitted (but not necessarily absorbed) per aisintegration is shown in Table 1 .

Table 1. Beta and gamma decay energy per disintegration in europium isotopes

(All energies in $\mathrm{MeV}$ )

\begin{tabular}{|c|c|c|c|c|c|c|c|c|}
\hline Isotope & $\begin{array}{l}\text { Half } \\
\text { life }\end{array}$ & $\begin{array}{l}\text { Decaya } \\
\text { mnde }\end{array}$ & $\begin{array}{l}\text { Fraction of } \\
\text { dooaye }(\%)\end{array}$ & $\mathrm{Q}^{\mathrm{b}}$ & $E_{p}^{c}$ & $\mathrm{E}_{\gamma}^{\mathrm{d}}$ & $\begin{array}{l}E^{e} \\
\text { LuldI }\end{array}$ & $\bar{\varepsilon}_{y y} f$ \\
\hline $15 \mathrm{am}_{\mathrm{Eu}}$ & $9.3 \mathrm{~h}$ & $E C$ & 23 & 1.907 & 0 & 1.907 & 1.907 & $\sim 0.9$ \\
\hline${ }_{152 m_{E u}}$ & $9.3 h$ & $\beta^{-}$ & $7 \%$ & 1.87 & 0.690 & 0.036 & 0.726 & $\infty .3$ \\
\hline${ }^{152 \mathrm{~g}} \mathrm{Eu}$ & $12 y$ & $\mathrm{EC}$ & 72 & 1.857 & 0 & 1.857 & 1.857 & $\sim 1.3$ \\
\hline $1528 \mathrm{Eu}$ & $12 y$ & $\beta-$ & 28 & 1.82 & 0.324 & 0.876 & 1.200 & $\approx 0.5$ \\
\hline${ }^{154} \mathrm{Eu}$ & $16 y$ & $B^{-}$ & 100 & 1.978 & 0.208 & 1.341 & 1.549 & $\sim 1.0$ \\
\hline${ }^{155} \mathrm{Eu}$ & $1.8 \mathrm{y}$ & $\mathrm{B}^{-}$ & 100 & 0.248 & 0.047 & 0.076 & 0.123 & $\sim 0.08$ \\
\hline
\end{tabular}

$a_{E C}=$ orbital electron capture.

${ }^{b} \mathrm{Q}=$ total transition energy = mass difference between initial and final systems.

${ }^{{ } E_{\beta}}=$ total kinetic energy of all beta particles emitted, on the average, in the decay of this nuclide, taking into account the abundance of the beta groups and the factors $\bar{E} / E_{\max }$ from Fig. 1 .

$\mathrm{d}_{\mathrm{E}_{\gamma}}=$ total gamma energy per decay.

$\mathrm{e}_{E_{\text {total }}}=E_{\beta}+E_{\gamma}=$ absorbable energy released per disintegration (but not necessarily absorbed in emitting body). $\quad\left(Q-E_{\text {total }}=\right.$ energy carried off by antineutrinos.)

$f_{\bar{G}_{\gamma}}=$ average gamma energy, MeV/photon. (Very approximate.) 


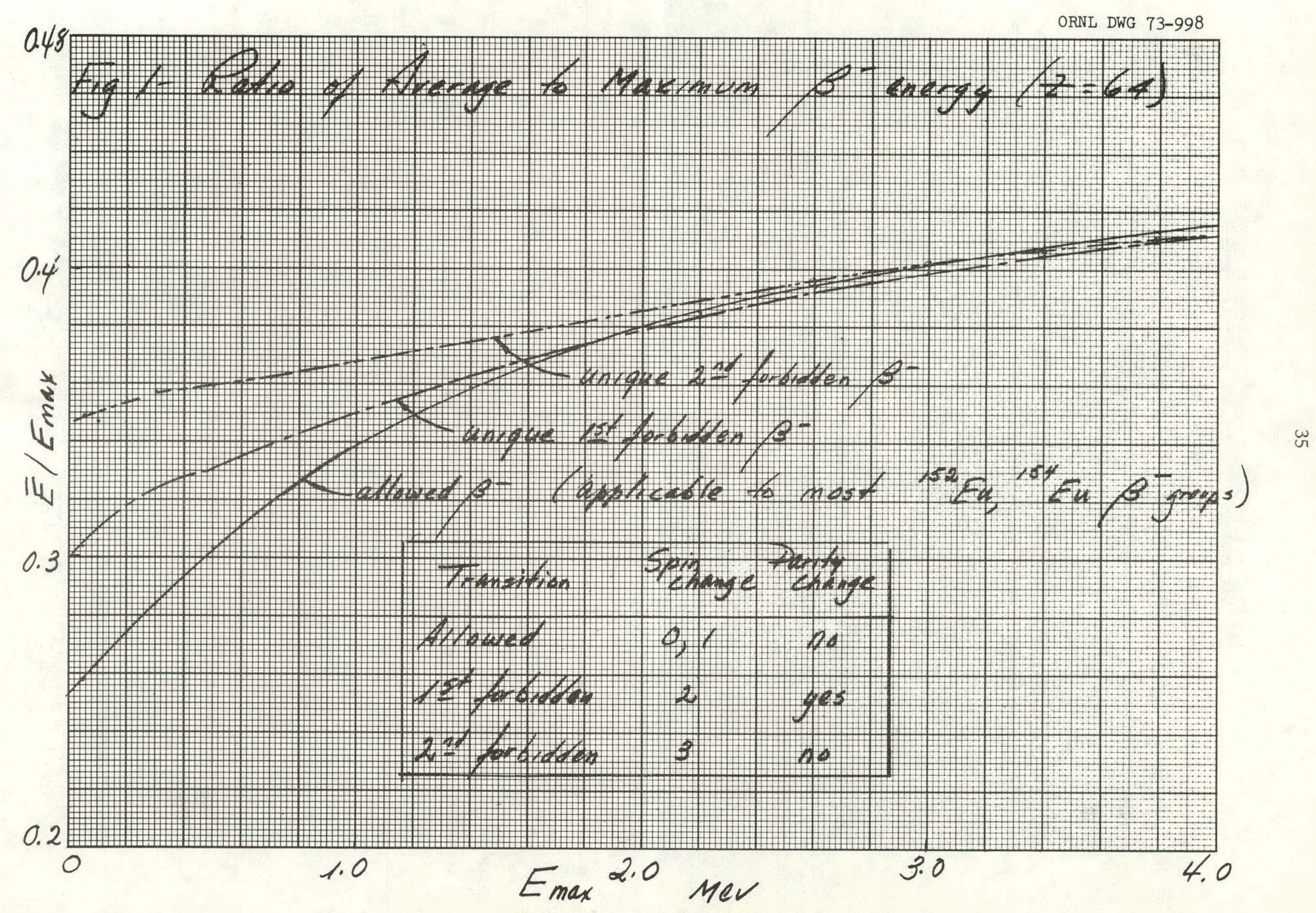




\subsection{Self-Absorption Factors for Gamma Rays}

While the beta particles are absorbed essentially at their point of origin, the gamma rays are more penetrating, and may escape from the body in which they are produced. We have estimated the absorption probabilities for europium decay gammas for uniform cylindrical rods of europium oxide of varying size and density, representing either single pins or - in an approximate way - clusters of pins. Gamma-ray absorption coefficients are given in many places; we used the graphs in Ref. 8 . Escape probabilities are given in Ref. 9, as a function of $\mu r$, the dimensionless product of the gamma-ray ahsnrption esefficient times the radius of the cylinder; the complement of this function is reproducen here as Fig. 2, and strictly speaking applies only to a uniformly distributed source. However, in the present case the source is not expected to be far from uniform, and we believe that the curve of Fig. 2 is a reasonable approximation to use here.

Perhaps a more serious question, in using Fig. 2, is whether the total gamma cross section (including scattering) or only the energyabsorption cross section should be used in calculating the parameter $\mu \mathrm{r}$. Depending on the material and on the gamma-ray energy, these may differ by a factor of 2 or more. Use of the total cross section presumaly leads to an underestimate of the escape fraction (an overestimate of the absorption fraction) since Compton-scattered gammas can subsequently escape, having left only part of their energy in the body. On the other hand, use of the energy-absorption cross section (whirh includes the photo-electric and pair-production cross sections and part of the scattering cross section) undoubtedly underestimates the absorption fraction because the scattered gammas (especially in high-7, materials) have a greatly increased probability of ahsorntion, relative to the uncollided gammas. (This statement may not be true for gammas with energies appreciably above the pair-production threshold, l MeV, but pair production is not a significant process for most of the decay gammas with which we are concerned here.)

The absorption fractions calculated here are based on the total cross section, but we also indicate the sensitivity of results to this 


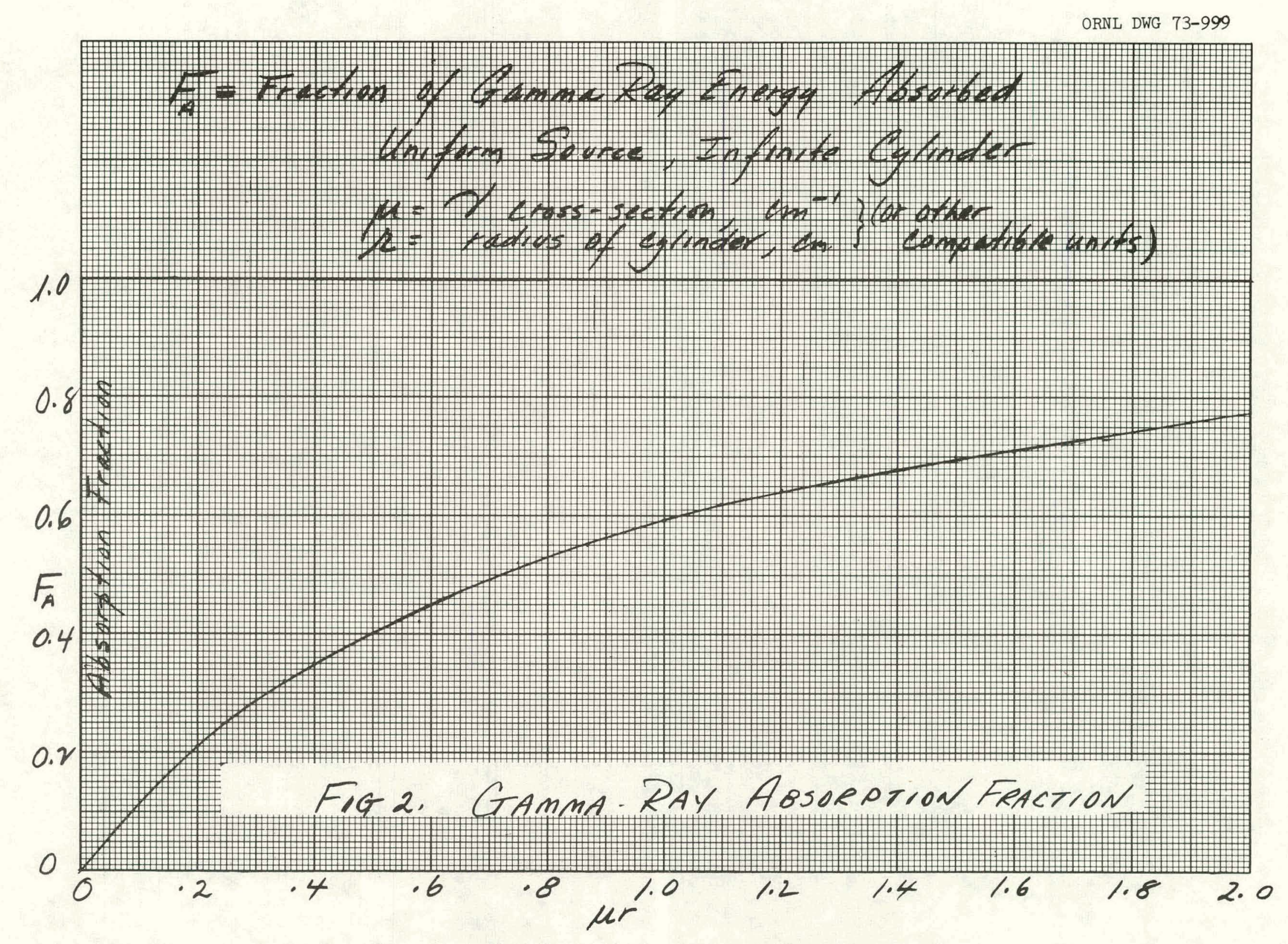


choice for the important cases (compare, for example, Figs.4 and 5, pages 17 and 18 ).

Gamma-ray absorption fractions are shown in Table 2, for clusters of $\mathrm{Eu}_{2} \mathrm{O}_{3}$ pins, simulated by single cylindrical rods as described in Table 3 .

Table 2. Gamma-ray absorption factors for simulated $\mathrm{Eu}_{2} \mathrm{O}_{3}$ clusters ${ }^{a}$

\begin{tabular}{|c|c|c|c|c|c|c|c|}
\hline \multirow{2}{*}{\multicolumn{2}{|c|}{$\begin{array}{l}\delta_{y}(\mathrm{McV}) \\
\sigma\left(\mathrm{cm}^{2} / \mathrm{g}\right)\end{array}$}} & \multicolumn{3}{|c|}{$p=6.85 \mathrm{~g} / \mathrm{cm}^{3}$} & \multicolumn{3}{|c|}{$\rho=3.43 \mathrm{~g} / \mathrm{cm}^{3}$} \\
\hline & & $30 \mathrm{~cm}^{2}$ & $40 \mathrm{~cm}^{2}$ & $30 \mathrm{~cm}^{2}$ & $60 \mathrm{~cm}^{2}$ & $80 \mathrm{~cm}^{2}$ & $100 \mathrm{~cm}^{\circ}$ \\
\hline $\begin{array}{l}0.1 \\
>1\end{array}$ & $\begin{array}{l}\mu r \\
F A\end{array}$ & $\begin{array}{r}>21.2 \\
\sim 1.0\end{array}$ & $\begin{array}{r}>24.4 \\
\approx 1.0\end{array}$ & $\begin{array}{r}>27.3 \\
\\
\sim 1.0\end{array}$ & $\begin{array}{r}>15.0 \\
\sim 1.0\end{array}$ & $\begin{array}{r}>17.3 \\
\sim 1.0\end{array}$ & $\begin{array}{r}>19.3 \\
\\
\sim 1.0\end{array}$ \\
\hline $\begin{array}{l}0.5 \\
0.15\end{array}$ & $\begin{array}{l}\mu r \\
F A\end{array}$ & $\begin{array}{r}3.2 \\
20.9\end{array}$ & $\begin{array}{r}3.7 \\
20.9\end{array}$ & $\begin{array}{r}4.1 \\
20.9\end{array}$ & $\begin{array}{r}2.3 \\
-0.8\end{array}$ & $\begin{array}{l}2.60 \\
20.8\end{array}$ & $\begin{array}{l}2.90 \\
20.8\end{array}$ \\
\hline $\begin{array}{l}0.9 \\
0.07\end{array}$ & $\begin{array}{l}\mu r \\
F A\end{array}$ & $\begin{array}{l}1.63 \\
0.72\end{array}$ & $\begin{array}{l}1.71 \\
0.73\end{array}$ & $\begin{array}{l}1.91 \\
0.76\end{array}$ & $\begin{array}{l}1.05 \\
0.61\end{array}$ & $\begin{array}{l}1.21 \\
0.64\end{array}$ & $\begin{array}{l}1.35 \\
0.67\end{array}$ \\
\hline $\begin{array}{l}1.0 \\
0.06\end{array}$ & $\begin{array}{l}\mu r \\
F A\end{array}$ & $\begin{array}{l}1.27 \\
0.65\end{array}$ & $\begin{array}{l}1.46 \\
0.69\end{array}$ & $\begin{array}{l}1.64 \\
0.72\end{array}$ & $\begin{array}{l}0.90 \\
0.56\end{array}$ & $\begin{array}{l}1.04 \\
0.60\end{array}$ & $\begin{array}{l}1.16 \\
0.63\end{array}$ \\
\hline $\begin{array}{l}1.3 \\
0.05\end{array}$ & $\begin{array}{l}\mu r \\
F A\end{array}$ & $\begin{array}{l}1.06 \\
0.61\end{array}$ & $\begin{array}{l}1.202 \\
0.64\end{array}$ & $\begin{array}{l}1.31 \\
0.67\end{array}$ & $\begin{array}{l}0.75 \\
0.51\end{array}$ & $\begin{array}{l}0.87 \\
0.55\end{array}$ & $\begin{array}{l}0.97 \\
0.58\end{array}$ \\
\hline $\begin{array}{l}1.0 \\
0.03^{h}\end{array}$ & $\begin{array}{l}\mu \mathrm{r} \\
\mathrm{FA}\end{array}$ & $\begin{array}{l}0.04 \\
0.47\end{array}$ & $\begin{array}{l}0.73 \\
0.50\end{array}$ & $\begin{array}{l}0.82 \\
0.54\end{array}$ & $\begin{array}{l}0.45 \\
0.38\end{array}$ & $\begin{array}{l}0.52 \\
0.41\end{array}$ & $\begin{array}{l}0.58 \\
0.44\end{array}$ \\
\hline
\end{tabular}

\begin{tabular}{|c|c|c|c|c|c|c|c|}
\hline \multirow{2}{*}{\multicolumn{2}{|c|}{$\begin{array}{l}{ }^{E} \gamma(\mathrm{MeV}) \\
\sigma\left(\mathrm{cm}^{2} / \mathrm{g}\right)\end{array}$}} & \multicolumn{3}{|c|}{$\rho=6.85 \mathrm{~g} / \mathrm{cm}^{3}$} & \multicolumn{3}{|c|}{$\rho=1.5 \mathrm{~g} / \mathrm{cm}^{3}$} \\
\hline & & $0.755 \mathrm{~cm}^{2}$ & $2.26 \mathrm{~cm}^{2}$ & $5.28 \mathrm{~cm}^{2}$ & $3.5 \mathrm{~cm}^{2}$ & $10 \mathrm{~cm}^{2}$ & $24 \mathrm{~cm}^{2}$ \\
\hline $\begin{array}{l}0.5 \\
0.15\end{array}$ & $\begin{array}{l}\mu r \\
F A\end{array}$ & $\begin{array}{l}0.50 \\
0.40\end{array}$ & $\begin{array}{l}0.87 \\
0.55\end{array}$ & $\begin{array}{l}1.33 \\
0.67\end{array}$ & $\begin{array}{l}0.23 \\
0.23\end{array}$ & $\begin{array}{l}0.41 \\
0.35\end{array}$ & $\begin{array}{l}0.62 \\
0.46\end{array}$ \\
\hline $\begin{array}{l}1.0 \\
0.06\end{array}$ & $\begin{array}{l}\mu r \\
F A\end{array}$ & $\begin{array}{l}0.20 \\
0.21\end{array}$ & $\begin{array}{l}0.35 \\
0.32\end{array}$ & $\begin{array}{l}0.53 \\
0.42\end{array}$ & $\begin{array}{l}0.09 \\
0.10\end{array}$ & $\begin{array}{l}0.16 \\
0.17\end{array}$ & $\begin{array}{l}0.25 \\
0.25\end{array}$ \\
\hline $\begin{array}{l}1.0 \\
0.03^{b}\end{array}$ & $\begin{array}{l}\mu r \\
F A\end{array}$ & $\begin{array}{l}0.10 \\
0.11\end{array}$ & $\begin{array}{l}0.17 \\
0.18\end{array}$ & $\begin{array}{l}0.27 \\
0.27\end{array}$ & $\begin{array}{l}0.05 \\
0.05\end{array}$ & $\begin{array}{l}0.08 \\
0.09\end{array}$ & $\begin{array}{l}0.13 \\
0.14\end{array}$ \\
\hline
\end{tabular}

a See Table 3 for details of geometrical representation.

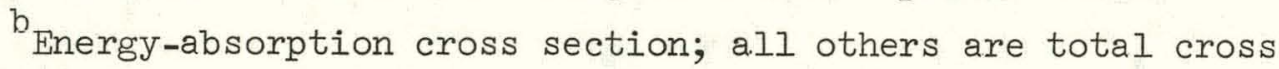
sections. 
Table 3. Simulated $\mathrm{Eu}_{2} \mathrm{O}_{3}$ pin clusters and equivalent uniform circular rods

\begin{tabular}{|c|c|c|c|c|c|c|}
\hline \multicolumn{2}{|c|}{ Pins simulated } & \multicolumn{5}{|c|}{ Equivalent uniform cylindrical rod } \\
\hline Number & $\begin{array}{c}\text { Diametera } \\
\text { (in.) }\end{array}$ & $\begin{array}{l}\text { Densityb } \\
\left(\mathrm{g} / \mathrm{cm}^{3}\right)\end{array}$ & $\frac{\text { Rod }}{\text { (in.) }}$ & $\frac{\text { diameter }}{(\mathrm{cm})}$ & $\begin{array}{l}\text { Area } \\
\left(\mathrm{cm}^{2}\right)\end{array}$ & $\begin{array}{c}\rho r \\
\left(\mathrm{~g} / \mathrm{cm}^{2}\right)\end{array}$ \\
\hline $\begin{array}{l}61 \\
61 \\
61\end{array}$ & $\begin{array}{l}0.31 \\
0.36 \\
0.40_{2}\end{array}$ & $\begin{array}{l}6.85 \\
6.85 \\
6.85\end{array}$ & $\begin{array}{l}2.43 \\
2.81 \\
3.14\end{array}$ & $\begin{array}{l}6.18 \\
7.136 \\
7.98\end{array}$ & $\begin{array}{l}30.0 \\
40.0 \\
50.0\end{array}$ & $\begin{array}{l}21.2 \\
24.4 \\
27.3\end{array}$ \\
\hline $\begin{array}{l}61 \\
61 \\
61\end{array}$ & $\begin{array}{l}0.31_{2} \\
0.36 \\
0.40_{2}\end{array}$ & $\begin{array}{l}3.43 \\
3.43 \\
3.43\end{array}$ & $\begin{array}{l}3.44 \\
3.97 \\
4.44\end{array}$ & $\begin{array}{r}8.74 \\
10.09 \\
11.29\end{array}$ & $\begin{array}{r}60.0 \\
80.0 \\
100.0\end{array}$ & $\begin{array}{l}15.0 \\
\frac{17.3^{c}}{19.3}\end{array}$ \\
\hline $\begin{array}{l}1 \\
3 \\
7\end{array}$ & $\begin{array}{l}0.386 \\
0.386 \\
0.386\end{array}$ & $\begin{array}{l}\frac{6.85}{6.85} \\
6.85\end{array}$ & $\begin{array}{l}0.386 \\
0.669 \\
1.021\end{array}$ & $\begin{array}{l}0.980 \\
1.697 \\
2.593\end{array}$ & $\begin{array}{l}0.755 \\
2.26 \\
5.28\end{array}$ & $\frac{3.36^{c}}{5.81}$ \\
\hline $\begin{array}{l}1 \\
3 \\
7\end{array}$ & $\begin{array}{l}0.386 \\
0.386 \\
0.386\end{array}$ & $\begin{array}{l}1.50 \\
1.50 \\
1.50 \\
\end{array}$ & $\begin{array}{l}0.825 \\
1.430 \\
2.182\end{array}$ & $\begin{array}{l}2.094 \\
3.627 \\
5.54\end{array}$ & $\begin{array}{r}3.45 \\
10.32 \\
24.1\end{array}$ & $\begin{array}{l}1.57 \\
2.72^{c} \\
4.16 c \\
\end{array}$ \\
\hline
\end{tabular}

aiameter of oxide pellet.

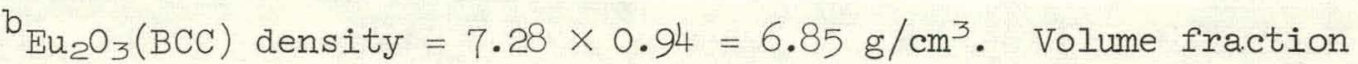
of $\mathrm{Eu}_{2} \mathrm{O}_{3}$ in clusters of pins is assumed to be ${ }^{0.5}$ in large FTR C.R. assemblies, 0.2 in small experimental EBR-II assemblies.

We consider these cases to be the most reasonable simulations of the actual cases they are intended to represent.

\subsection{Saturation Factors, Duty Factors}

For an irradiation period that is not long compared to the halflife of the induced radioactive species, the disintegration rate is less than the production rate by the saturation factor

$$
S \equiv\left(1-e^{-\lambda t}\right),
$$

where $\lambda$ is the decay constant.

The following table lists saturation factors for the three principal Eu activities considered here. 
Table 4. Saturation factors for irradiated europium

\begin{tabular}{clll}
\hline $\begin{array}{c}\text { Irradiation period } \\
\text { (years) }\end{array}$ & $1^{152 m_{\mathrm{Eu}}}$ & $152 g_{\mathrm{Eu}}$ & ${ }^{154} \mathrm{Eu}$ \\
\hline 1 & 1.0 & 0.0561 & 0.0424 \\
2 & 1.0 & 0.109 & 0.083 \\
3 & 1.0 & 0.159 & 0.122 \\
4 & 1.0 & 0.206 & 0.159 \\
\hline
\end{tabular}

For the results that follow, we have used lie suluration factors for a one-year irradiation period. We calculate the disintegration rate for each active species as the product of this saturation factor, the production rate discussed in Section 1.1, and a reactor duty factor appropriate to each nuclide. For the 9.3-hr $152 m_{E u}$ isomer, we use a duty factor of 1.0; for 12-yr ${ }^{152 g} \mathrm{Eu}$ and $16-\mathrm{yr}{ }^{154} \mathrm{Eu}$ we use a. duty factor of 0.7 .

This procedure does not take into account any reduction in the activity of ${ }^{152 g} \mathrm{Eu}$ or ${ }^{154} \mathrm{Eu}$ owing to neutron capture by these nuclides (which would lead in the first case to stable ${ }^{153} \mathrm{Eu}$, and in the second to $1.8-\mathrm{yr}{ }^{155} \mathrm{Eu}$, whose decay energy is much less than that of ${ }^{154} \mathrm{Eu}$ ). While we have also neglected the contribution of such active products as ${ }^{153} \mathrm{Sm},{ }^{153} \mathrm{Gd}$, and ${ }^{155} \mathrm{Eu}$, we would not expect these entirely to compensate for the above reduction because their decay energy is much lower than that of ${ }^{152} \mathrm{Eu}$ and ${ }^{154} \mathrm{Eu}$, a.s shown in Table 5.

Thus, the decay heat that we calculate is somewhat high. However, the burnup lifetime of all these nuclides is long compared to the irradiation period (see section 3), so the error caused by this approximation cannot be more than a few percent. 
Table 5. Decay energy of some rare-earth isotopes

\begin{tabular}{|c|c|c|}
\hline Isotope & Half-life & Transition energy (MeV) \\
\hline $152 m_{\mathrm{Eu}}$ & $9.3 \mathrm{hr}$ & $Q_{B_{-}}=1.87, Q_{E C}=1.907$ \\
\hline $152 g \mathrm{Eu}$ & $12 \mathrm{yr}$ & $\mathrm{Q}_{B^{-}}=1.82, \mathrm{Q}_{\mathrm{EC}}=1.857$ \\
\hline${ }^{152} \mathrm{Sm}$ & Stable & \\
\hline${ }^{152} \mathrm{Cd}$ & St.ah 1e & \\
\hline${ }^{153} \mathrm{Sm}$ & $47 \mathrm{hr}$ & $Q_{B_{-}}=0.80$ \\
\hline${ }^{153} \mathrm{Gd}$ & $242 d$ & $Q_{E C}=0.24$ \\
\hline${ }^{151} \mathrm{Eu}$ & $16 \mathrm{yx}$ & $Q_{B_{-}}-1.078$ \\
\hline${ }^{155} \mathrm{Eu}$ & $1.81 \mathrm{yr}$ & $Q_{B_{-}}=0.248$ \\
\hline
\end{tabular}

\subsection{Results of Afterheat Calculations}

Results of the afterheat calculations, carried out as described in the preceding sections, are shown in Figs. 3 through 8. Cases A, B, C, and D (Figs. 3 through 6 respectively) are intended to represent various clusters of $\mathrm{Eu}_{2} \mathrm{O}_{3}$ pins, as follows:

A: single 0.386 in. diam pin, density $=6.85 \mathrm{~g} / \mathrm{cm}^{3}$;

B: three such pins, smeared density $=1.5 \mathrm{~g} / \mathrm{cm}^{3}$;

C: seven such pins, smeared density $=1.5 \mathrm{~g} / \mathrm{cm}^{3}$;

D: 61-0.36 in. diam pins, smeared density $=3.43 \mathrm{~g} / \mathrm{cm}^{3}$.

(See Tables 2 and 3 for additional data.)

The independent variables for the straight-line graphs of Figs. 3 through 7 are the ratio $r \equiv \bar{\sigma}\left({ }^{15}{ }^{\mathrm{Eu}}\right) / \bar{\sigma}\left({ }^{153} \mathrm{Eu}\right)$ and the fraction $f_{11}=$ $\bar{\sigma}\left({ }^{15}{ }^{\mathrm{Eu}} \rightarrow{ }^{152 g} \mathrm{Eu}\right) / \bar{\sigma}\left({ }^{15} I_{\mathrm{Eu}}\right)$, i.e., the fraction of neutron captures in ${ }^{151} \mathrm{Eu}$ that produces the $9.3 \mathrm{hr}$ isomer. On the basis of data from various sources (see Appendix B), we believe that probable values of these variables in the EBR-II neutron spectrum (Row 7) are:

$$
\begin{aligned}
r & \sim 1.5, \\
f_{11} & \approx 0.5 .
\end{aligned}
$$

More work is needed to determine these cross-section ratios more closely. 
42

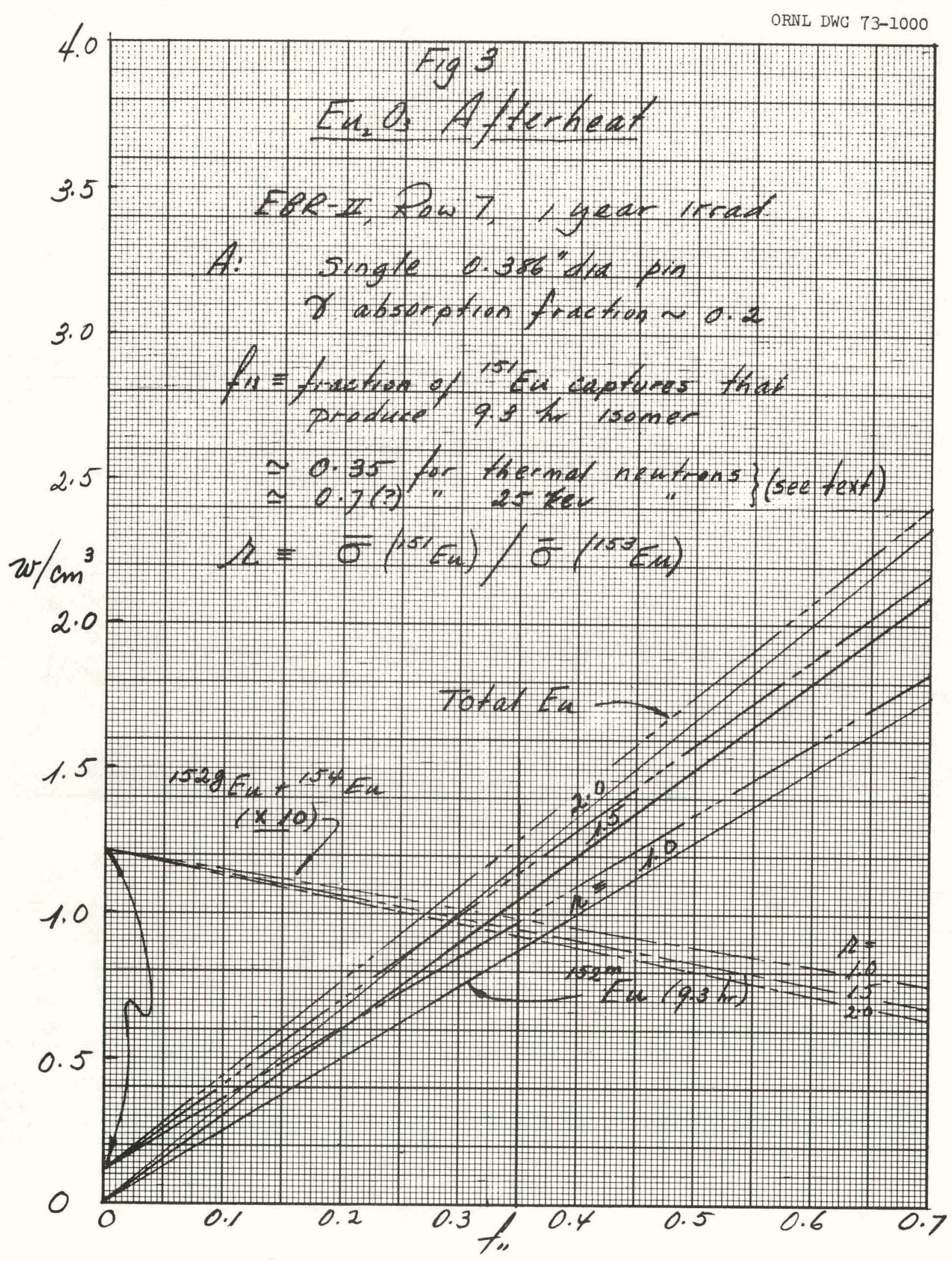

16 
43

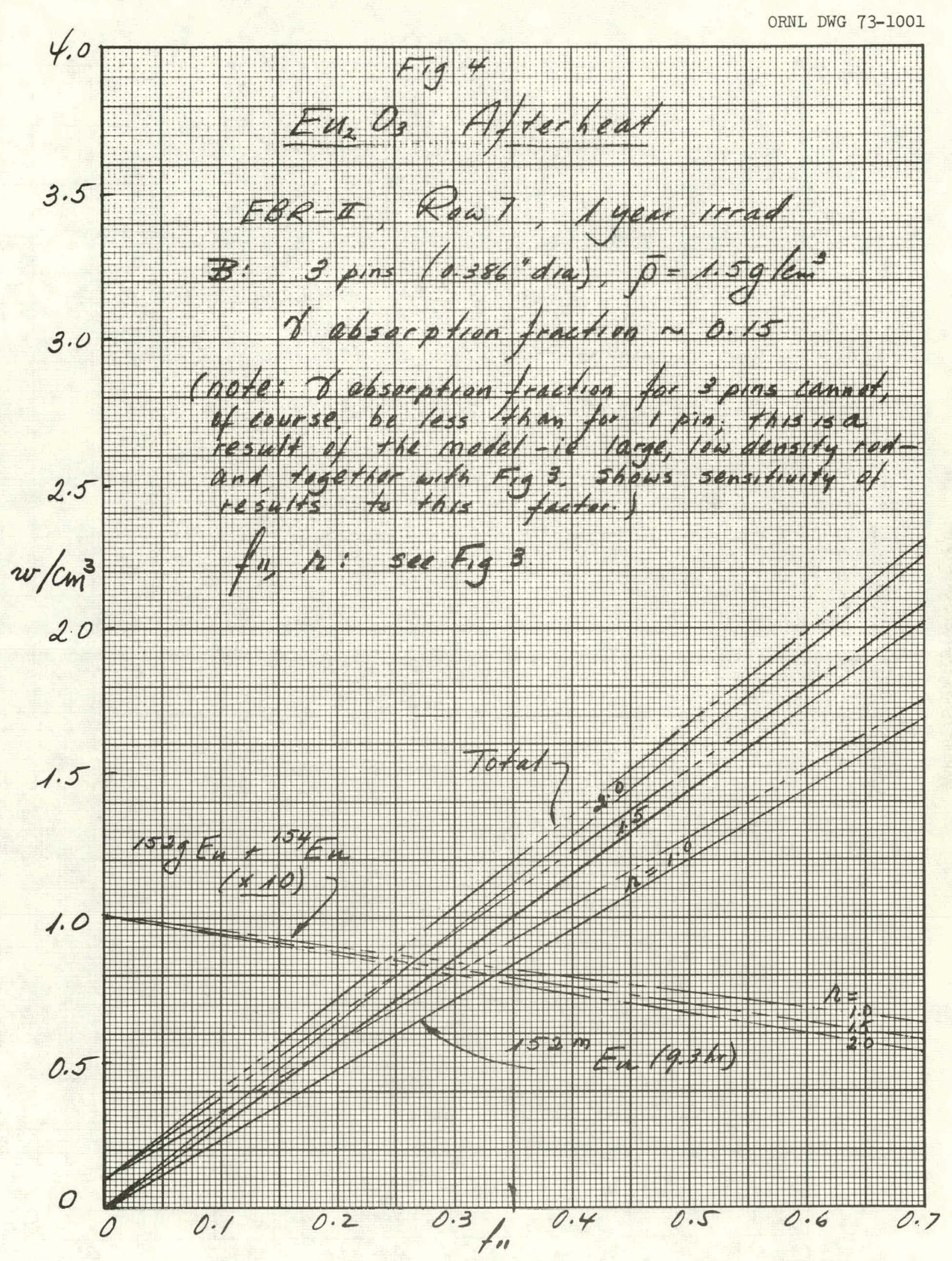


ORNL DWG 73-1002

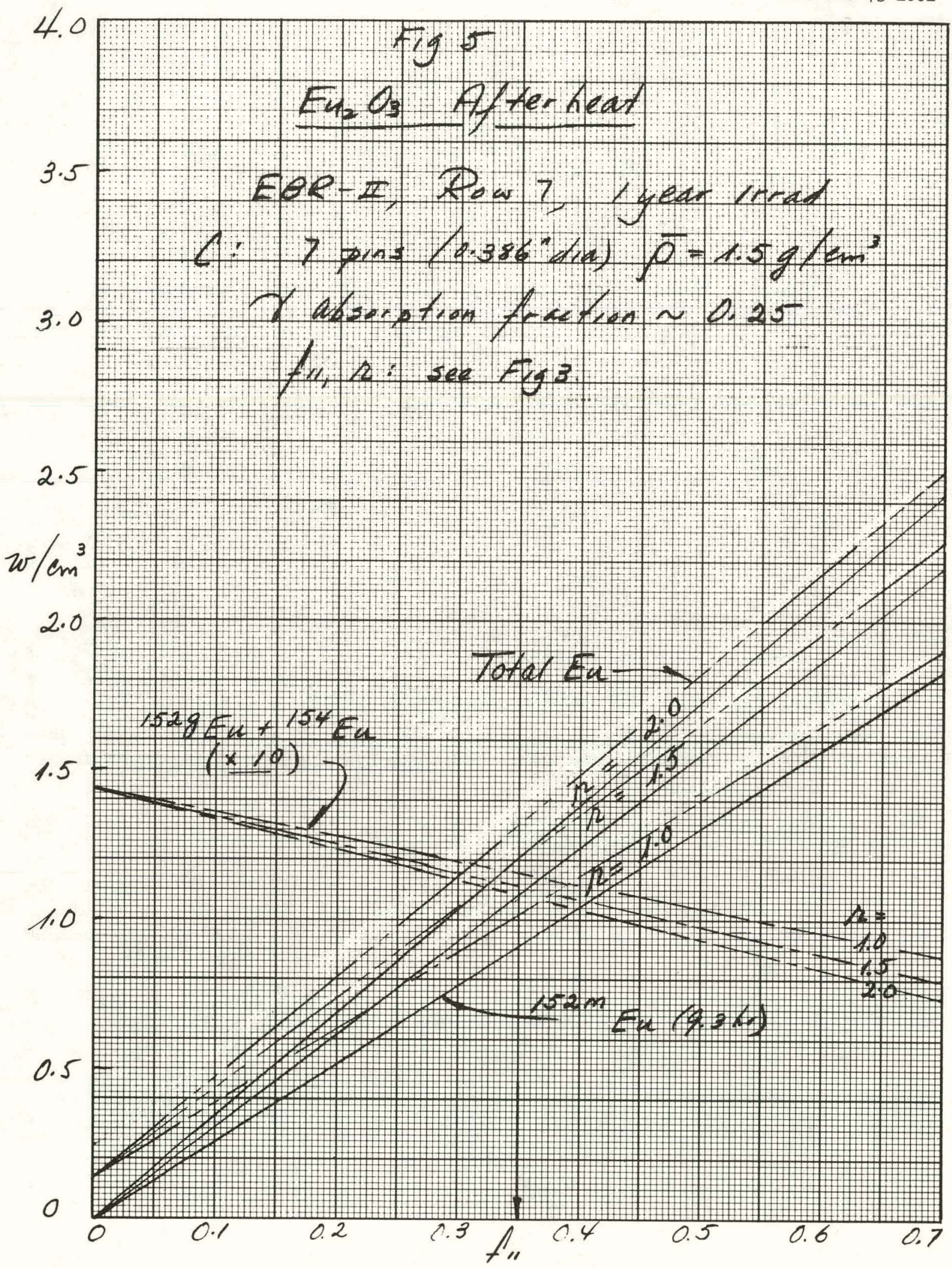


45

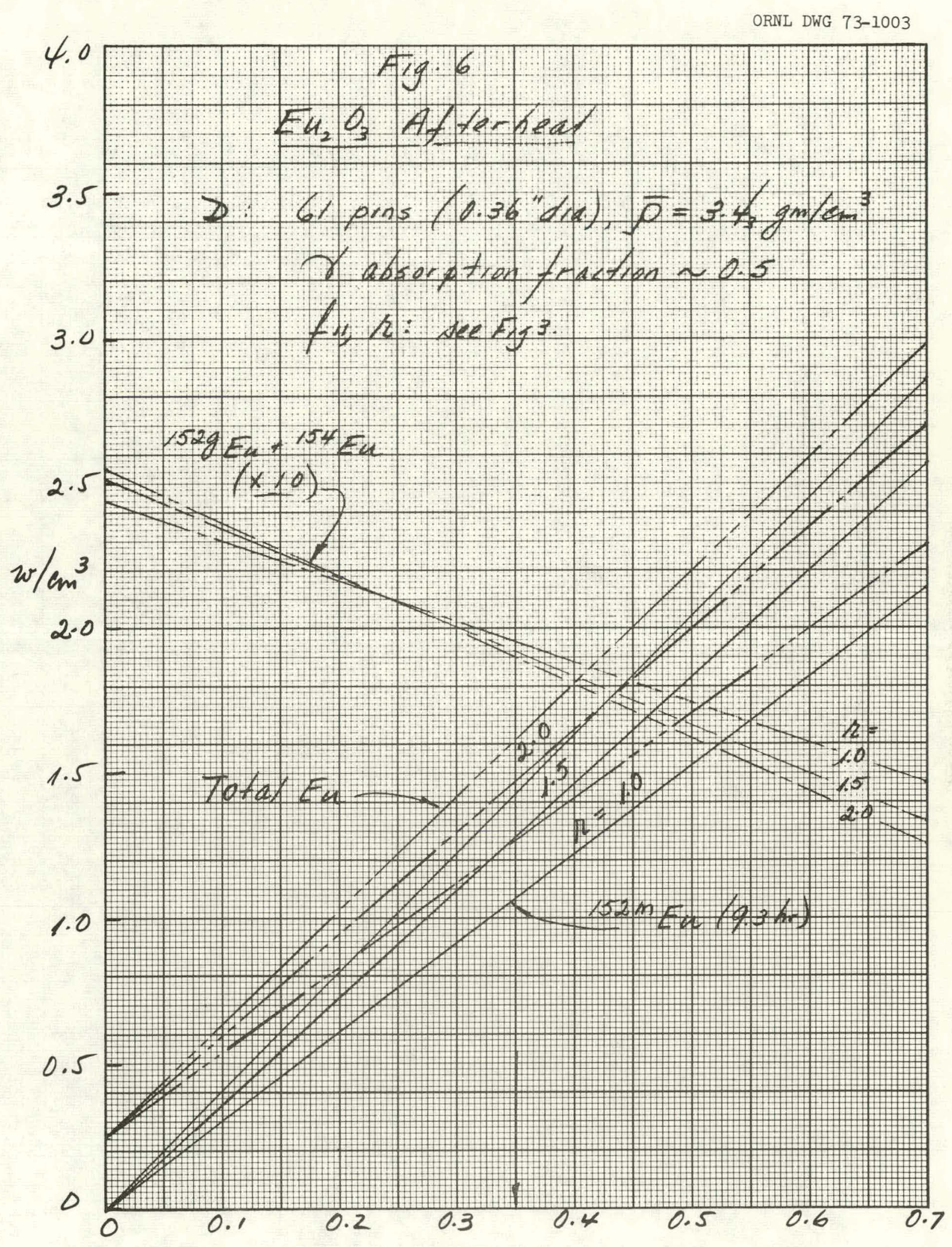

19 


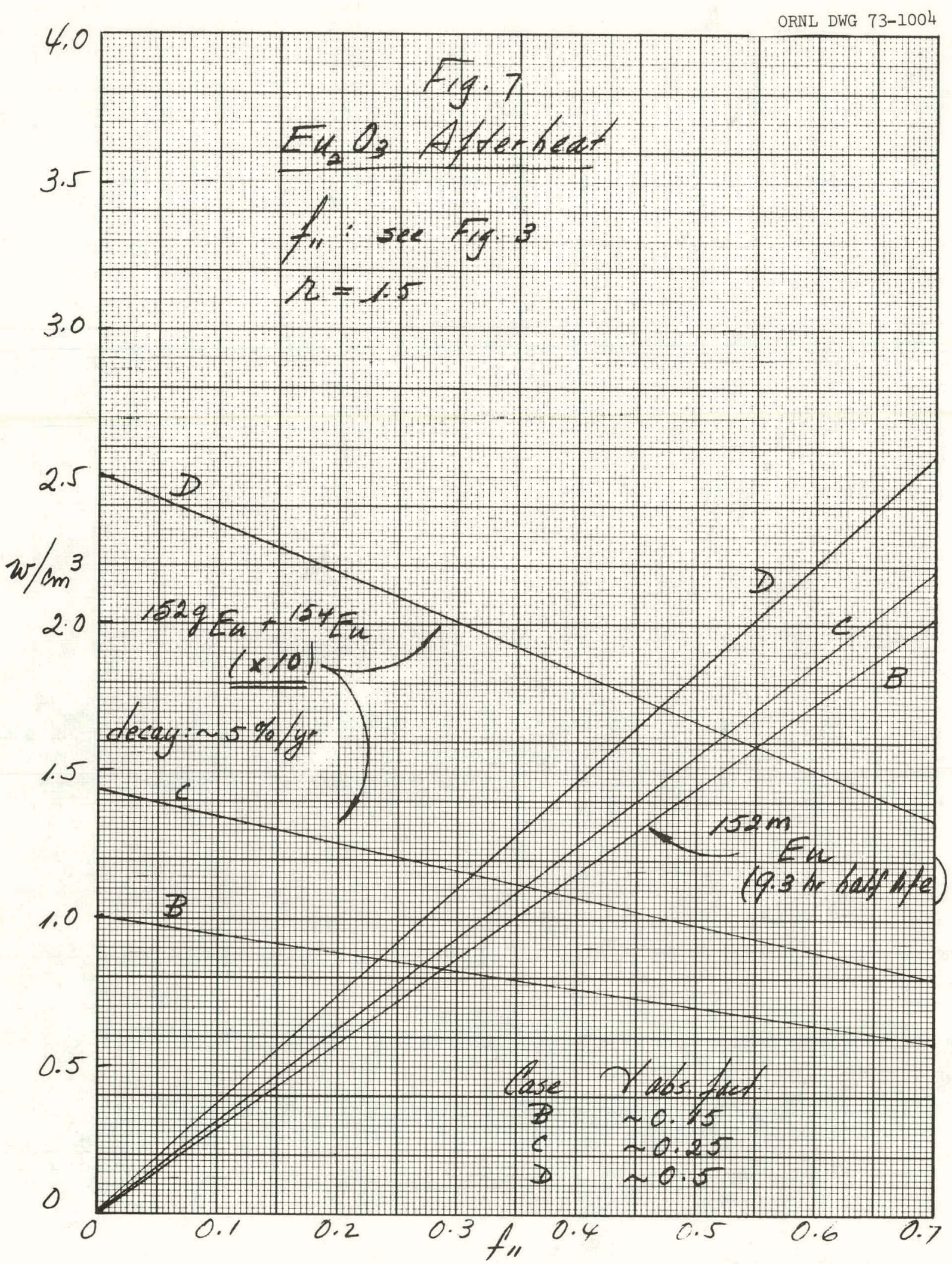




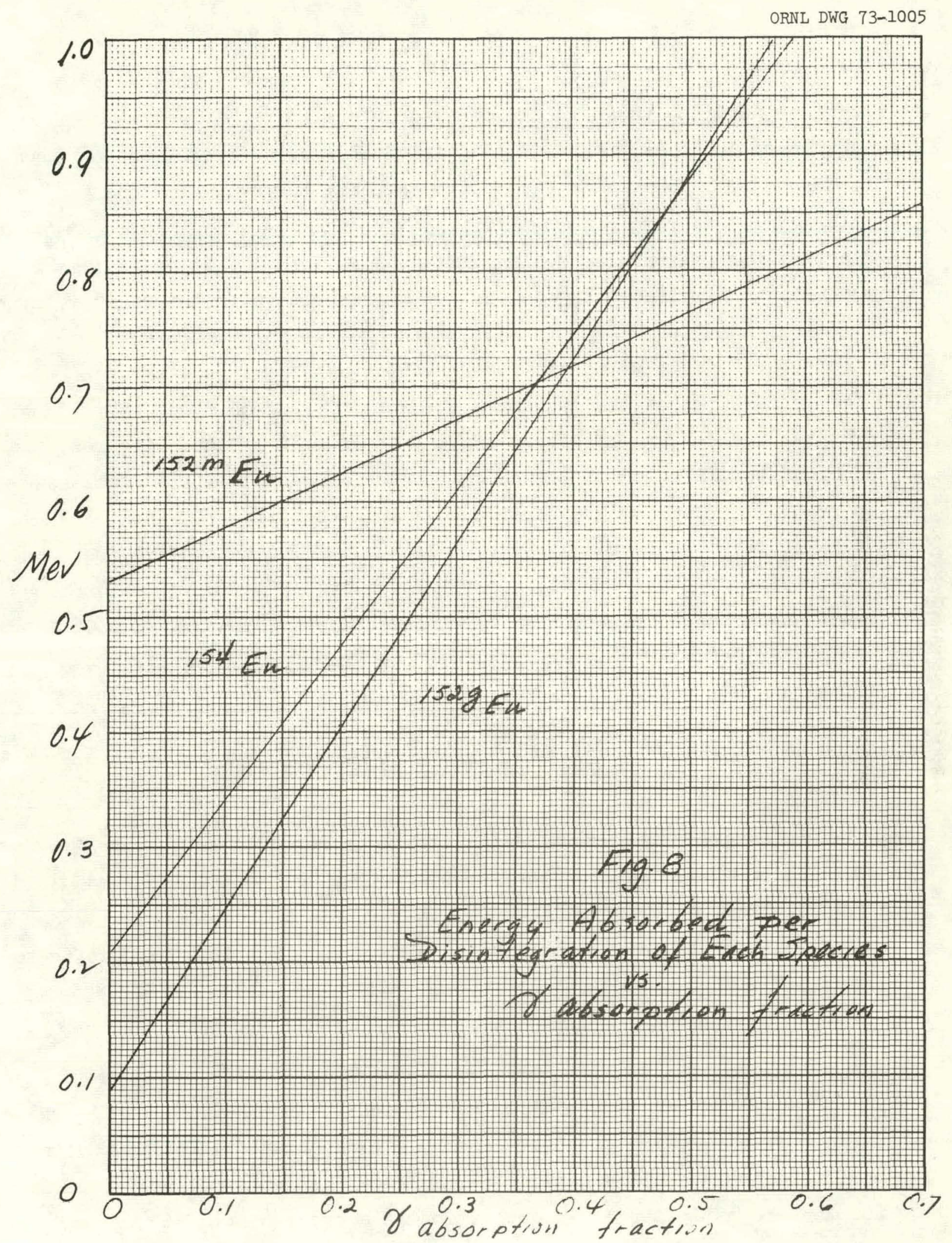


Figures 3 through 6 show the decay heat (in $\mathrm{w} / \mathrm{cm}^{3}$ ) due to the $9.3 \mathrm{hr}{ }^{152 \mathrm{~m}} \mathrm{Eu}$, that due to the long-lived isotopes ${ }^{152 g} \mathrm{Eu}$ and ${ }^{154} \mathrm{Eu}$ together, and the totals. The decay heat due to ${ }^{152 m_{E u}}$ dominates for short cooling times; it is quite sensitive (i.e., directly proportional) to the poorly known ratio $f_{l l}$, but of course dies away with the $9.3 \mathrm{hr}$ hallf-life. The remaining contribution from ${ }^{1529} \mathrm{Eu}$ and ${ }^{154} \mathrm{Eu}$ is essentially constant for reasonable cooling times (half-lives 12 , 16 years); it is much less sensitive to $f_{1 l}$ and is quite insensitive to the ratio $r$, since the decay energies ${ }^{152 g} \mathrm{Eu}$ and for ${ }^{154} \mathrm{Eu}$ are not very different.

Tigure 7 merely repeats some of the graphs of Figs 4 turough 6 for different values of the gamma-ray absorption fraction, and for the most probable value of $r, r=1.5$. (Note that in each of these figures, the combined contribution of ${ }^{152 g} \mathrm{Eu}$ and ${ }^{154} \mathrm{Eu}$ is multiplied by 10 for ease of reading on the same scale as the dominant contribution from ${ }^{152 m_{E u}} \mathrm{E}$ )

In Fig. 8, the energy absorbed is shown for each nuclide, per disintegration of that nuclide, as a function of the gamma-ray absorption fraction. Thus, the effect of varying assumptions concerning both production rates and the gamma absorption fraction can readily be deduced.

\section{GAMMA HEATTNG DURING OPERATION}

Estimates of the gamma-heating to be expected in $\mathrm{Eu}_{2} \mathrm{O}_{3}$ pins irradiated in EBR-II, during reactor operation, were obtained by adjusting: data for iron and uranium, as given in the EBR-II Experimenters Guide ${ }^{10}$, to account for the difference in gamma-ray cross sections between these materials and europium.

\subsection{Energy-Absorption Cross Sections}

Gamma-ray energy-absorption coefficients, from Ref. 8, are shown in Table 6 as a function of photon energy. Also shown are ratios of these coefficients, useful in making the needed adjustments. (The coefficients for Eu were estimated by interpolation of a cross-plot of log $\mu$ vs $z$ for each photon energy.) 
Table 6. Energy-absorption coefficients

$$
\left(\mu-\mathrm{cm}^{2} / \mathrm{g}\right)
$$

\begin{tabular}{|c|c|c|c|c|c|c|c|c|}
\hline & \multicolumn{7}{|c|}{$\mathrm{E}_{\gamma}-\mathrm{MeV}$} \\
\hline & & 0.3 & 0.5 & 0.6 & 0.7 & 0.8 & 0.9 & 1.0 \\
\hline 1. & $\mathrm{Fe}(\mathrm{z}=26)$ & 0.037 & 0.029 & 0.028 & 0.027 & 0.027 & 0.026 & 0.026 \\
\hline 2. & $\begin{array}{l}\mathrm{U}(92) \\
\mathrm{U} / \mathrm{Fe}\end{array}$ & $\begin{array}{l}0.46 \\
12\end{array}$ & $\begin{array}{l}0.16 \\
5.5\end{array}$ & $\begin{array}{l}0.115 \\
4.1\end{array}$ & $\begin{array}{l}0.090 \\
3.3\end{array}$ & $\begin{array}{l}0.074 \\
2.7\end{array}$ & $\begin{array}{l}0.063 \\
2.4\end{array}$ & $\begin{array}{l}0.056 \\
2.2\end{array}$ \\
\hline & $\begin{array}{l}\mathrm{Ta}(73) \\
\mathrm{Ta} / \mathrm{Fe}\end{array}$ & $\begin{array}{l}0.26 \\
7.0\end{array}$ & $\begin{array}{l}0.091 \\
3.1\end{array}$ & $\begin{array}{l}0.067 \\
2.4\end{array}$ & $\begin{array}{l}0.054 \\
2.0\end{array}$ & $\begin{array}{l}0.046 \\
1.7\end{array}$ & $\begin{array}{l}0.041 \\
1.6\end{array}$ & $\begin{array}{l}0.036 \\
1.4\end{array}$ \\
\hline 4 . & $\begin{array}{l}\mathrm{Ag}(47) \\
\mathrm{Ag} / \mathrm{Fe}\end{array}$ & $\begin{array}{l}0.088 \\
2.4\end{array}$ & $\begin{array}{l}0.040 \\
1.4\end{array}$ & $\begin{array}{l}0.039 \\
1.4\end{array}$ & $\begin{array}{l}0.030 \\
1.1\end{array}$ & $\begin{array}{l}0.028 \\
1.0\end{array}$ & $\begin{array}{l}0.027 \\
1.0\end{array}$ & $\begin{array}{l}0.026 \\
1.0\end{array}$ \\
\hline 5. & $\begin{array}{l}\mathrm{Al} \text { (13) } \\
\mathrm{Al} / \mathrm{Fe}\end{array}$ & $\begin{array}{l}0.029 \\
0.8\end{array}$ & $\begin{array}{l}0.029 \\
1.0\end{array}$ & $\begin{array}{l}0.029 \\
1.0\end{array}$ & $\begin{array}{l}0.029 \\
1.1\end{array}$ & $\begin{array}{l}0.028 \\
1.0\end{array}$ & $\begin{array}{l}0.028 \\
1.1\end{array}$ & $\begin{array}{l}0.027 \\
1.0\end{array}$ \\
\hline 6. & $\begin{array}{l}\mathrm{Eu}^{\mathrm{a}}(63) \\
\mathrm{Eu} / \mathrm{Fe} \\
\mathrm{Eu} / \mathrm{Ta}\end{array}$ & $\begin{array}{l}0.185 \\
5.0 \\
0.71\end{array}$ & $\begin{array}{l}0.067 \\
2.3 \\
0.74\end{array}$ & $\begin{array}{l}0.052 \\
1.9 \\
0.78\end{array}$ & $\begin{array}{l}0.043 \\
1.6 \\
0.80\end{array}$ & $\begin{array}{l}0.037 \\
1.4 \\
0.80\end{array}$ & $\begin{array}{l}0.034 \\
1.3 \\
0.83\end{array}$ & $\begin{array}{l}0.030 \\
1.2 \\
0.83\end{array}$ \\
\hline
\end{tabular}

astimated by interpolation between curves for $\mathrm{Sn}(\mathrm{Z}=50)$ and Ta. $(Z=73)$.

\subsection{Gamma Hea.ting}

From Ref. 10, Table C-V, we obtain data for gamma-heating rates in uranium and iron, reproduced in part in the following table:

\begin{tabular}{|c|c|c|c|c|}
\hline \multirow{2}{*}{$\begin{array}{l}\text { Distance, reactor } \\
\text { centerline to } \mathrm{S} / \mathrm{A} \\
\text { centerline }(\mathrm{cm})\end{array}$} & \multirow{2}{*}{$\begin{array}{c}\text { Grid } \\
\text { Position }\end{array}$} & \multicolumn{3}{|c|}{ Gamma-heating rate $(\mathrm{w} / \mathrm{g})$} \\
\hline & & $\mathrm{U}$ & $\mathrm{Fe}$ & $\mathrm{U} / \mathrm{Fe}$ \\
\hline $\begin{array}{l}30.62 \\
31.18 \\
32.81 \\
35.36 \\
32.81 \\
35.84 \\
36.80 \\
38.64 \\
41.25\end{array}$ & $\begin{array}{l}7 N 4 \\
7 N 3,5 \\
7 N 2,6 \\
7 N 1(T) \\
7 N 6(T) \\
8 N 4,5 \\
8 N 3,6 \\
8 N 2,7 \\
8 N 1\end{array}$ & $\begin{array}{r}11.9 \\
10.8 \\
9.2 \\
5.8 \\
5.2 \\
7.4 \\
7.1 \\
6.1 \\
5.6\end{array}$ & $\begin{array}{l}3.9 \\
3.7 \\
3.4 \\
2.0 \\
1.6 \\
1.7 \\
1.5 \\
1.3 \\
1.1\end{array}$ & $\begin{array}{l}3.05 \\
2.92 \\
2.71 \\
2.90 \\
3.25 \\
4.35 \\
1.7 \\
4.7 \\
5.1\end{array}$ \\
\hline
\end{tabular}


Presumably the reason that the ratio of heating in uranium to that in iron increases with increasing distance away from the core centerline is that the gamma spectrum gets softer, due to scattering, at greater distances from the source. We note that the ratic in Row 7 is about 3, and from Table 6 we may infer an "effective" gamma energy of about 0.7-0.8 MeV. For this same energy range (again from Table 6), the ratio of heating (per gram) in Eu to that in Fe would be about 1.5. Thus, if the hea.ting rate in $\mathrm{Fe}$ is about $3.5-4 \mathrm{w} / \mathrm{g}$, we might expect that in $\mathrm{Eu}$ to be $5-6 \mathrm{w} / \mathrm{g}$. If the low figure for position $7 \mathrm{~N} 6(\mathrm{t})$ is used, i.e., $1.6 \mathrm{w} / \mathrm{g}$ for Fe, we might expect about $2.5 \mathrm{w} / \mathrm{g}$ fur Eu. The latter figure would be more consistent with the figure of $2.772 \mathrm{w} / \mathrm{g}$ (at the reactor midplane) that Da.le Dyslin gives for Ta in capsule 027.11 Using the ratio 0.8 from Table 6 , we would scale this to $2.2 \mathrm{w} / \mathrm{g}$ for $\mathrm{Eu}_{2} \mathrm{O}_{3}$ a.t the midplane. This is at best an approximate first estimate of gamma hea.ting in $\mathrm{E}_{2} \mathrm{O}_{3}$.

\section{BURNUP OF $\mathrm{EU}_{2} \mathrm{O}_{3}$}

We estimate the change in $\mathrm{Eu}_{2} \mathrm{O}_{3}$ neutron-capture rate, as a function of irradiation time, on the basis of data given in the following tahle:

\begin{tabular}{lccc}
\hline Isotope & $\begin{array}{c}\text { Atom density } \\
\left(\text { atoms } / \mathrm{cm}^{3}\right)\end{array}$ & $\begin{array}{c}\text { Neutron } \\
\text { a.bsorption } \\
\text { (ncutrons } / \mathrm{cm}^{3} \text { sec) }\end{array}$ & $\begin{array}{c}\text { Isotope burnup } \\
\text { rate } \\
\text { (fraction/yr) }\end{array}$ \\
\hline${ }_{151} \mathrm{Eu}$ & $1.12 \times 10^{22}$ & $2.9 \times 10^{13}$ & 0.0814 \\
$153 \mathrm{Eu}$ & $1.22 \times 10^{22}$ & $2.1 \times 10^{13}$ & 0.0543 \\
\hline
\end{tabular}

We assume that the capture products $\left({ }^{152} \mathrm{Eu}\right.$ or $\left.{ }^{154} \mathrm{Eu}\right)$ or their decay products ( ${ }^{152} \mathrm{sm}, 152 \mathrm{Gd}$ ) have on the average half the neutron-absorption cross section of their neutron-capture precursors (see Appendix B). Thus, assuming an initial capture rate of $5 \times 10^{13}$ neutrons $/ \mathrm{cm}^{3} \mathrm{sec}$ in $\mathrm{Eu}_{2} \mathrm{O}_{3}$, and with time measured in equivalent full-power years, we would expect, as a first approximation, the following variations of reactivity worth with irradiation time: 
Relative reactivity:

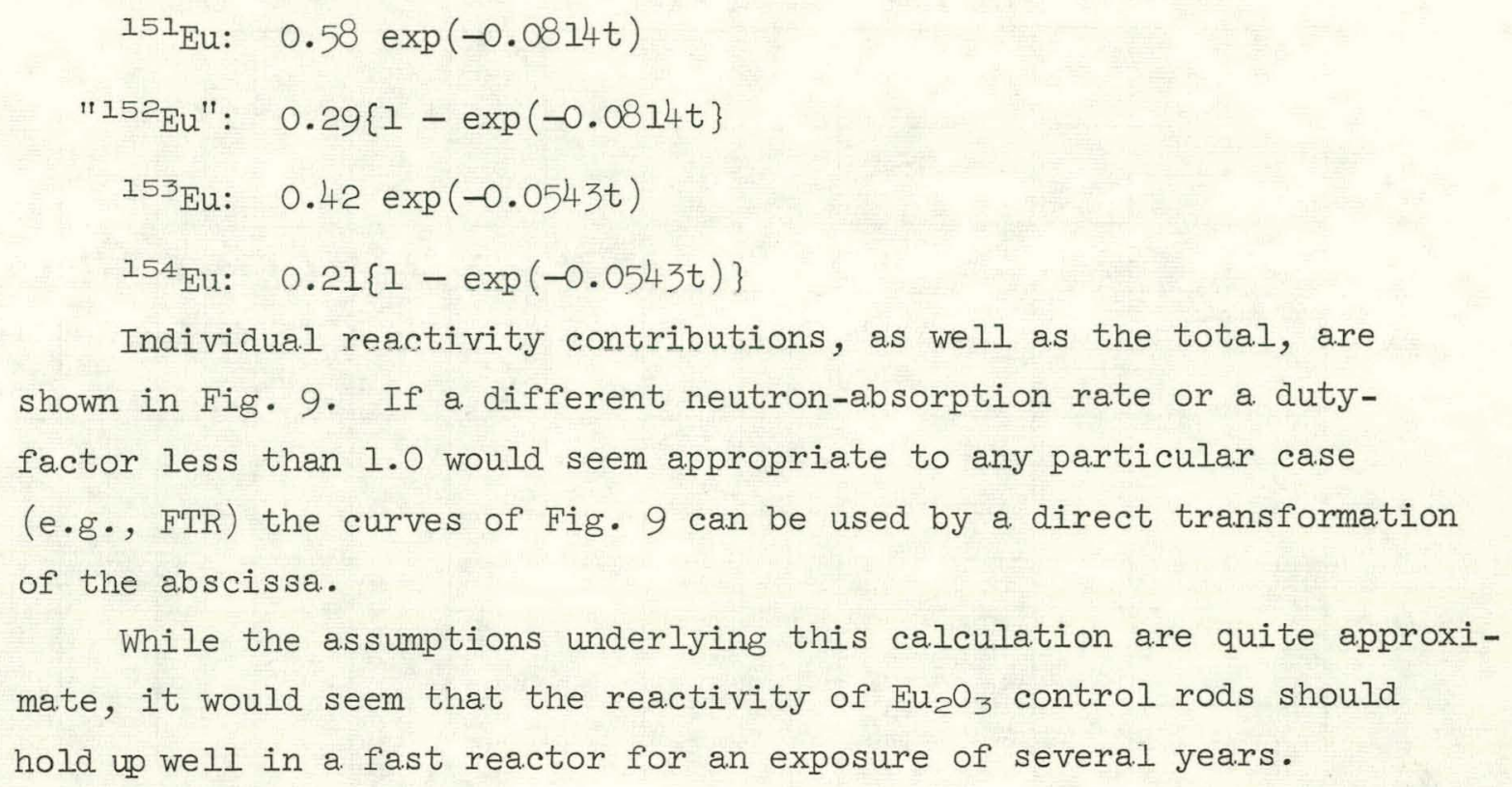


52

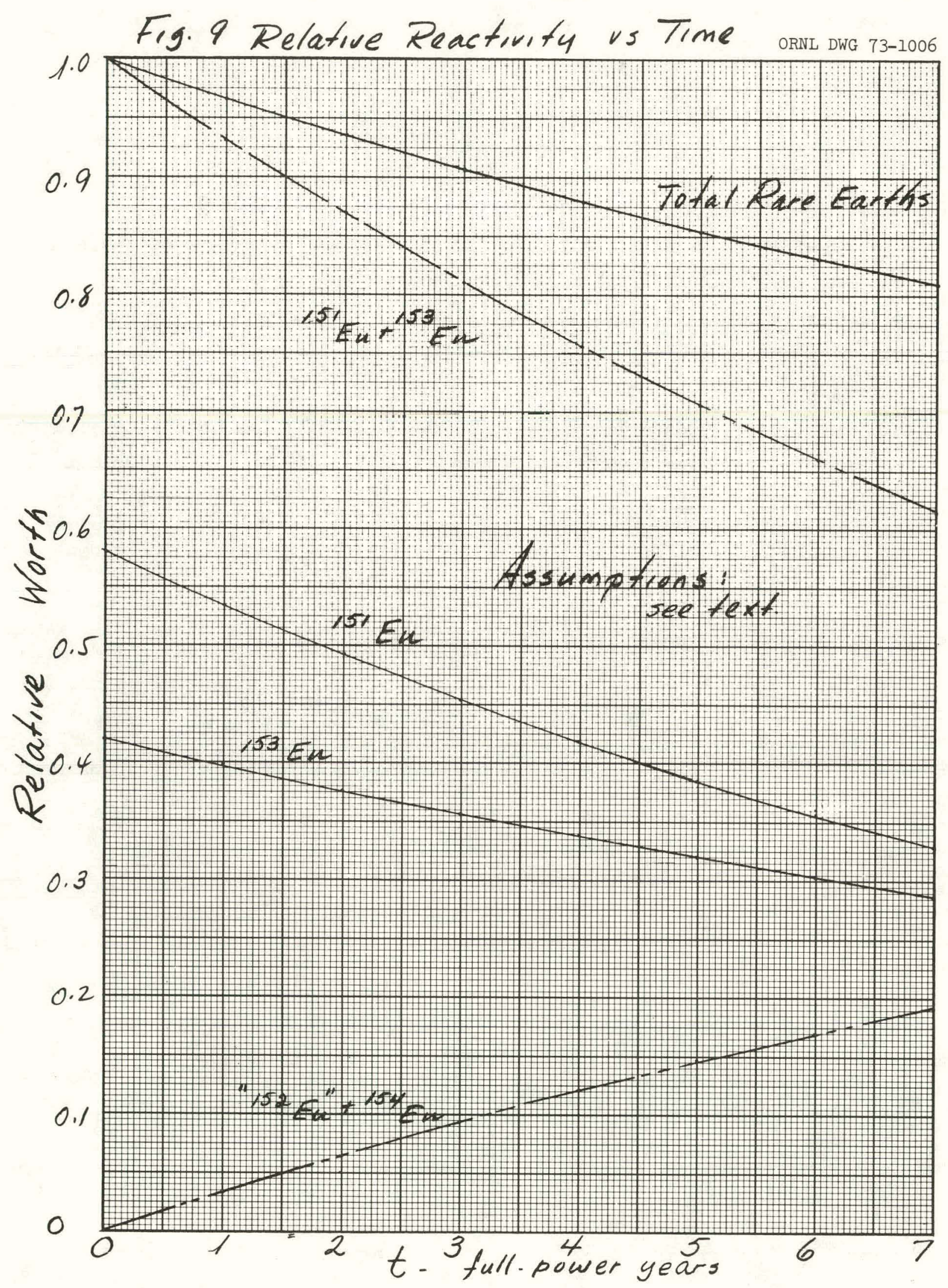

26 
APPENDIX A

Self-Shielding and Volumetric Reactivity Worths

Tuttle and Springer ${ }^{3}$ found that the reactivity of tantalum specimens was more affected by neutron self-shielding than were those of either europium or boron absorbers. The effect may be illustrated by tabulating (or plotting) the reactivity worth (in cents/gram) a.s a function of the "optical thickness" Ne of the absorber, where $N$ is the number of absorber a.toms $/ \mathrm{cm}^{3}$ and $\bar{l}$ is the mean chord length of the absorbing body. (For example, for a long cylinder, $\bar{l}=d$, the diameter.) Self-shielding factors, derived from Re . 3, are given in Table 7 .

Table 7 . Relative reactivity worth vs $\mathrm{N} \bar{l}$

\begin{tabular}{lll}
\hline$N \bar{b}$ & $T a$ & Eu \\
\hline 0 & 1.00 & 1.00 \\
0.01 & 0.83 & 0.95 \\
0.02 & 0.77 & 0.93 \\
0.04 & 0.70 & 0.91 \\
0.06 & 0.65 & 0.89 \\
0.10 & 0.60 & 0.86 \\
\hline
\end{tabular}

Optical thicknesses of single rods approximately equivalent to $\mathrm{Eu}_{\supset} \mathrm{O}_{3}$ pins or clusters of pins are shown in Table 8 .

Table 8. Optical thicknesses of $\mathrm{Eu}_{2} \mathrm{O}_{3}$ rods

\begin{tabular}{|c|c|c|c|c|c|}
\hline \multirow{2}{*}{$\begin{array}{l}\text { Pin } \\
\text { diameter } \\
\text { (in.) }\end{array}$} & \multirow{2}{*}{$\begin{array}{c}\text { Number of } \\
\text { pins }\end{array}$} & \multicolumn{2}{|c|}{ Equivalent rod } & \multirow{2}{*}{$\frac{\mathrm{N}}{(\operatorname{atoms} / \mathrm{b}-\mathrm{cm})}$} & \multirow{2}{*}{$\begin{array}{c}N \bar{l} \\
(\text { atoms } / \mathrm{b})\end{array}$} \\
\hline & & $\bar{l}(\mathrm{~cm})$ & density $\left(\mathrm{g} / \mathrm{cm}^{3}\right)$ & & \\
\hline 0.386 & 1 & 0.98 & 6.85 & 0.023 & 0.023 \\
\hline 0.386 & 3 & 1.70 & 6.85 & 0.023 & 0.040 \\
\hline 0.386 & 3 & 3.63 & 1.5 & 0.005 & 0.018 \\
\hline 0.386 & 7 & 3.34 & 1.5 & 0.005 & 0.020 \\
\hline 0.36 & 1 & 0.95 & 6.85 & 0.023 & 0.021 \\
\hline 0.36 & 61 & 10.5 & 3.43 & 0.0115 & 0.12 \\
\hline
\end{tabular}


Thus, with Tuttle and Springer's results as shown in Table 7, we would expect self-shielding factors of about 0.9 for EBR-II test specimens and approximately 0.8 for 61-pin clusters in the FTR.

Tuttle and Springer's results may also be used to relate the volumetric reactivity worths of typical $\mathrm{Eu}_{2} \mathrm{O}_{3}$ and $\mathrm{Ta}$ specimens. For the $\mathrm{Eu}_{2} \mathrm{O}_{3}$ rods of Table 8, Ref. 3, gives worths of about $19.4 \mathrm{~m} / \mathrm{g} \mathrm{Eu}$. For the large Ta rod of Ref. I (0.67 in. in diameter) a value of $3.27 \mathrm{~m} k / \mathrm{g} \mathrm{Ta}$ is indicated. Hence, we have, for this case,

$$
\begin{aligned}
& \mathrm{R}_{I} \equiv \frac{\left(\text { wnrth } / \mathrm{cm}^{3} \mathrm{~F}_{\left.1.1 \mathrm{~g}_{3}\right)}\right.}{\left(\text { worth } / \mathrm{cm}^{3} \mathrm{Ta}\right)}=\frac{(19.1 \mathrm{m \phi} / \mathrm{g} \mathrm{\textrm {Eu }})}{(3.27 \mathrm{m \phi} / \mathrm{g} \mathrm{Ta})} \frac{\left(5.92 \mathrm{~g} \mathrm{Eu} / \mathrm{cm}^{3} \mathrm{Tu} \cdot \mathrm{O}_{3}\right)}{\left(16.6 \mathrm{~g} \mathrm{Ta} / \mathrm{cm}^{3} \mathrm{Ta}\right)} \\
& -2.12 \frac{\mathrm{m} \phi / \mathrm{cm}^{3} \mathrm{Eu}_{2} \mathrm{O}_{3}}{\mathrm{~m} \phi / \mathrm{cm}^{3} \mathrm{Ta}}
\end{aligned}
$$

Corresponding values for small (unshielded or infinite-dilution) samples are:

$$
R_{0}-\frac{(20.6)(5.92)}{(5.83)(16.6)}=1.26 \frac{\mathrm{m} \phi / \mathrm{cm}^{3} \mathrm{Eu}_{2} \mathrm{O}_{3}}{\mathrm{~m} \phi / \mathrm{cm}^{3} \mathrm{Ta}}
$$

These results are consistent with the range 1.5 to 2 given in Section 1.1, and the value 2 chosen there is to be compared to the value $R_{I}=2.12$ given here. 


\section{APPEIDIX B}

Cross Sections

Information concerning neutron cross sections of europium has been drawn from several sources (Ref. 5, 12-14). We have not undertaken a careful revicw of these cross sections, nor have we undertaken to average them carefully over the spectrum to be expected in EBR-II. Both of these tasks should probably be undertaken.

The $(n, \gamma)$ cross sections of ${ }^{151} \mathrm{Eu}$ and ${ }^{153} \mathrm{Eu}$ relative to that of ${ }^{18}{ }^{1} \mathrm{Ta}$ and to each other are shown in Table 9, based on data from Ref. 12 (shown here in Fig. 10). As a rough average over the EBR-II spectrum, $\sigma\left({ }^{15}{ }^{\mathrm{Eu}}\right) / \sigma\left({ }^{153} \mathrm{Eu}\right) \sim 1.5$ and $\sigma(\mathrm{Eu}) / \sigma(\mathrm{Ta}) \sim 3-4$.

Table 9. Approximate relative $(n, \gamma)$ cross sections of $\mathrm{Ta}$ and $\mathrm{Eu}^{12}$

\begin{tabular}{|c|c|c|c|}
\hline \multirow{2}{*}{$\begin{array}{l}\text { Neutron } \\
\text { energy } \\
(\mathrm{keV})\end{array}$} & \multirow{2}{*}{$\frac{\sigma\left({ }^{151} \mathrm{Eu}\right)}{\sigma\left({ }^{\left.181_{\mathrm{Ta}}\right)}\right.}$} & \multirow{2}{*}{$\frac{\sigma\left({ }^{15}{ }^{1} \mathrm{Eu}\right)}{\sigma\left({ }^{153} \mathrm{Eu}\right)}$} & $0.5 \sigma_{151}+0.5 \sigma_{153}$ \\
\hline & & & $\sigma_{181}$ \\
\hline $\begin{array}{l}0.2 \\
0.5 \\
1.0 \\
3 \\
10 \\
30 \\
50 \\
100\end{array}$ & $\begin{array}{c}3.0 \\
3.4 \\
4.4 \\
4.1 \\
4.5 \\
4.7 \\
4.4 \\
(3.8)\end{array}$ & $\begin{array}{l}1.9 \\
1.4 \\
1.5 \\
1.5 \\
1.4 \\
1.4 \\
1.3\end{array}$ & $\begin{array}{l}2.3 \\
2.9 \\
3.7 \\
3.4 \\
3.9 \\
4.1 \\
3.9\end{array}$ \\
\hline
\end{tabular}

The partial cross section of ${ }^{151} \mathrm{Eu}$ for formation of the $9.3 \mathrm{hr}$ isomer of ${ }^{152} \mathrm{Eu}$ is even more difficult to determine. For thermal neutrons, the fraction, $f_{11}$, is about 0.35 .12 For $25 \mathrm{keV}$ neutrons (using the partial cross section from Ref. 5 and the total cross section from Ref. 12) it appears that the fraction is closer to 0.7 . This would be consistent with the increase in the ratio $\sigma\left(151 \rightarrow 152 m_{2}\right) / \sigma\left(151 \rightarrow 152 m_{1}\right)$ a.lso noted by comparison of data from Ref. 5 and Ref. 12. We just don't know what the fraction $f_{I I}$ should be, averaged over the EBR-II spectrum, but guess that it might be in the range of 0.5 to 0.7 , or even higher. 


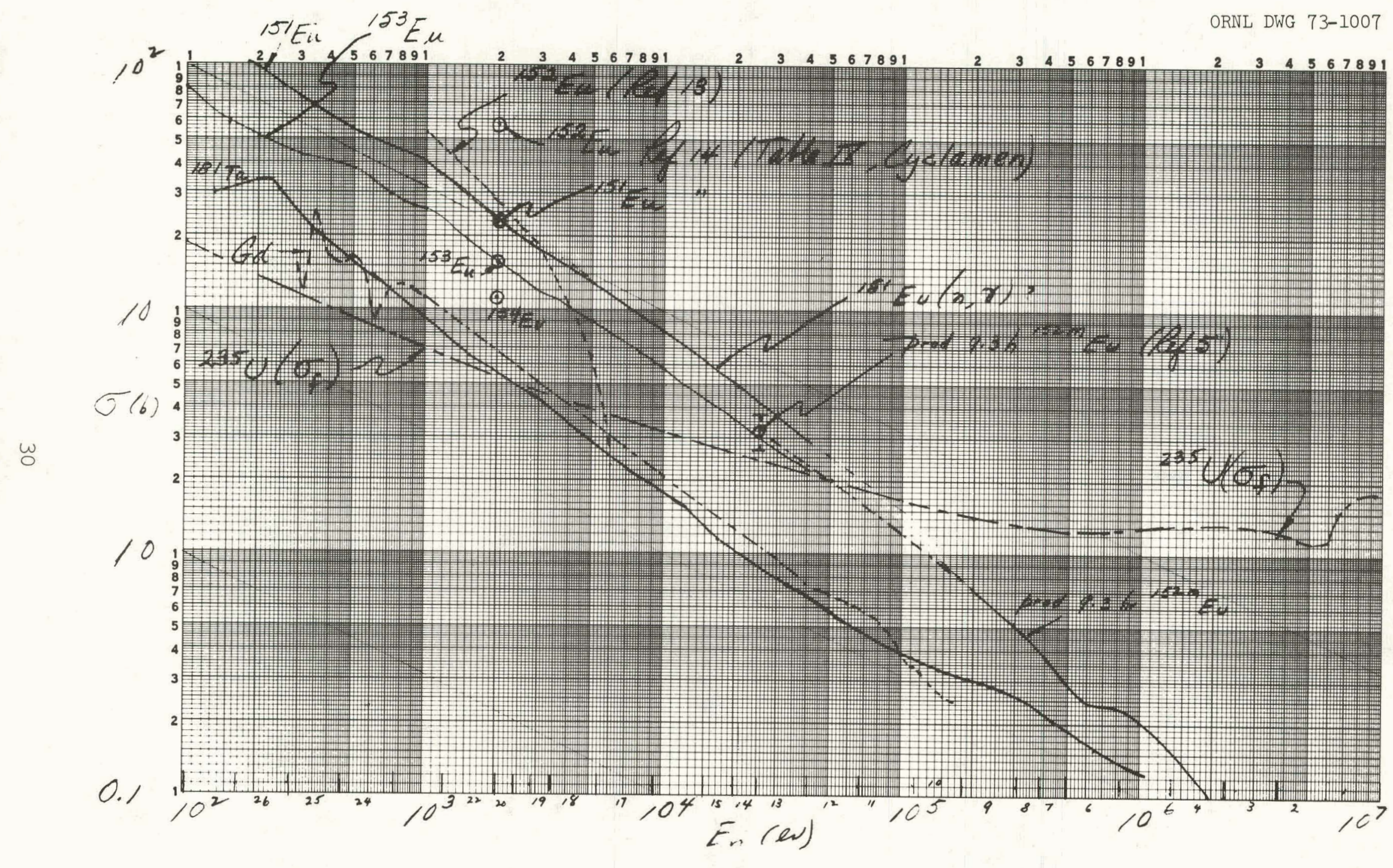

Fig. 10 
The cross sections of ${ }^{152} \mathrm{Eu}$ and ${ }^{154} \mathrm{Eu}$ are not well determined. From Fig. 2 of Ref. 14, we might conclude that $\sigma_{152} / \sigma_{151} \sim 1-2$, and $\sigma_{154} / \sigma_{153} \sim 0.5-1$. From Ref. 13 , we might conclude $\sigma_{152} / \sigma_{151} \lesssim 1$. The cross sections of ${ }^{152} \mathrm{Sm}$ and ${ }^{152} \mathrm{Gd}$ are also relevant (especially the latter). Judging solely from the fact that the cross section of natural gadolinium is about one-third that of natural europium (gleaned from Fig. 10) we might expect $\sigma\left({ }^{152} \mathrm{Gd}\right)<\sigma\left({ }^{151^{1}} \mathrm{Eu}\right)$, but this is hardly a proof. In order to estimate the reactivity loss of $\mathrm{Eu}_{2} \mathrm{O}_{3}$ control rods, due to burnup, with some initial margin of conservatism, we tentatively assume that $\sigma_{152} / \sigma_{151} \simeq \sigma_{154} / \sigma_{153} \simeq 1 / 2$, where " 152 " in-

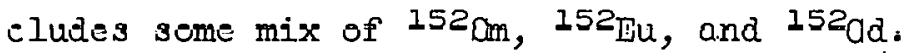
More work can and should be done on these cross sections. 
REFERENCES

1. G. I. Ragan, Afterheat in Ta. Rods Irradiated in EBR-II, ORNL-TM (in preparation).

2. D. I. Stenstrom, Argonne National Laboratory, private communication to H. T. Kerr, ORNL, December 1972.

3. R. J. Tuttle and T. H. Springer, Reactivity Worths of Boron, Tantalum, and Europium in a Fast Reactor Spectrum, Nuc. Sci. Eng., 49,468 (1972).

4. J. G. Delene, Alternate Control Materials for LMFBRs, internal memurarlürn, Augusli 29, 1968.

3. A. L. Rau asill J. R. Rau, Causs Becliuns dill Isumer Rablus rur Some Neutron Capture Reactions, J. Phys. A:Gen. Phys., 5, 1262 (Aug. 1972).

6. J. C. Widman, J. Mantel, N. H. Horwitz, and E. R. Powsner, Average Energy of Beta Spectra, Int. Jour. Appl. Rad. and Iso., 19, 1-14, (1968).

7. C. M. Lederer, J. M. Hollander, and I. Perlman, Table of Isotopes, Sixth Edition, John Wiley and Sons, New York (1967).

8. USAEC, Reactor Shielding Design Manual, T. H. Rockwell, ed., McGraw-Hill (1956).

9. M. L. Storm, H. Hurwitz, Jr., and G. M. Roe, Gamma-Ray Absorption Distributions for Plane, Spherical and Cylindrical Geometries, KAPL-783, 1952.

10. Argonne National Laboratory, Guide for Irradiation Experiments in EBR-II, Appendix C (Revised), from J. H. Kittel, September 6, 1972.

11. EBR-II Absorber Test, Capsule 027 Data Sheet, ORNL-Dwg-MI0090-EM344D, Rev. 1 (June 30, 1972).

12. BNL-323, Second Edition, Supplement 2, Vols. I-III, May 1966.

13. M. V. Harlow et a.1. in WASH 1127, Reports to the AEC Neutron Cross Section Advisory Committee, April 15-17, p. 123 (1969).

14. D. W. Barr and J. J. Devaney, Kilovolt Europium Capture Cross Sections, LASL-3643 (April 1967). 
SUPPLEMENT II

CONSIDERATIONS ON THE PHASE STABILITY OF EUROPIUM SESQUIOXIDE 
THIS PAGE

WAS INTENTIONALLY

LEFT BLANK 
CONSIDERATIONS ON THE PHASE STABILITY OF EUROPIUM SESQUIOXIDE

\author{
V. L. Burdick*
}

INTRODUCTION

The cubic structure (C-type) of $\mathrm{Eu}_{2} \mathrm{O}_{3}$ has been observed by many investigators and studied extensively by Rau ${ }^{2}$ and Stecura. ${ }^{2}$ Preparation of the C-type has been accomplished by decomposition of various europium compounds including carbonates, oxalates, hydroxides, nitrates, and sulfates and through oxidation of fluorides and chlorides. Whenever the decomposition or oxidation reactions are carried out at temperatures below about $1000^{\circ} \mathrm{C}$, the C-type structure is found. When the oxide is heated above about $1100^{\circ} \mathrm{C}$ a crystallographic transition from C-type to B-type (monoclinic) occurs. ${ }^{2}$ This transition appeared to be irreversible to some investigators $1-3$ and reversible to others. ${ }^{4,5}$ The transformation involves a density change of about 10\% and a change in cation coordination from 6 in the c-type to 7 in the B-type.

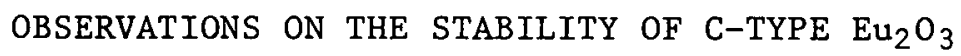

Unpublished long-term tests at ORNL $(700 \mathrm{hr})$ at $900^{\circ} \mathrm{C}$ in vacuum have not caused any $\mathrm{C} \rightarrow \mathrm{B}$ transformation. In addition to this observation on the apparent irreversibility of the $C \rightarrow B$ transition, Brauer ${ }^{6}$ cites other evidence for the metastability of cubic europia. In addition, Bärnhausen's 7 results on oxidizing $\mathrm{EuO}$ and $\mathrm{Eu}_{3} \mathrm{O}_{4}$ in air at 300 to $400^{\circ} \mathrm{C}$ were considered surprising. He produced $\mathrm{B}$-type $\mathrm{Eu}_{2} \mathrm{O}_{3}$ at these low temperatures. Brauer concluded that the lower density C-type europia

*Research participant from $\Lambda$ ffred University, Alfred, New York. 
resulted from lower density starting materials, such as the salts mentioned above, while the denser $\mathrm{B}$-type resulted from the high density $\mathrm{EuO}$ and $\mathrm{Eu}_{3} \mathrm{O}_{4}$. Topotactic tendencies in the decomposition reactions could be responsible for the C-type product. This idea seems consistent with a simplified picture of the decomposition of $\mathrm{Eu}(\mathrm{OH})_{3}$ as follows:

$$
2 \mathrm{Eu}(\mathrm{OH})_{3}+\mathrm{Eu}_{2} \mathrm{O}_{3}+3 \mathrm{H}_{2} \mathrm{O} \uparrow
$$

The basic structural unit in the hydroxide is ninefold coordinated cations, while in cubic europia it is sixfold coordinated cations. If one takes the average of three water molecules from two structural units of the hydroxide, then six oxygen ions are left for each cation and a simple collapse of this unit leaves the correct coordination for the formation of C-type oxide.

Brale ${ }^{8}$ has prepared $\mathrm{B}$-type europia at $400^{\circ} \mathrm{C}$ through precipitation of oxides from anhydrous rare earth nitrates dissolved in molten mixtures of alkali nitrates. Seed crystals of C-type europia added to the solution did not nucleate C-type precipitates at $400^{\circ} \mathrm{C}$. It was concluded that the B-type structure must be the stable one at $400^{\circ} \mathrm{C}$. However, no mention was made of further heat treatment (above $400^{\circ} \mathrm{C}$ ) of the precipitates to observe possible transformation to the C-form at elevated temperatures.

Recently revised thermochemical data ${ }^{9}$ on $\mathrm{Eu}_{2} \mathrm{O}_{3}$ indicate that the C-type is stable up to about $1100^{\circ} \mathrm{C}$. The free energy difference between the two phases is small [i.e., $\Delta \mathrm{G}$ transition $\mathrm{C} \rightarrow \mathrm{B}$ is given as $1.94 \pm 0.38$ (kcal/mole) at room temperature, $1.16 \pm 0.59$ at $427^{\circ} \mathrm{C}$, and $0.70 \pm 0.70$ at $827^{\circ} \mathrm{C}$ ]. It is possible that small impurity concentrations, strain energy, and surface energy could affect the transition drastically since these effects could become more important than the free energy of transition. Similarly, these effects could 
have been operative during the thermochemical measurements and affected $\Delta G$ values obtained.

\section{OTHER EXAMPLES OF METASTABLE OXIDE PHASES}

The formation of metastable oxide phases by decomposition or oxidation reactions is not uncommon. For example, ${ }^{10} \gamma-\mathrm{Al}_{2} \mathrm{O}_{3}$ torms upon decomposition of the monohydrate $\mathrm{AlO} \cdot \mathrm{OH}$ at about $400^{\circ} \mathrm{C}$. This phase is cubic and consists of a defect spinel structure. Further heating results in the formation of the $\theta$ phase at about $1000^{\circ} \mathrm{C}$ and finally the stable rhombohedral phase, $\alpha-\mathrm{Al}_{2} \mathrm{O}_{3}$, is formed at about $1200^{\circ} \mathrm{C}$. These transitions are irreversible and represent changes which increase the density of alumina. The formation of the metastable phases is apparently controlled by topotactic effects since decomposition of the trihydrate does not produce the same reaction scheme.

In zirconia, which is structurally related to fluorite just as C-type europia is, the high-temperature tetragonal form cannot be quenched in. The. structure of the pure oxide reverts to the monoclinic form below about $850^{\circ} \mathrm{C}$. However, tetragonal zirconia can be produced by decomposing zirconium nitrate and alkoxide or by oxidizing the chloride at low temperatures. ${ }^{11}$ This metastable phase remains until the oxide is heated to about 500 to $600^{\circ} \mathrm{C}$, whereupon the monoclinic form is produced. With further heating, the monoclinic form transforms to tetragonal at about 1100 to $1200^{\circ} \mathrm{C}$. This transition to a more symmetrical structure involves an increase in density and a change in cation coordination from 7 to 8 .

Thus, it is apparent that metastable or unstable oxide phases can be produced rather readily and with the high activation energy normally associated with atomistic processes in oxides, some of these phases can persist 
up to reasonably high temperatures. It is possible that C-type $\mathrm{Eu}_{2} \mathrm{O}_{3}$ is really metastable below about $1100^{\circ} \mathrm{C}$ but if it is stable, the activation energy required to make the transition $B \rightarrow C$ is just not available below the transition region.

One further consideration of the $B \rightarrow C$ transition should be made. That is the possibility of a hysteresis in the transition similar to that in the zirconia transition. In the literature surveyed thus far, only Huekstra ${ }^{5}$ has heat treated monoclinic europia well below the $1100^{\circ} \mathrm{C}$ range. His experiments where the monoclinic type was held at $950^{\circ} \mathrm{C}$ for three weeks showed partial transformation to the C-type structure. These results suggest that further studies of the transition should be undertaken to determine if the hysteresis effect is present and, if so, to examine the mechanism of the transition to determine if it is one of the continuous type as proposed for $\mathrm{ZrO}_{2}$ by Grain and Garvie. ${ }^{12}$ For zirconia, they found that the transformation could be accounted for by small motions of oxygen ions (less than an interatomic distance) rather than a wholly reconstructive process. Although the coordination number of z1iconlum ions changes, the diffusionless process can prevail when rotation of certain oxygen ions is considered. The continuous transformation develops by means of domains of tetragonal zirconia growing in the monoclinic matrix. The formation of the domain need not be nucleated. Considerable strain energy is involved for the domain interfaces are coherent and there is a large volume difference (about $10 \%$ ) between the two phases. The strain energy can halt the transition at any point in the transition region, and then the temperature must be changed to cause further transformation. For the reverse reaction, a different amount of strain would be associated with growing monoclinic domains in a tetragonal matrix. Thus, the origin of the hysteresis. A crystallite size effect was observed where grains smaller than a domain would contain no strain energy and 
thus the heat of transition and therefore the rate of transition would be size dependent.

A similar mechanism could prevail in $\mathrm{Eu}_{2} \mathrm{O}_{3}$ although Stecura ${ }^{2}$ has proposed a reconstructive type. It is possible that only small rearrangements of the lattice need to be made rather than a gross diffusional-type rearrangement. Detailed analysis of the relationships between the B- and C-types should be made to determine the possible transition mechanisms.

An assessment of the literature cited concerning the stability of the $\mathrm{C}-$ and $\mathrm{B}$-modifications of $\mathrm{Eu}_{2} \mathrm{O}_{3}$ leads to the following conclusions:

1. C-type $\mathrm{Eu}_{2} \mathrm{O}_{3}$ is stable at temperatures up to about $1100^{\circ} \mathrm{C}$. Observations of the monoclinic form prepared below this temperature are considered to be in the metastable region.

2. The $\mathrm{C} \rightarrow \mathrm{B}$ transition appears to be irreversible because: (a) the activation energy for the $B \rightarrow C$ transition is too high and the kinetics too slow in the temperature range required, or (b) there is a hysteresis in the transition and that most attempts to observe the transition have been made at temperatures too high for it to occur, or (c) impurities have impeded the transition.

\section{CONSIDERATIONS FOR IRRADIATION BEHAVIOR}

One primary consideration of the behavior of $\mathrm{Eu}_{2} \mathrm{O}_{3}$ under fast neutron irradiation is the stability of the different crystallographic modifications. The transformation between cubic and monoclinic forms is of most interest because of the temperature range at which it supposedly occurs and the rather drastic change in density during the transition.

Studies of radiation-induced phase transitions in oxides are confined mostly to zirconia. Wittels et al. ${ }^{13}$ concluded from irradiation experiments on 
pure and doped zirconia that fission fragment fluxes associated with $10^{15}$ to $10^{16}$ fissions $/ \mathrm{cm}^{3}$ produce a monoclinic to face-centered cubic phase change in zirconia. Additionally, the presence of uranium in $\mathrm{ZrO}_{2}$ in concentrations less than 0.38 wt \% does not act as a nucleation or stabilization agent. Fast neutrons alone did not appear to induce the transition in doses up to $6.3 \times 10^{20}$ neutrons $/ \mathrm{cm}^{2}$. In contrast, Adam and $\operatorname{Cox}^{14}$ reported that either fast neutrons or fission fragments could induce the phase transition only if the zirconia contained impurity atoms that could nucleate and/or stabilize the cubic phase. The cubic phase was determined to be of the fluorite type and its density appeared to be about 6 to $7 \%$ greater than that of the monoclinic phase.

Adam and $\mathrm{Cox}^{14}$ found $100 \%$ trans formation to the cubic phase for $\mathrm{ZrO}_{2}$ films on alloy. substrates but only partial transformation in bulk oxides. Wittels and Sherrill $1^{15}$ found that regions on the order of $100 \AA$ radius resulted from the radiation-induced transition and in other work ${ }^{13}$ considerable strain was obviously present in transformed material. These observations suggest some correlations to the mechanism of phase transitions in zirconia discussed above. Thus, the question of microstructural effects, especially the shape, size, and size distrubution of zirconia, still remains. Additionally, the difference in behavior of films and bulk samples suggests a microstructural effect.

It is interesting to note the similarity in the spacing of lattice planes in the cubic zirconia produced by irradiation by Wittels et al. ${ }^{13}$ and in cubic zirconia prepared by Mazdiyasni et al. ${ }^{16}$ by decomposing zirconium alkoxides. Using the lattice parameter $5.09 \AA$ from Wittels et al. ${ }^{13}$ and indexing the d-spacings from Mazdiyasni et al., ${ }^{16}$ the following 
interplanar spacings for a fluorite-type cell are found (rounded to three figures):

\begin{tabular}{lrr} 
hk $\ell$ & Wittels et al. & Mazdiyasni \\
\cline { 2 - 3 } 111 & $2.94 \AA \AA$ & $2.95 \AA$ \\
002 & $2.55 \AA$ & $2.53 \AA$ \\
220 & $1.80 \AA \AA$ & $1.81 \AA$ \\
311 & $1.53 \AA$ & $1.54 \AA$
\end{tabular}

Without accounting for lattice defects, the density of the cubic phase calculated from these data is 6 to $7 \%$ greater than that of the monoclinic phase, which is stable at low temperatures. Apparently the cubic form can more easily accommodate the strain introduced by fast neutron irradiation or alternatively the effect of strain energy and surface energy is such that the more symmetrical structure prevails. It should be noted that the decomposed alkoxide ${ }^{16}$ produced zirconia particles less than $50 \AA$ in average particle size and that the cubic form transformed to tetragonal at about $300^{\circ} \mathrm{C}$ in powders with an average size of $50 \AA$. The particle size of these decomposed alkoxides are of the same order as the $100 \AA$ "regions" noted by Wittels and Sherrill in irradiation-induced cubic zirconia.

A radiation-induced transformation in $\mathrm{BaTiO}_{3}$ from tetragonal to cubic has been observed by Wittels and Sherrill. ${ }^{17}$ The lattice of the cubic (perovskite-type) phase induced by radiation was considerably expanded over the cubic structure produced by heating tetragonal $\mathrm{BaTiO}_{3}$ to above $120^{\circ} \mathrm{C}$. The results from the $\mathrm{ZrO}_{2}, \mathrm{BaTiO}_{3}$, and $\mathrm{UO}_{2}$ radiation behavior led Wittels et al. ${ }^{23}$ to conclude that if several allotropic forms of a given nonmetallic material can exist, then the structures with highest symmetry will be the most stable under irradiation. This conclusion is drawn irrespective of classical thermodynamic behavior of the materials. The effects of high temperature 
during irradiation are not known for $\mathrm{ZrO}_{2}$, but it was concluded that the zirconia transition was probably not thermally induced.

Radiation effects on other oxides, $\mathrm{Al}_{2} \mathrm{O}_{3}$ and $\mathrm{MgO}$, have not induced phase transitions. 18 Other macroscopic effects observed were lattice expansion, lower density, lower thermal conductivity, and grain boundary cracking in some cases. High-purity, fine-grained materials performed the best. For $\mathrm{Al}_{2} \mathrm{O}_{3}$ above $1100^{\circ} \mathrm{C}$, in-reactor annealing was rapid enough to reduce damage but above $1230^{\circ} \mathrm{C}$ damage increased.

Ileavily irradiatcd cryotalline quarta $\left(\mathrm{SiO}_{2}\right)$ has nearly the same density as hịhly irradiated fused silical9 (vitreous). Upon annealing, the quartz becomes vitreous indicating that the quartz lattice has been subjected to so many atomic displacements that thermodynamically it is equivalent to the glassy state. No mention is made as to whether the quartz transforms to glass via high cristobalite (cubic form of $\mathrm{SiO}_{2}$ ) or simply quartz to glass.

In order to predict the behavior of a material under irradiation, the macroscopic changes discussed in the foregoing must be examined on an atomistic scale. In general, the macroscopic changes are related to the phenomena of irradiation-induced vacancies and interstitials, spikes, ordering and clustering of atoms or defects, and to enhanced diffusion processes.

Thermally induced phase transitions can be thought of as processes which occur in order to decrease the free energy of the system by relieving strain energy caused by increased defect concentrations or anisotropic thermal dilation and by gaining configurational entropy. These processes in oxides often involve transformation to structures of higher symmetry and higher cation coordination. Additionally, there is often a small change in internal energy and a high activation energy for oxide transitions. 
Irradiation-induced phase transitions in zirconia and barium titanate have proceeded in the direction of high temperature modifications. Apparently the irradiation has an effect similar to thermal treatment (i.e., a defect concentration and lattice strain energy develops such that the high temperature modification becomes more stable). Annealing effects under high temperature irradiation are not reported.

For $\mathrm{Eu}_{2} \mathrm{O}_{3}$ then, the predicted behavior under fast neutron irradiation is that the monoclinic modification would be more stable than the cubic form and that the higher temperature hexagonal form should be the most stable. The behavior could be analogous to that of $\mathrm{Cm}_{2} \mathrm{O}_{3}$ under self-radiation from $\alpha-$ decay of ${ }^{244} \mathrm{Cm}$ as reported by Mosley. ${ }^{20}$ The C-type $\mathrm{Cm}_{2} \mathrm{O}_{3}$ exhibited lattice swelling, phase transformation, and apparent formation of amorphous, oxide, whil. under similar conditions the monoclinic (B-type) showed little change in lattice parameters; however, loss of. structure increased gradually with time. There is no way to assess the degree to which the predicted phase transitions will occur since annealing effects are unknown. For europia, the only way to determine this is by irradiation experiments.

\section{PROPOSED THERMAL STABTTLTTY EXPERTMENTS}

1. Long-term, carefully controlled heat treatments on high-purity monoclinic europia should be carried out at temperatures ranging from 750 to $950: C$ to confirm the reversibility (irreversibility) of the $\mathrm{C} \rightarrow \mathrm{B}$ transition.

2. Monoclinic $\mathrm{Eu}_{2} \mathrm{O}_{3}$ prepared by oxidizing EuO at $400^{\circ} \mathrm{C}$ should be checked for metastability by heat treatments as in Item 1 above.

3. The crystallite size effects should be checked on C-type and B-type $\mathrm{Eu}_{2} \mathrm{O}_{3}$. Samples of various grain sizes (e.g., $100 \AA$ up to $100 \mu \mathrm{m}$ ) should be prepared and then the temperature and rates of transitions should be studied. 
REFERENCES

1. R. C. Rau, "X-ray Crystallographic Studies of Europium Oxides and Hydroxides," Proc. of the 3rd Conference on Rare Earth Research (1963), Gordon \& Breach Science Publishers, New York, 1964.

2. S. Stecura, "Crystallographic Modifications and Phase Transformation Rates of Five Rare Earth Sesquioxides," U.S. Bureau of Mines Report of Investigations 6616 (1964).

3. R. S. Ruth and S. J. Bchutider, "Pliase Equilibria in Gystems Involving the Rare Earth Oxides. Part I. Polymorphism of the Oxides of the Trivalent Rare-Earth Ions," J. Ree. NBS 64A(4): 309-16 (1960).

4. I. Warshaw and R. Roy, "Polymorphism of the Kare Earth Sesquioxides," J. Phys. Chem. 65: 2048-51 (1961).

5. H. R. Hoekstra, "Phase Relationships in the Rare Earth Sesquioxides at High Pressure," Inorg. Chem. 5(5): 754-57 (1966).

6. G. Brauer, "Structural and Solid State Chemistry of Pure Rare Earth Oxides and Hydroxides," pp. 434-58 in Progress in the Science and Technology of the Rare Earths, Vol. 3, ed. by L. Eyring, 1968.

7. H. Bärnighausen, "Untersuchungen am System EuO-Eu $\mathrm{E}_{3}, "$ J. Prakt. Chem. $34(4): \quad 1-14(1966)$.

8. G. Brauer, "Precipitation of Rare Ëarth Oxides from Molten SaLts," pp. 38்-iu in Proc. of the 6th Kare Earth Research Conference, 1967.

9. G. C. Fitzgibbon, E. J. Huber, Jr., and C. E. Holley, Jr., "Enthalpy of Formation of Europium Sesquioxide," J. Chem. Thermodynamics 4: 349-58 (1972).

10. B. A. Scott and W. H. Horsman, "Structural Changes During the Production of Corundum by Calcination of Gibbsite and Their Influence on Fabrication," Trans. Brit. Ceram. Soc. 69(2): 37-43 (1970). 
11. R. C. Garvie, "Zirconium Dioxide and Some of Its Binary Systems," Chap. 4 in High Temperature Oxides, Refractory Materials Vol. 5-II, ed. by Alper, Academic Press, New York, 1970.

12. C. F. Grain and R. C. Garvie, "Mechanism of the Monoclinic to Tetragonal Transformation of Zirconium Dioxide," U.S. Bureau of Mines Report of Investigations 6619 (1965).

13. M. C. Wittels, J. O. Stiegler, and F. A. Sherrill, "Radiation Effects in Uranium-Doped Zirconia," J. Nucl. Energy, $A / B$ 16: 237-44 (1962). 14. (a) J. Adam and B. Cox, Reactor Science and Technology (J. Nucl. Energy, Part A) 11: 31 (1959).

(b) J. Adam and B. Cox, Phys. Rev. Letters 3: 543 (1959).

15. M. C. Wittels and F. A. Sherrill, J. AppZ. Phys. 27: 643 (1956).

16. K. S. Mazdiyasni, C. T. Lynch, and J. S. Smith, "Metastable Transitions of Zirconium Oxide Obtained from Decomposition of Alkoxides," J. Amer. Ceram. Soc. $49(5)$ : 286-87 (1966).

17. M. C. Wittels and F. A. Sherrill, J. Appl. Phys. 28: 606 (1957).

18. G. W. Keilholtz, R. E. Moore, and H. E. Robertson, Effects of Fast Neutrons on Polycrystalline Alumina and Other Electrical Insulators at Temperatures from 60 to $1230^{\circ} \mathrm{C}$, ORNL-4678 (1971).

19. W. Primak and E. Edwards, Phys. Rev. 128: 2580 (1962).

20. W. C. Mosley, "Self-Radiation Damage in Cm-244 Oxide and Aluminate," .T. Amer. Ceram. Soc. 54(10): 475-79 (1971). 
SUPPLEMENT III

CRITIQUE OF THERMAL CONDUCTIVITY DATA 


\section{PAGES 73 to 74 WERE INTENTIONALLY LEFT BLANK}




\section{CRITIQUE OF THERMAL CONDUCTIVITY DATA*}

The thermal conductivity data available 1,2 has been obtained from samples of less than theoretical density. Work at ORNL on oxides has indicated that the appropriate term for correction of such data is

$$
\lambda_{\text {meas }}=\lambda_{\text {I. D. }}\left[\frac{1-\mathrm{P}}{1+\frac{1}{2} \mathrm{P}}\right]
$$

where $\lambda_{\text {T.D. }}$ is the thermal conductivity of theoretically dense material and $\lambda_{\text {meas }}$ is the thermal conductivity of material with $P$ closed volume fraction porosity works well. ${ }^{3}$ It is quite possible that the $89 \%$ dense sample of Kiparisov et al. 1 had some open porosity which would cause a small error in this equation. The data from references 1 and 2 as corrected to theoretiçal density are plotted in Fig. III(1).

The high-temperature data of Grüling and Schickfluss-Borges were obtained at the European Transuranium Institute which has an electron-beam thermal diffusivity device ${ }^{4}$ which has generated good data on $\mathrm{UO}_{2}$. To determine $\lambda$ from diffusivity $(\alpha)$ one uses

$$
\lambda=\alpha \rho C_{p}
$$

where $\rho$ is the density and $C_{p}$ is the specific heat at constant pressures; and although the $\alpha$ data is probably correct, the $\mathrm{C}_{\mathrm{p}}$ input is definitely wrong and possibly badly wrong. They are using $\mathrm{C}_{\mathrm{p}}$ values from drop calorimeter ${ }^{5}$ data at lower temperatures and assuming $C_{P}$ does not change will T. Actually

$$
C_{p}=C_{v}\left[1+\gamma \alpha_{v} T\right]
$$

*Adapted from a study by J. P. Moore. 
where $C_{v}$ is the specific heat at constant volume, $\alpha_{v}$ is the volumetric expansion coefficient, and $\gamma$ is the Gruneisen constant. Since $C_{p}$ does increase with $\mathrm{T}, \lambda$ calculated from Eq. (2) would be expected to be higher than Grüling and Schickfluss-Borges indicate so that the conclusion is that their $\lambda$ data are too low at the higher $T$ values. There are other effects which cause $\mathrm{C}_{\mathrm{p}}$ to increase as the melting point $\left(2330^{\circ} \mathrm{C}\right)$ is approached which make this problem even more severe. In addition to the problems of using low $\mathrm{T}$ data on $\mathrm{C}_{\mathrm{P}}$ at high $\mathrm{l}$, it appears that the existing low $\mathrm{T}$ data on $\mathrm{C}_{\mathrm{P}}$ is somewhat suspect based on the imprecision in the results ${ }^{5}$ and the fact that they were from enthalpy measurements.

The technique of Kiparisov et $a .^{1}$ which generated the lower $\mathrm{T}$ data appears to be better than most longitudinal heat flow systems which have been used unwisely at high $\mathrm{T}$ on low $\lambda$ materials. Their paper where the device is described in detail has not been examined closely, but since they were monitoring $T$ at many positions and were apparently checking radial flow in some manner, maybe it can be assumed that they also did a good job of getting the heater in uniform contact with the specimen. Even if they did everything correctly, the system will be in error because the thermal conductivity of the insulation is only about 2 orders of magnitude lower than the sample $\lambda$ and perfect guarding still is not adequate. Since $\lambda$ of the insulation and $\lambda$ of the specimen converge with increasing $T$, the problem and hence the error becomes more severe with increasing $\mathrm{T}$.

Figure III(1) includes data from references 1 and 2 as corrected to theoretical density using Eq. (1) and error bands are included about the data. The band about the data of Kiparisov et al. was calculated from their stated maximum error of $9 \%$ which is probably not too high in view of 


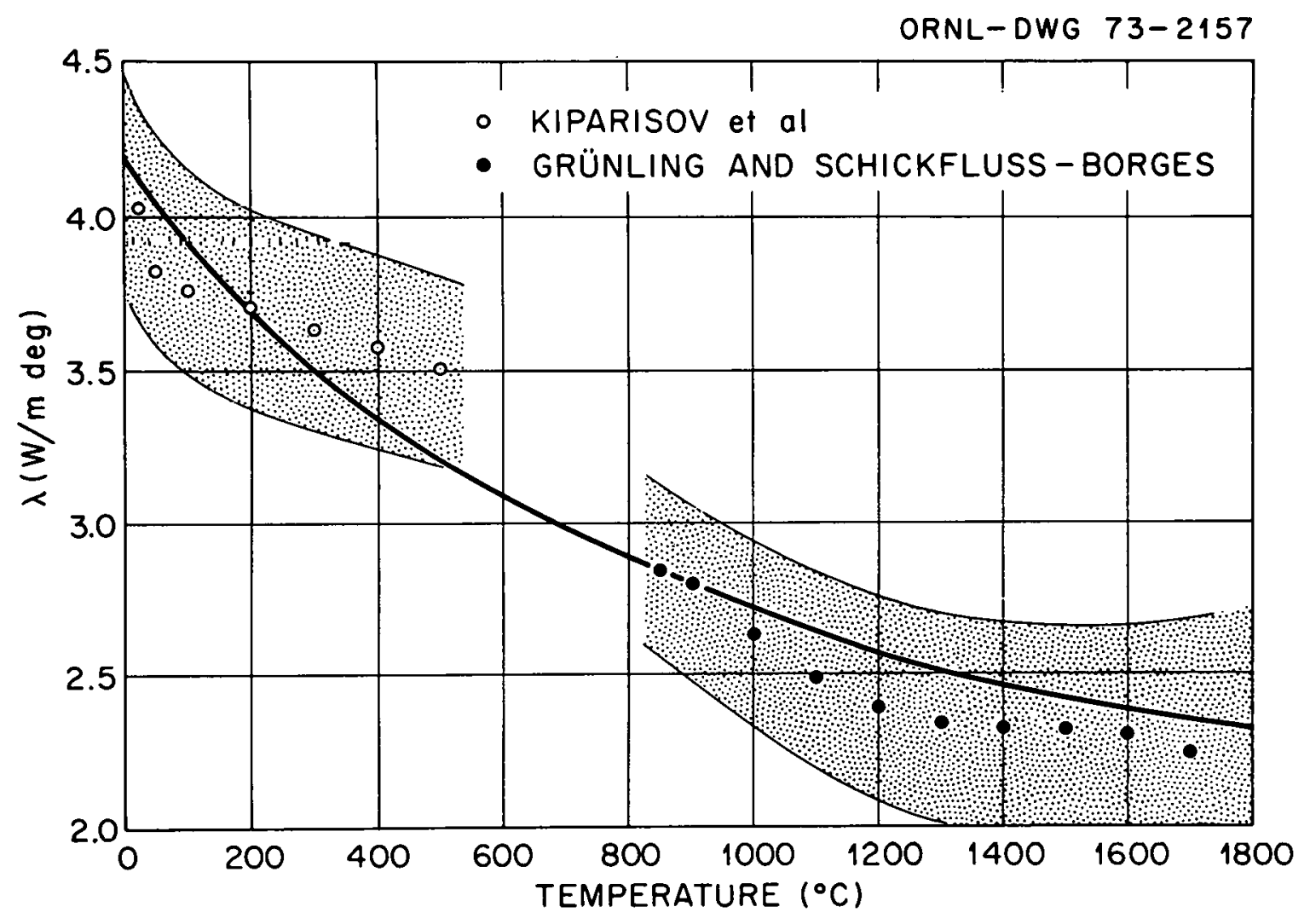

Fig. III(1). Thermal Conductivity of Monoclinic $\mathrm{Eu}_{2} \mathrm{O}_{3}$. 
the problems involved with their technique. The band about the data of Grünling and Schickfluss-Borges includes a 5\% uncertainty on the $\alpha$ determination and a $5 \%$ uncertainty on the $\mathrm{C}_{\mathrm{p}}$ at $800^{\circ} \mathrm{C}$ which increases to $15 \%$ at $1700^{\circ} \mathrm{C}$. Keeping in mind that the low $\mathrm{T}$ data are probably in error most at the high $\mathrm{T}$ end of its range and that the high-temperature data is probably most nearly correct where some $C_{p}$ data exist, a "best-guess" line has been drawn through the results. This line is probably representative of unirradiated fine-grain polycrystalline $\mathrm{Eu}_{2} \mathrm{O}_{3}$ in the monoclinic form to within about $\pm 20 \%$, but in view of the spread in $\lambda$ among the rare-earth oxides it appears that the thermal conductivity of $\mathrm{Eu}_{2} \mathrm{O}_{3}$ should be measured with a radial heat flow technique.

\section{REFERENCES}

1. S. S. Kiparisov, et al., "Thermal Conductivity of $\mathrm{Eu}_{2} \mathrm{O}_{3}$," Izvest. Akad. Nauk. SSSR Neorg. Mater. $\underline{7}(6), 1073$ (1971).

2. Grüling and Schickfluss-Borges, Siemens AG. Bericht, No, 112/70 (Dec. 8, 1970).

3. J. P. Moore and D. L. McElroy, J. Am. Cer. Soc. 54(1), 40 (1971).

4. H. E. Schmidt, M. Van den Berg, and I, Van der Hoek, High TemperaturesHigh Pressures, 1969, Vo1. 1, page 309.

5. C. E. Curtis and A. G. Tharp, J. Am. Cer. Soc. 42, 151 (1959). 
(2) Central Research Library NRNI - Y-12. Technical Library, Document Reference

(10) Laboratory Records Department Laboratory Records, ORNL R.C. ORNL Patent Office G. M. Adamson, Jr.

P. Angelini

R. L. Beatty

R. J. Beaver

E. S. Bomar

V. L. Burdick

T. A. Butler

G. W. Clark

R. E. Clausing

J. A. Conlin

J. H. Coobs

W. H. Cook

J. A. Cox

R. S. Crouse

F. L. Culler

J. E. Cunningham

J. H. DeVan

J. R. DiStefano

(3) R. G. Donnelly

D. A. Dyslin

W. P. Eatherly

J. I. Federer

W. F. Ferguson

M. Fontana

R. J. Gray

K. W. Haff

R. L. Hamner

W. O. Harms

(3) M. R. Hill

F. J. Homan
H. Inouye

P. R. Kasten

E. Lamb

J. M. Leitnaker

A. L. Lotts

T. S. Lundy

M. M. Marlin

W. R. Martin

C. L. Matthews

R. W. McClung

W. T. McDuffee

D. L. McElroy

C. J. McHargue

J. P. Moore

R. A. Olsted

R. B. Parker

(5) A. E. Pasto

P. Patriarca

A. M. Perry

S. Peterson

G. L. Ragan

P. L. Ritterihouse

J M Robbins

A. Schaffhauser

J. L. Scott

J. D. Sease

G. M. Slaughter

J. O. Stiegler

D. B. Trauger

W. E. Unger

T. N. Washburn

A. M. Weinberg

J. R. Weir, Jr.

J. W. Woods

H. L. Yakel 
Subcontractors and Consultanls

CORNELL UNIVERSITY, DEPARTMENT OF MATERIALS SCIENCE AND ENGINEERING, Ithaca, N.Y. 14850

G. V. Smith

KNOLLS ATOMIC POWER LABORATORY, P.O. Box 1072, Schenectady, N.Y. 12301

W. K. Anderson

UNIVERSITY OF CALIFORNIA, LRL, INORGANIC MATERIALS RESEARCH DIVISION, Berkeley, California 99720

Leo Brewer

UNIVERSITY OF CALIFORNIA, REVELLE COLLEGE, DEPARTMENT OF PHYSICS, P.O. Box 109,

La Jolla, California 92037

Walter Kohn

UNIVERSITY OF ILLINOIS, DEPARTMENT OF PHYSICS, Urbana, Illinois 61801

W. S. Williảms

UNIVERSITY OF KENTUCKY, DEPARTMENT OF METALLURGICAL ENGINEERING. Lexingt,n, Kentucky 40506

R. S. Mateer

EXTERNAL DISTRIBUTION

(271 copies)

USAEC DIVISION OF REACTOR RESEARCH AND DEVELOPMENT, Washington, D.C. 20545

(2) Direclur

USAEC-RDT SENIOR SITE REPRESENTATIVE, Oak Ridge National Laboriatory, Oak Ridge, Tenn. 37830

USAEC OAK RIDGE OPERATIONS OFFICE, P.O. Box E, Oak Ridge, Tenn. 37830

Research and Technical Support Division

USAEC TECHNICAL INFORMATION CENTER, Office of Information Services, P.O. Box 62, Oak Ridge, TN 37830

For distribution as shown in TID-4500 Distribution Category, UC-79b (Fuels and Materials Engineering Development); UC-79d (LMFBR - Physics); UC-79e (LMFBR - Reactor Core Systems)

(2.67) 
OAK RIDGE NATIONAL LABORATORY

OPERATED BY

UNION CARBIDE CORPORATION

NUCLEAR DIVISION

\section{CAMBOilo:}

POST OFFICE BOX X

OAK RIDGE, TENNESSEE 37830

\section{SPECIAL 4TH CLASS RATE BOOKS}

